University of Rhode Island

DigitalCommons@URI

Open Access Dissertations

2017

\title{
Molecular-Level Design of Nanoscale Environments for Enhanced Single-Molecule Sensing
}

Julie Christine Whelan

University of Rhode Island, jwhelan@chm.uri.edu

Follow this and additional works at: https://digitalcommons.uri.edu/oa_diss

\section{Recommended Citation}

Whelan, Julie Christine, "Molecular-Level Design of Nanoscale Environments for Enhanced SingleMolecule Sensing" (2017). Open Access Dissertations. Paper 633.

https://digitalcommons.uri.edu/oa_diss/633

This Dissertation is brought to you for free and open access by DigitalCommons@URI. It has been accepted for inclusion in Open Access Dissertations by an authorized administrator of DigitalCommons@URI. For more information, please contact digitalcommons-group@uri.edu. 


\section{MOLECULAR-LEVEL DESIGN OF NANOSCALE ENVIRONMENTS FOR ENHANCED SINGLE- MOLECULE SENSING \\ BY}

JULIE CHRISTINE WHELAN

A DISSERTATION SUBMITTED IN PARTIAL FULFILLMENT OF THE REQUIREMENTS FOR THE DEGREE OF DOCTOR OF PHILOSOPHY

IN CHEMISTRY

UNIVERSITY OF RHODE ISLAND 
DOCTOR OF PHILOSOPHY DISSERTATION

OF

JULIE CHRISTINE WHELAN

APPROVED:

Dissertation Committee:

Major Professor Jason R. Dwyer

William B. Euler

Arijit Bose

Nasser H. Zawia

DEAN OF THE GRADUATE SCHOOL

UNIVERSITY OF RHODE ISLAND

2017 


\begin{abstract}
Single molecule studies depend upon precise control over the chemical and physical structure of the nanoscale sensing instrumentation and environment, and this demand is particularly stringent in the case of nanopores, a unique tool for singlemolecule sensing and manipulation. The size and shape of the nanopores are critical to their function, and each facet, alone, presents experimental hurdles; this dissertation contains an approach to address both, simultaneously. A method for electroless deposition of gold onto solid-state silicon nitride nanopores has been developed to provide a foundation for precision tailoring of surface properties and nanopore size to study single analyte molecules and their interactions with other molecules of interest. This study was designed to develop a set of tools to directly modify the surface of silicon nitride, and through this approach, to customize the nanopore size and surface properties for various molecular systems under investigation. The techniques discussed in this dissertation were successfully used to electrolessly deposit gold into silicon nitride pores, to create customized nanopores. These nanopores were characterized via a non-imaging, conductance-based, technique developed in this research group, and subsequently used to study the translocation of DNA molecules through the pores.
\end{abstract}




\section{ACKNOWLEDGMENTS}

I would like to extend my sincerest thanks to all the people who helped me get to this point in my life. First, to my parents; thank you for your love, your unconditional support, and for always believing me when I told you, "just one more semester." Thank you to my four wonderful siblings, my brothers- and sister-in-law, and my nieces and nephews; your unwavering encouragement has kept me going.

To the friends that I've met through this program: I can't thank you enough for the lunches, the trivia nights, the cookouts, and the camaraderie. I feel so lucky to have been a part of such a supportive department through my time at URI. The biggest 'thank you' goes to my partner in life- where would I be without you? It's hard to believe that we started as undergrads together 12 years ago, and now we are finishing grad school together, ready to start the next adventure! You made this worth it.

Many, many thanks to all the colleagues I've had the privilege of working beside in the Dwyer group. Buddini and Nuwan- thank you for your help, your inspiration, and your friendship; I can't wait to see where life takes the two of you! I hope the newest members, Jon and Rob, find being a part of the Dwyer group fulfilling, and that you both take advantage of all the opportunities that come with that membership.

Lastly, I would like to acknowledge Dr. Dwyer. 


\section{PREFACE}

Please be advised that this dissertation is in manuscript format.

Supplemental information appears in the Appendices. 


\section{TABLE OF CONTENTS}

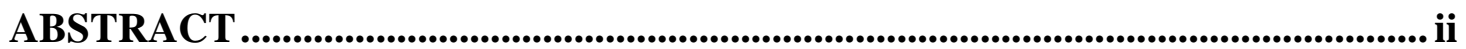

ACKNOWLEDGMENTS .......................................................................................

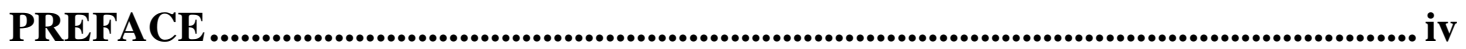

TABLE OF CONTENTS...................................................................................................... v

LIST OF REACTION SCHEMES...................................................................... viii

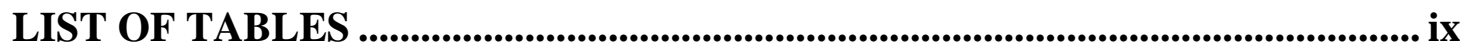

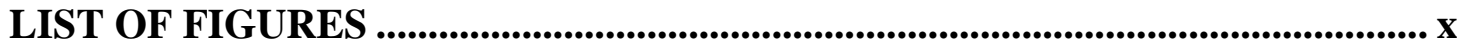

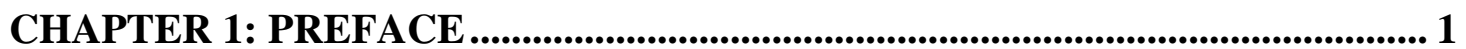

CHAPTER 1 ...................................................................................................................... 2

INTRODUCTION TO SINGLE-MOLECULE STUDIES ....................................... 2

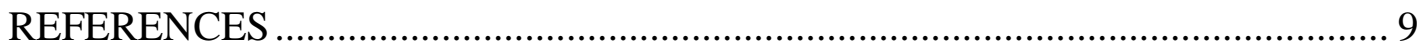

MANUSCRIPT 2: PREFACE ........................................................................................... 17

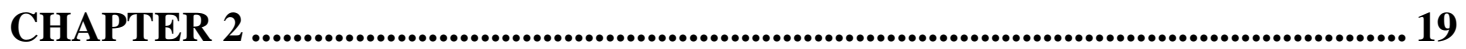

ELECTROLESS PLATING OF THIN GOLD FILMS DIRECTLY ONTO

SILICON NITRIDE THIN FILMS AND INTO MICROPORES ................... 19

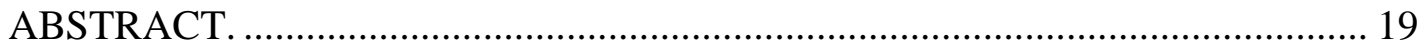

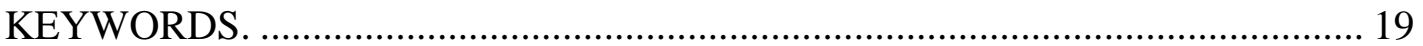

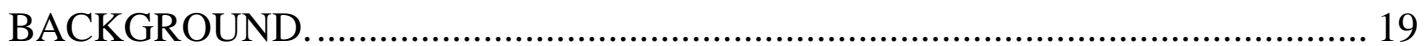

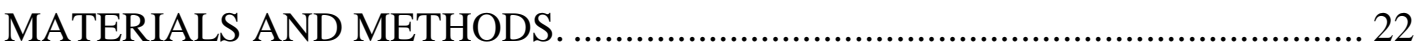

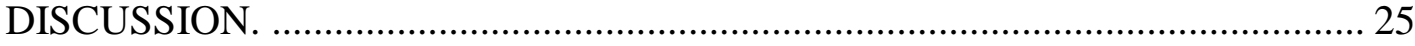

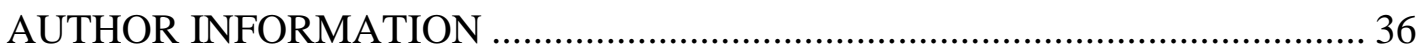

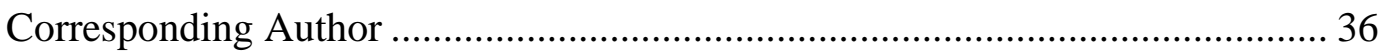

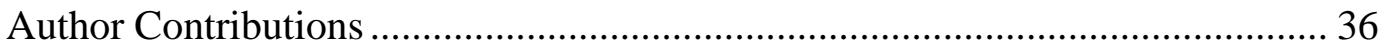

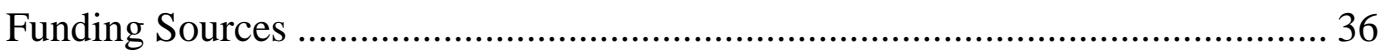




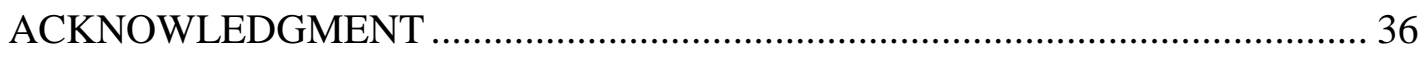

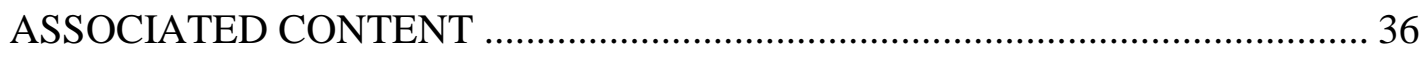

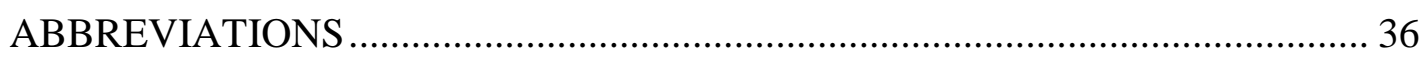

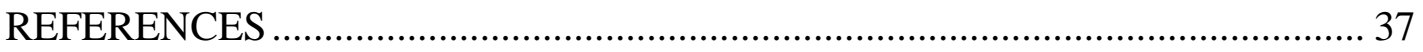

CHAPTER 3: PREFACE ........................................................................................ 42

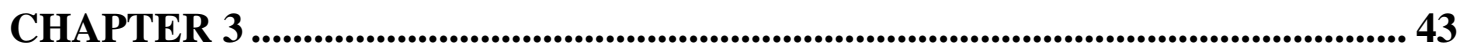

ELECTROLESS PLATING OF THIN GOLD FILMS DIRECTLY INTO SILICON NITRIDE NANOPORES FOR SINGLE MOLECULE SENSING

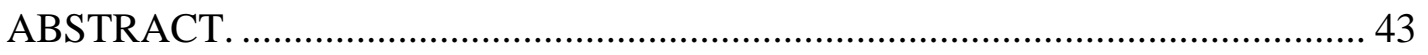

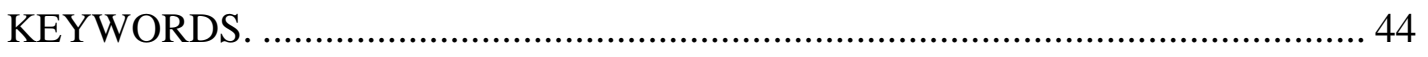

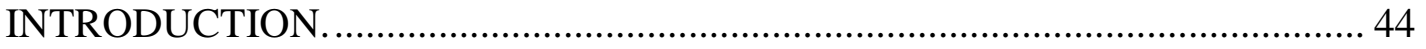

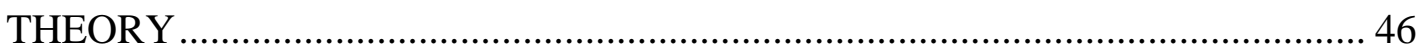

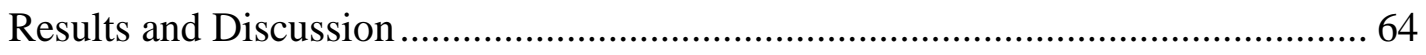

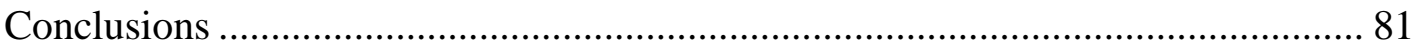

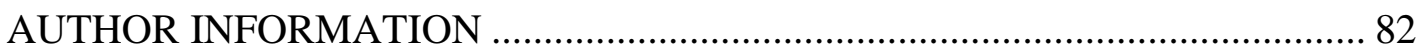

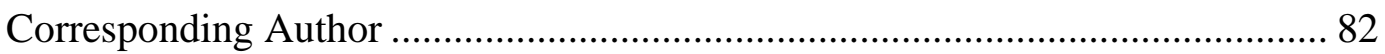

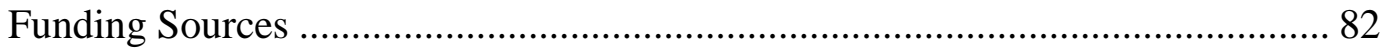

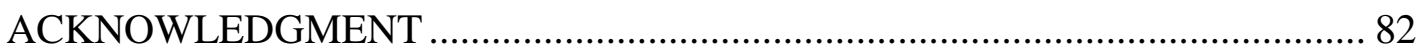

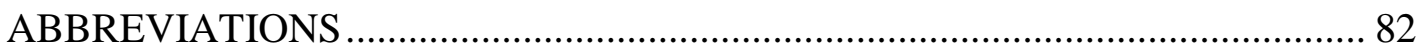

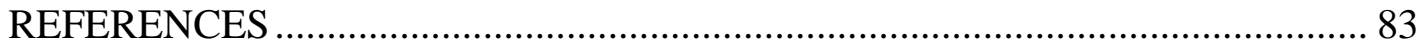

APPENDIX 1: CHAPTER 2 SUPPORTING INFORMATION ...........................91

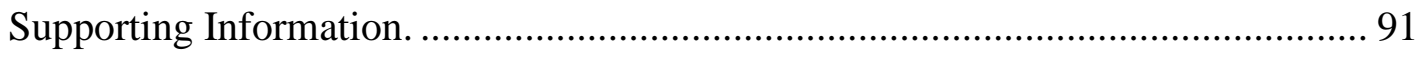

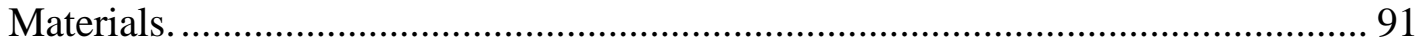

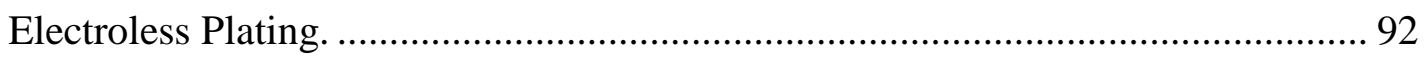

Planar and Microporous Silicon Nitride Substrates............................................. 92

Self-Assembled Monolayer Coating and Removal.................................................. 93

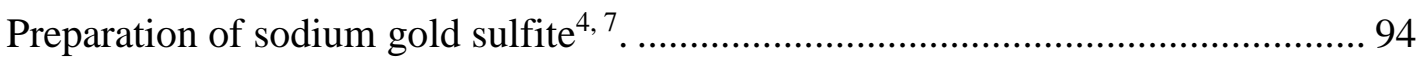

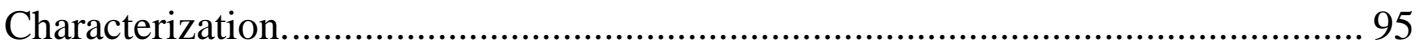




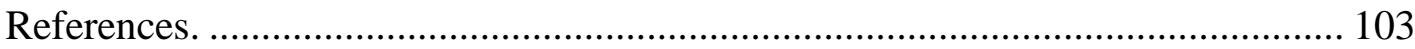

APPENDIX 2: CHAPTER 3 SUPPORTING INFORMATION ....................... 105

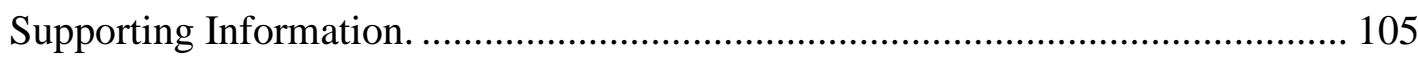

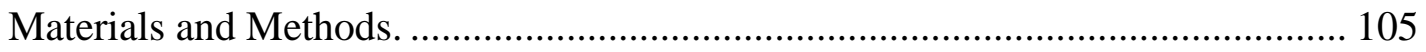

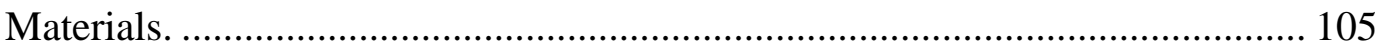

Dielectric Breakdown Nanopore Fabrication. ............................................... 106

Self-Assembled Monolayer Coating and Removal. ......................................... 112

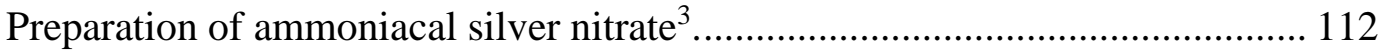

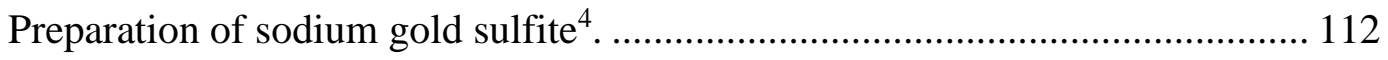

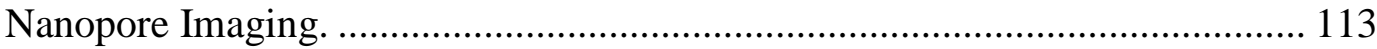

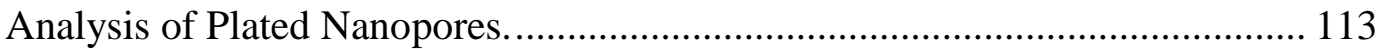

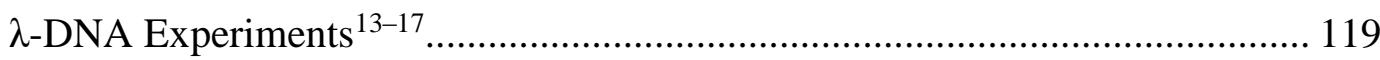

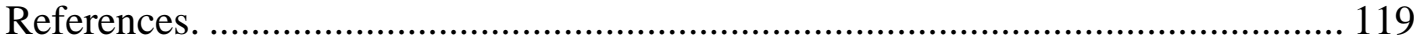




\section{LIST OF REACTION SCHEMES}

SCHEME

PAGE

Scheme 1. Electroless plating of silicon nitride. The silicon nitride-coated substrates are plasma-cleaned of organics and HF-etched before the surface is exposed to $\mathrm{Sn} 2+$ ions which are oxidized during the redox-driven deposition of an elemental silver layer. Gold plating begins with galvanic displacement of the elemental silver......... 24 Scheme S2. Electroless plating of silicon nitride. The silicon nitride-coated substrates are HF-etched before the surface is exposed to $\mathrm{Sn} 2+$ ions which are oxidized during the redox-driven deposition of an elemental silver layer (reaction a) Gold plating begins with galvanic displacement of the elemental silver (reaction b) and proceeds also by formaldehyde reduction (reaction c) 


\section{LIST OF TABLES}

TABLE

PAGE

Table 1. Table of calculated surface charge density values for nanopores of various

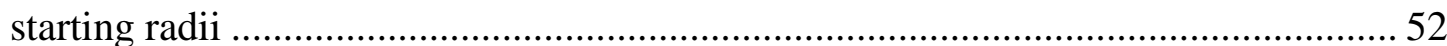




\section{LIST OF FIGURES}

FIGURE

PAGE

\section{Chapter 1}

Figure $1.1 \alpha$-hemolysin nanopore structure16, left, with view17 of protein inserted into lipid bilayer membrane (right), with single-stranded DNA translocating through the pore from one side of the membrane to the other. 3

Figure 1.2 Solid-state silicon nitride nanopore experimental setup. The nanopore is mounted in a Teflon cell, and provides the only opening between two wells containing an electrolytic solution. $\mathrm{Ag} / \mathrm{AgCl}$ electrodes in each well provide current measurements based on a voltage applied. A molecule electrophoretically driven, by the applied voltage, through the nanopore is said to translocate, and will result in a corresponding change $25,33,34$ in current magnitude when the molecule is within the nanopore, disrupting the normal voltage-driven ionic flow.................................. 5

Figure 1.3 Gold-plated solid-state silicon nitride nanopore functionalized with a polyethylene glycol-thiol self-assembled monolayer (SAM). The thin gold film provides a method of controlling the pore diameter, as does changing the terminal functional group to vary the chain length of the molecules forming the SAM39,49,54. Increased extension of longer chains into the pore interior should shrink the effective pore diameter. The SAM terminal group also provides control over the chemical environment within the nanopore. 7 


\section{Chapter 2}

Figure 2.1. (a) Photograph array of plating results at $3^{\circ} \mathrm{C}$. Top row, left-to-right $-\mathrm{HF}$ etch omitted, $1 \mathrm{~h}$ plating after HNO3 preparation, HNO3 step replicate, plasmacleaned only (subsequent steps omitted). Bottom row, left-to-right, Scheme 1 followed for plating times of 30 minutes, 1 hour, 2 hours, and 3 hours. The scratches in the film arose during handling of the chips. (b) Adhesive tape could lift most of the gold film to give an edge for (c) AFM measurements of electroless gold deposition film thickness as a function of time and temperature.

Figure 2.2 SEM images of a film after $2 \mathrm{~h}$ of gold plating at $3^{\circ} \mathrm{C}$. The inset is of the same film at lower magnification.

Figure 2.3 Measured spectra from $1 \mathrm{~cm} 2$ silicon nitride substrates soaked in $0.01 \mathrm{M}$ NBT for 5 minutes: from a substrate electrolessly gold-plated at $3^{\circ} \mathrm{C}$ for 3 hours (red), from the same chip plasma cleaned, annealed at $280^{\circ} \mathrm{C}$ for 20 minutes, and plasma cleaned again before NBT exposure (blue), and from a sputtered (30s) gold film

(black).

Figure 2.4 Gold coating can be seen to cover (a) the planar membrane and curved inner pore surface of the free-standing membrane area, with its uncoated equivalent shown in (c). A purposefully fractured membrane in (b) shows the gold coating on the micropore surface and the silicon nitride membrane (dark line) with intact gold coating. In image (d), plating also occurred on the bottom of the 200nm-deep well where it intersects with the silicon substrate. 35

\section{Chapter 3}

Figure 3.1 IV curves from an $8 \mathrm{~nm}$-radius $\mathrm{SiN}_{\mathrm{x}}$ nanopore fabricated in a 13 -nm-thick 
membrane, measured in $1 \mathrm{M}$ (dotted), $0.1 \mathrm{M}$ (dashed), and $0.01 \mathrm{M}$ (solid) potassium chloride solution, buffered to $\mathrm{pH} 7$ with $10 \mathrm{mM}$ HEPES. Pore conductance values are $99.5,17.0,6.0 \mathrm{nS}$, respectively. 48

Figure 3.2 Three conductance models fit to the same data points. IV curves of a single $\mathrm{SiN}_{\mathrm{x}}$ pore in a $13-\mathrm{nm}$-thick silicon nitride membrane were measured at $0.01,0.1$, and 1M, pH 7 HEPES- buffered potassium chloride electrolyte. The three conductance models shown are a bulk-only fit (dotted), which overestimates the pore radius and diverges from the data points at all but the highest ionic strengths; bulk and surface term fit (dashed), which underestimates the pore radius and diverges from the data at very low ionic strengths; and the combined bulk, surface, and access resistance terms (solid) that fits the data across all ionic strengths. The pore radii extracted with each parameter are indicated in the legend........................................................... 50 Figure 3.3 Vertical cutaways through a bare silicon nitride nanopore (A), the same pore after electroless gold-plating (B), and the gold pore after functionalizion with an incomplete thiol-terminated SAM (C). To simplify calculations, the incomplete SAM is modelled as an ideally equivalent configuration of complete monolayer covering a fraction, $\phi$, of the available surface area, (D). The total effective thickness of the gold coating plus the thickness of the monolayer, $\delta$, defines the decrease in radius of the coated pore region, and the increase in pore length.

Figure 3.4 Nanopore conductance fits before (blue, fit using Equation 3) and after (red, fit using Equation 15) electroless plating a single, nominally-10-nm-long, 9.2nm-radius $\mathrm{SiN}_{\mathrm{x}}$ nanopore with a film of electroless gold, followed by self-assembly of a methyl-(PEG) $)_{4}$-thiol monolayer, totaling $5.2 \mathrm{~nm}$ in effective thickness and $54 \%$ in 
fractional coverage. There are two fit regions seen post-functionalization, which converge at $0.2 \mathrm{M}$ - the point of $90 \% \mathrm{~K}^{+}$saturation of the monolayer for this given pore, given its particular degree of coverage (inset). The maximum number of potassium ions that could be bound to the SAM within this pore $\left(\mathrm{m}_{\mathrm{B}}\right)$ was 282 ; below that number, at electrolyte concentrations less than $0.2 \mathrm{M}$ there is one fit region, and above the saturation point, the trace features a second region. 63

Figure 3.5 A nanoporous silicon nitride membrane prior to plating (a, left), contrasted to electroless gold after plating (a, right). In an example where the gold film was intentionally removed by a gentle scrape with plastic tweezers (b), the gold film inside the pores can still be seen, and the underlying silicon nitride substrate is visible in contrast with the gold-plated portion of the membrane. The inset in (b) shows the area that was not covered by the gasket in the center, with various scratches due to handling, with the gasket-masked outer edge showing electron charging effects (bright outer regions) upon the non-gold-plated region of the insulating silicon nitride surface. A cross-section (c) of the same membrane reveals the gold film penetrated throughout the nanopores and on the top side of the membrane, although the film had not plated to continuous coverage. The viewing angle for the fractured membrane seen in (c) obscures the bottom halves of the coated pore, obscuring the gold in those regions from view. Debris resulting from the fracturing process can also be seen in panel (c) of this figure, and is not representative of an unfractured surface. 65

Figure 3.6 Asymmetric plating conditions. After full sensitization steps were carried out on both sides of the membrane, one solution well was filled with the reducing agent — formaldehyde (blue) — and the other side with the formaldehyde-free gold 
plating bath (orange). The nanopore provides a mixing area for the two solutions, resulting in deposition of gold onto the tin-sensitized surface where the two solutions meet. 68

Figure 3.7 Layered EDS image of two 5x5 nanoarrays drilled into a free-standing silicon nitride membrane, with the corresponding electron image inset in the upper-left corner. Prior to purchase of the substrate, LPCVD silicon nitride was deposited onto a silicon support wafer, which was anisotropically etched to reveal a free-standing portion of the silicon nitride (center rectangular region on images). A helium-ion microscope was used to create the two arrays of nanopores indirectly seen here through the plated footprints. The individual energy channels shown at right correspond to (clockwise) silver, gold, silicon, and tin x-rays signals. The micron-scale crystals seen around the edge of the silicon nitride window in the center are comprised largely of tin and silver, and the gold channel fails to show localized build-ups of gold. We hypothesize that incomplete solution exchanges between steps left residual tin and silver on the surface of the membrane, which were later reduced by formaldehyde during the final 3-hour gold-plating step of the procedure. ${ }^{89,90}$ Such crystals are not seen in the area around the nanopore arrays, themselves, where gold is found in the highest concentrations. The light dispersion of gold across the entire silicon nitride membrane attests to the mass transport of gold ions through the pore, and was most likely facilitated by the gentle rocking of the membrane during the plating process. The sharp contrast between the dusting of gold coating the entire surface and the gold plated around the pore arrays provides evidence for supporting the mass-transport process of gold and formaldehyde through the nanopore array. 70 
Figure 3.8 The IV-curve-measured conductance values of two different nanopores in silicon nitride (30 nm declared nominal thickness) after a series of treatment steps. The step numbers correspond to the treatments in order: (1) $2.5 \%$ HF etch series, total of 30 minutes etch in 10 minute increments; (2) 30 minutes electroless gold deposition at $3{ }^{\circ} \mathrm{C}$; (3) after 12 hour soak in $0.1 \mathrm{mM}$ mPEG-SH (average molecular weight 5000 $\mathrm{Da}$, structure seen in inset) $\mathrm{SAM}$ at $3{ }^{\circ} \mathrm{C}$; (4) plasma-cleaning to remove SAM; (5) second 30 min electroless gold deposition at $3^{\circ} \mathrm{C}$; (6) SAM of mPEG-SH (pore 1) and carboxy-PEG-SH (pore 2, average molecular weight $5000 \mathrm{Da}$, structure shown in inset), after immersion of pores for 12 hours in appropriate $0.1 \mathrm{mM}$ solution at $3^{\circ} \mathrm{C}$. Equation 3 was used to determine the pore sizes at steps 0, 1, 2, 4, and 5. Equation 15 was used for calculating the coating thickness and fractional coverage at steps 3 and 6 , with the starting radius taken from the calculation used in the previous step. Note that the coating thickness is an effective combined thickness of the gold plus the SAM.

Figure 3.9 Nanopore conductance values as a function of electrolyte concentration for a 4.2-nm radius $\mathrm{SiN}_{\mathrm{x}}$ pore before (blue) and after (red) electroless gold deposition and $\mathrm{m}(\mathrm{PEG})_{4}-\mathrm{SH}$ monolayer assembly. A $40 \%$ complete layer of 1.8-nm-thick gold+SAM was calculated using Equation 15. This nanopore was used for subsequent $\lambda$-DNA analysis. 75

Figure 3.10 Ten minutes of data acquisition at $200 \mathrm{mV}$ for a single dielectric breakdown pore with a starting radius of $4.2 \mathrm{~nm}$ by Equation 3, coated to a final radius of $2.4 \mathrm{~nm}$. The pore was plated with a gold film and functionalized with a $40 \%$ complete monolayer of $\mathrm{m}(\mathrm{PEG})_{4}-\mathrm{SH}$ with a total effective gold+SAM thickness of 
$1.8 \mathrm{~nm}$, as calculated by Equation 14. Current populations are shown with no analyte (black trace) and with $33.6 \mathrm{pM} \lambda$-DNA in $1 \mathrm{M} \mathrm{KCl}, 10 \mathrm{mM}$ HEPES, $\mathrm{pH}=7$ electrolyte in a single well of the Teflon holder (red trace, 97 events extracted). Data was acquired with an Axopatch 200B sampled at $100 \mathrm{kHz}$ and low-pass filtered at $10 \mathrm{kHz} \ldots \ldots \ldots \ldots . . .76$

Figure 3.11 Representative $\lambda$-DNA translocation events from a single 10 -minute run from one well containing $33.6 \mathrm{pM} \lambda$-DNA in a $500 \mu \mathrm{L}$ well containing $1 \mathrm{M} \mathrm{KCl}$ electrolyte, buffered to $\mathrm{pH} 7$ with $10 \mathrm{mM}$ HEPES, to a second $500 \mu \mathrm{L}$ well containing only the electrolyte. The coated pore radius was calculated to be $2.4 \mathrm{~nm}$ using Equation 14 and $40 \%$ coverage of a 1.8-nm-thick gold+mPEG 4 -SH monolayer....... 79

Figure 3.12. Heat map generated from 1078 events resulting from the translocation of 33.6pM $\lambda$-DNA in a $500 \mu \mathrm{L}$ well containing $1 \mathrm{M} \mathrm{KCl}$ electrolyte, buffered to $\mathrm{pH} 7$ with $10 \mathrm{mM}$ HEPES, to a second $500 \mu \mathrm{L}$ well containing only the electrolyte. The pore radius calculated from the conductance was found to be $2.4 \mathrm{~nm}$ after coating $(4.8 \mathrm{~nm}$ starting radius, $40 \%$ fractional coating of effective thickness $1.8 \mathrm{~nm}$ ), while the pore radius calculated from the $0.80 \mathrm{I} / \mathrm{I}_{0}$ population seen in Figure 3.10 was found to be $2.5 \mathrm{~nm}$. The color scale corresponds to the number of events at a given blockage magnitude and duration. A value of 0 for $\mathrm{I} / \mathrm{I}_{0}$ would represent total blockage of the pore, and conversely, a value of 1.0 represents a fully open pore. 80

\section{Appendices}

\section{Appendix 1}

Chapter 2 Supporting Information Figure S1. Elemental analysis of gold films. At left, XPS scans comparing a sputtered gold film with an electrolessly plated gold film. The 
curves are vertically offset for clarity. At right, EDS profiling confirms the gold composition of one of the larger surface particles

Chapter 2 Supporting Information Figure S2c XPS spectra at key steps in the application of Scheme 1, and after selected control experiments. The label given to each spectrum indicates the terminal steps of Scheme 1 (or control experiment variation) that were performed on the substrate. The control data center on the effect of HF etching (performed or omitted) and tin sensitization (with standard solution or tin-free control). The scattered points are experimental data, and solid lines are used for the fit to the data (individual components and their sum). Each plot includes the center value and (width) of each component used to fit the experimental spectrum.

Elements shown are O1s (a), $\mathrm{Si} 2 \mathrm{p}(\mathrm{b})$, and $\mathrm{Sn} 3 \mathrm{~d}(\mathrm{c})$. 102

\section{Appendix 2}

Chapter 3 Supporting Information Figure S1. Schematic of Teflon holder for asymmetric electroless plating of micro- and nanoporous substrates. The silicon support chip is mounted in between two silicone gaskets, which fit into a recessed area between the two halves of the Teflon holder. Small channels in the holder allow the solutions in each well to come into contact with one half of the chip, with the only mixing points of the two solutions being the pores in the silicon nitride membrane......

Chapter 3 Supporting Information Figure S1. Schematic of Teflon holder for asymmetric electroless plating of micro- and nanoporous substrates. The silicon support chip is mounted in between two silicone gaskets, which fit into a recessed area between the two halves of the Teflon holder. Small channels in the holder allow the 
solutions in each well to come into contact with one half of the chip, with the only mixing points of the two solutions being the pores in the silicon nitride membrane.....

Chapter 3 Supporting Information Figure S2. Silicon nitride nanopore before (blue) and after (red) electroless gold + SAM deposition. Initial pore radius was calculated to be $7.98 \mathrm{~nm}$, with a gold+ SAM coating of effective thickness of $5.1 \mathrm{~nm}$ covering $27.2 \%$ of the pore surface.

Chapter 3 Supporting Information Figure S3. Silicon nitride nanopore before (blue) and after (red) electroless gold + SAM deposition. Initial pore radius was calculated to be $7.67 \mathrm{~nm}$, with a gold+ SAM coating of effective thickness of $4.0 \mathrm{~nm}$ covering $53.5 \%$ of the pore surface. 116

Chapter 3 Supporting Information Figure S4. Silicon nitride nanopore before (blue) and after (red) electroless gold + SAM deposition. Initial pore radius was calculated to be $8.84 \mathrm{~nm}$, with a gold+ SAM coating of effective thickness of $3.8 \mathrm{~nm}$ covering $75.6 \%$ of the pore surface.

Chapter 3 Supporting Information Figure S5. Silicon nitride nanopore before (blue) and after (red) electroless gold + SAM deposition. Initial pore radius was calculated to be $5.08 \mathrm{~nm}$, with a gold + SAM coating of effective thickness of $2.9 \mathrm{~nm}$ covering $17.8 \%$ of the pore surface. 


\section{CHAPTER 1: PREFACE}

\section{INTRODUCTION TO SINGLE-MOLECULE STUDIES}

This manuscript was submitted for the thesis proposal of Julie C. Whelan in March of 2015. 


\section{CHAPTER 1}

\section{INTRODUCTION TO SINGLE-MOLECULE STUDIES}

Life as we know it is made possible by countless molecular interactions, the study of which can pose daunting challenges to researchers. In particular, the class of receptor-ligand interactions is responsible for everything from mood regulation to seeing in color ${ }^{1}$, and studying the chemistry and mechanisms behind these binding and unbinding events can provide invaluable information for the medical and bioengineering fields. The default approach by which to study individual molecular interactions has been that of single molecule microscopy ${ }^{2-10}$, where the majority of the tools and equipment required are macroscopic. Bulk studies and crystal structures cannot provide the level of information that could be gleaned from studying individual molecular interactions. Single molecule studies offer promising insight into molecular dynamics and open up a world of possibilities for developing future biomimetic and biocompatible technology ${ }^{11-14}$.

Biologically-relevant molecular interactions occur in an incredibly welldefined environment that takes tremendous effort, special preparation, and special approaches to replicate, or approximate, using traditional chemical tools. Protein nanopores are widespread in nature and, as a biological structural element, offer highly reproducible nanoscale channels with rich internal surface chemistry. They are thus a compelling tool that could be used to better explore molecular interactions. Early work focused on one nanopore, a naturally occurring 

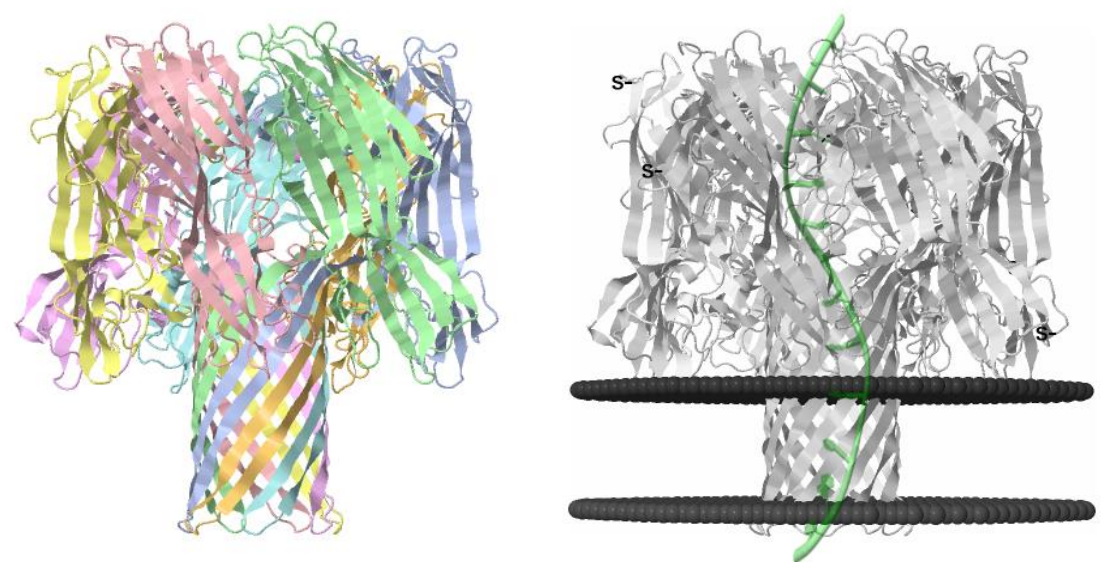

Figure $1.1 \alpha$-hemolysin nanopore structure ${ }^{16}$, left, with view ${ }^{17}$ of protein inserted into lipid bilayer membrane (right), with single-stranded DNA translocating through the pore from one side of the membrane to the other. 
transmembrane protein called $\alpha$-hemolysin that spontaneously forms nanometer molecular-scale holes in cell membranes ${ }^{13,15}$. This protein, derived from Staphylococcus aureus, can self-assemble in artificially created lipid bilayers, where it forms a single channel from one side of the lipid membrane to the other ${ }^{15}$ (Figure 1.1).

Borrowing tools from nature has its benefits, but biological nanopores can be difficult to adapt structurally to different analyte molecules, and their supporting lipid bilayers are only stable for a short duration in a narrow range of chemical conditions. Evolution has perfected their form to fit their function, and without genetic engineering $^{11,18-21}$, alpha-hemolysin pores have only a set repertoire of analyte molecules with which they can be used. The need for more customizable pores to study a wider range of analytes led to the development of man-made nanopores. When a molecular-scale hole is drilled through a thin, free-standing membrane, a solid-state nanopore is born. Such a membrane can be used to divide two halves of an electrochemical cell (Figure 1.2), and when an applied voltage drives charged molecules through the single opening between the two halves of the cell, a single molecule sensor is born. By monitoring the current passing through the pore, and the changes that occur as target molecules reside inside the nanopore, information about the size, shape, and charge of the analyte can be determined ${ }^{22-25}$, and more sophisticated experiments can elucidate diffusion and binding kinetics for various ligand-receptor interactions ${ }^{26-32}$.

Silicon nitride has emerged as a ubiquitous substrate material in the world of nanofabrication, including to fabricate solid-state nanopores, due to its accessibility and suite of favorable properties such as durability and electrical insulation ${ }^{35-39}$. 


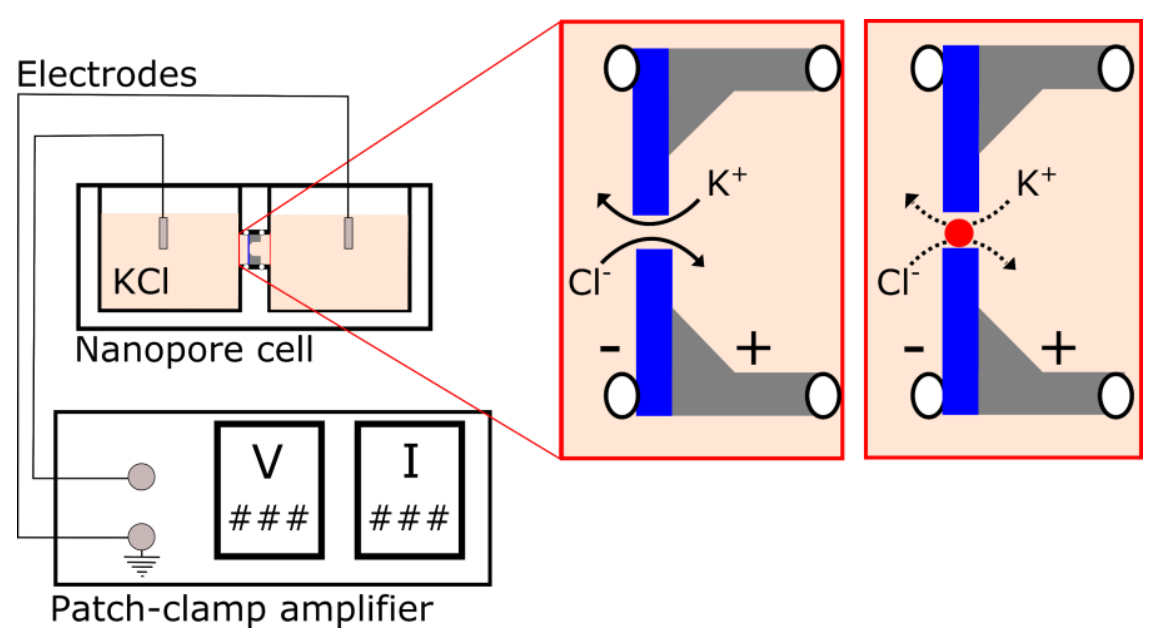

Figure 1.2 Solid-state silicon nitride nanopore experimental setup. The nanopore is mounted in a Teflon cell, and provides the only opening between two wells containing an electrolytic solution. $\mathrm{Ag} / \mathrm{AgCl}$ electrodes in each well provide current measurements based on a voltage applied. A molecule electrophoretically driven, by the applied voltage, through the nanopore is said to translocate, and will result in a corresponding change $25,33,34$ in current magnitude when the molecule is within the nanopore, disrupting the normal voltage-driven ionic flow. 
Careful and creative design can leverage this constellation of beneficial properties to create versatile tools for chemical analysis. Nanopores with molecular-scale diameters can be fabricated by a number of methods, with varying degrees of difficulty $y^{40-47}$, but precision control over the sub-attoliter interior of the nanopore continues to remain extremely challenging. Such control, however, is imperative when a single analyte molecule is electrophoretically driven into a constrained channel ${ }^{19,33,48}$, and control over the local chemical environment of the pore would open up new types of experiments and allow for a broader range of analyte studies. This requires a way to directly chemically modify the surface of solid-state silicon nitride nanopores. nitride nanopores.

Surface-deposited thin gold films offer a way to exert control over the chemical environment of a nanopore ${ }^{39,49-52}$. By electroless deposition of gold onto all sensitized surfaces of a silicon nitride nanopore, a blank canvas for chemical modification is created ${ }^{39}$ that is much less challenging than the native silicon nitride surface. Well established gold-thiol chemistry can then be employed to form selfassembling monolayers (SAM) on the gold-plated surface of the nanopore ${ }^{53}$. This offers a way to chemically define the physical size and volume of the nanopore, and results in total chemical control over the interior of the pore, as demonstrated in Figure 1.3.

The process of metal plating the solid-state silicon nitride nanopore, itself, proves challenging. With nanopores in particular, traditional physical deposition methods, such as vapor deposition or sputtering, are not amenable to coating the entire nanoscale three-dimensional surface while keeping the pore unobstructed. Electroless 


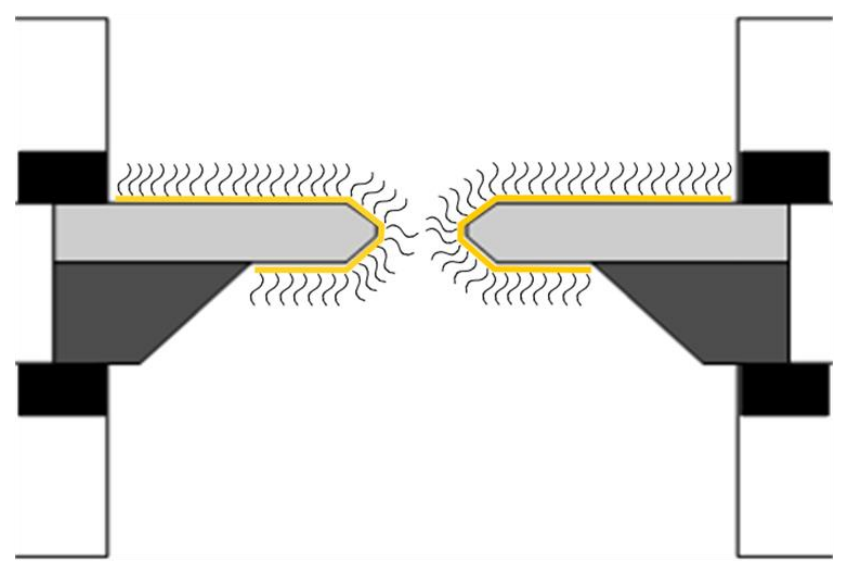

Figure 1.3 Gold-plated solid-state silicon nitride nanopore functionalized with a polyethylene glycol-thiol self-assembled monolayer (SAM). The thin gold film provides a method of controlling the pore diameter, as does changing the terminal functional group to vary the chain length of the molecules forming the SAM ${ }^{39,49,54}$. Increased extension of longer chains into the pore interior should shrink the effective pore diameter. The SAM terminal group also provides control over the chemical environment within the nanopore. 
deposition is an alternative, solution-based method for metallizing insulating substrates such as silicon nitride. Electroless deposition differs from the more familiar electrodeposition in that the surface onto which the metal is being plated does not have to be conductive, and no external or applied voltage is required to reduce the metal of choice onto the surface. The benefit of electroless plating, beyond the self-catalyzing series of redox reactions that allows for precise control over the metal deposition, is that it is totally solution-based and does not require any specialized equipment. By controlling various parameters of the plating procedure, such as $\mathrm{pH}$ and plating time, the thickness and nanostructure of the deposited gold coating can be modified. The complex and varied surface chemistry of silicon nitride -it is, in part, this complex silicon nitride surface chemistry that motivates use of gold as the surface functionalization base- does not lend itself to a straight-forward application of current electroless deposition techniques ${ }^{38,55}$. Thus, it is necessary to develop a new procedure to overcome the challenges of electroless deposition onto silicon nitride substrates. The physical dimensions of the nanopore can then be tuned by the plated gold thickness. Fine-tuning of the sizes and chemistry of the nanopore can occur through the self-assembly of thiol-terminated molecules on the gold surface.

The ability to coat all surfaces of a solid-state silicon nitride nanopore opens up the possibility for innumerable studies on previously studied ${ }^{22-24,30,31}$, as well as new, analyte molecules. This ability provides a means to chemically control a surface to design a volume to exact physical and chemical specifications, for use as a tool with which to then explore the world on a single-molecule level. The project in this dissertation studies various facets of solid-state nanopore design and applications to 
single-molecule sensing. First, a method for the deposition of gold onto silicon nitride is explored. Then, self-assembled monolayers (SAM) will be studied in nanopores and the effect their terminal functional groups have on the nanopore function. Lastly, the gold- and SAM-coated nanopores provide a platform for studying individual receptor-

ligand interactions by nanopore force spectroscopy $\left(\mathrm{NFS}^{26,29,31,32,56}\right)$, measured as a voltage-dependence of translocation of a ligand through a receptor-functionalized pore, or as the time-dependence of rupture of a receptor-ligand pair.

\section{REFERENCES}

1. Ji, T. H., Grossmann, M. \& Ji, I. G Protein-coupled Receptors I. Diversity of Receptor-Ligand Interactions. J. Biol. Chem. 273, 17299-17302 (1998).

2. Hell, S. W. \& Kroug, M. Ground-state-depletion fluorescence microscopy: A concept for breaking the diffraction resolution limit. Appl. Phys. B 60, 495-497 (1995).

3. Klar, T. A., Jakobs, S., Dyba, M., Egner, A. \& Hell, S. W. Fluorescence microscopy with diffraction resolution barrier broken by stimulated emission. Proc. Natl. Acad. Sci. 97, 8206-8210 (2000).

4. Dickson, R. M., Cubitt, A. B., Tsien, R. Y. \& Moerner, W. E. On/off blinking and switching behaviour of single molecules of green fluorescent protein. Nature $\mathbf{3 8 8}$, 355-358 (1997).

5. Moerner, W. E. \& Kador, L. Optical detection and spectroscopy of single molecules in a solid. Phys. Rev. Lett. 62, 2535-2538 (1989).

6. Betzig, E. et al. Imaging Intracellular Fluorescent Proteins at Nanometer Resolution. Science 313, 1642-1645 (2006). 
7. Betzig, E. Proposed method for molecular optical imaging. Opt. Lett. 20, 237-239 (1995).

8. Bustamante, C., Smith, S. B., Liphardt, J. \& Smith, D. Single-molecule studies of DNA mechanics. Curr. Opin. Struct. Biol. 10, 279-285 (2000).

9. Rief, M., Oesterhelt, F., Heymann, B. \& Gaub, H. E. Single Molecule Force Spectroscopy on Polysaccharides by Atomic Force Microscopy. Science 275, 1295-1297 (1997).

10. Hummer, G. \& Szabo, A. Free energy reconstruction from nonequilibrium singlemolecule pulling experiments. Proc. Natl. Acad. Sci. 98, 3658-3661 (2001).

11. Branton, D. et al. The potential and challenges of nanopore sequencing. Nat. Biotechnol. 26, 1146-1153 (2008).

12. Ma, L. \& Cockroft, S. L. Biological Nanopores for Single-Molecule Biophysics. ChemBioChem 11, 25-34 (2010).

13. Howorka, S. \& Siwy, Z. Nanopore analytics: sensing of single molecules. Chem. Soc. Rev. 38, 2360-2384 (2009).

14. Bayley, H. \& Martin, C. R. Resistive-Pulse Sensing From Microbes to Molecules. Chem. Rev. 100, 2575-2594 (2000).

15. Song, L. et al. Structure of staphylococcal alpha-hemolysin, a heptameric transmembrane pore. Science 274, 1859-1866 (1996).

16. Image of heptameric $\alpha$-hemolysin (7AHL) (Song, L., Hobaugh, M., Shustak, C., Cheley, S., Bayley, H., Gouaux, J.E., Structure of staphylococcal alpha-hemolysin, a heptameric transmembrane pore. Science, 274, 1859-1866, (1996.)) created with 
Jmol: an open source Java viewer for chemical structures in $3 D$.

http://www.jmol.org.

17. Image of synthetic DNA dodecamer (1BNA) (Drew, H.R., Wing, R.M., Takano, T., Broka, C., Tanaka, S., Itakura, K., Dickerson, R.E., Structure of a B-DNA dodecamer: conformation and dynamics, Proc. Natl. Acad. Sci. USA, 78, 21792183, (1981).) created with Jmol: an open source Java viewer for chemical structures in 3D. http://www.jmol.org.

18. Mohammad, M. M., Iyer, R., Howard, K.R, McPike, M.P., Borer, P.N., Movileanu, L. Engineering a Rigid Protein Tunnel for Biomolecular Detection. $J$. Am. Chem. Soc. 134, 9521-9531 (2012).

19. Mohammad, Prakash, S., Matouschek, A. \& Movileanu, L. Controlling a Single Protein in a Nanopore through Electrostatic Traps. J. Am. Chem. Soc. 130, 40814088 (2008).

20. Movileanu, L. Interrogating single proteins through nanopores: challenges and opportunities. Trends Biotechnol. 27, 333-341 (2009).

21. Howorka, S., Cheley, S. \& Bayley, H. Sequence-specific detection of individual DNA strands using engineered nanopores. Nat. Biotechnol. 19, 636-639 (2001).

22. Astier, Y., Braha, O. \& Bayley, H. Toward Single Molecule DNA Sequencing: Direct Identification of Ribonucleoside and Deoxyribonucleoside 5'Monophosphates by Using an Engineered Protein Nanopore Equipped with a Molecular Adapter. J. Am. Chem. Soc. 128, 1705-1710 (2006).

23. Clarke, J. et al. Continuous base identification for single-molecule nanopore DNA sequencing. Nat. Immunol. 4, 265-270 (2009). 
24. Meller, A., Nivon, L. \& Branton, D. Voltage-Driven DNA Translocations through a Nanopore. Phys. Rev. Lett. 86, 3435-3438 (2001).

25. Deamer, D. W. \& Branton, D. Characterization of Nucleic Acids by Nanopore Analysis. Acc. Chem. Res. 35, 817-825 (2002).

26. Dudko, O. K., Mathé, J., Szabo, A., Meller, A. \& Hummer, G. Extracting Kinetics from Single-Molecule Force Spectroscopy: Nanopore Unzipping of DNA Hairpins. Biophys. J. 92, 4188-4195 (2007).

27. Wiggin, M., Tropini, C., Tabard-Cossa, V., Jetha, N. N. \& Marziali, A. Nonexponential Kinetics of DNA Escape from $\alpha$-Hemolysin Nanopores. Biophys. J. 95, 5317-5323 (2008).

28. Firnkes, M., Pedone, D., Knezevic, J., Döblinger, M. \& Rant, U. Electrically Facilitated Translocations of Proteins through Silicon Nitride Nanopores: Conjoint and Competitive Action of Diffusion, Electrophoresis, and Electroosmosis. Nano Lett. 10, 2162-2167 (2010).

29. Tropini, C. \& Marziali, A. Multi-Nanopore Force Spectroscopy for DNA Analysis. Biophys. J. 92, 1632-1637 (2007).

30. Hornblower, B. et al. Single-molecule analysis of DNA-protein complexes using nanopores. Nat. Methods 4, 315-317 (2007).

31. Keyser, U. F. et al. Direct force measurements on DNA in a solid-state nanopore. Nat. Phys. 2, 473-477 (2006).

32. Tabard-Cossa, V. et al. Single-Molecule Bonds Characterized by Solid-State Nanopore Force Spectroscopy. ACS Nano 3, 3009-3014 (2009). 
33. Fan, R. et al. DNA Translocation in Inorganic Nanotubes. Nano Lett. 5, 16331637 (2005).

34. Karnik, R., Duan, C., Castelino, K., Daiguji, H. \& Majumdar, A. Rectification of Ionic Current in a Nanofluidic Diode. Nano Lett. 7, 547-551 (2007).

35. Mueller, C., Harb, M., Dwyer, J. R. \& Miller, R. J. D. Nanofluidic Cells with Controlled Pathlength and Liquid Flow for Rapid, High-Resolution In Situ Imaging with Electrons. J. Phys. Chem. Lett. 4, 2339-2347 (2013).

36. Ciarlo, D. R. Silicon Nitride Thin Windows for. Biomed. Microdevices 4, 63-68 (2002).

37. Williams, K. R. \& Muller, R. S. Etch rates for micromachining processing. J. Microelectromechanical Syst. 5, 256-269 (1996).

38. Habraken, F. H. P. M. \& Kuiper, A. E. T. Silicon nitride and oxynitride films. Mater. Sci. Eng. R Rep. 12, 123-175 (1994).

39. Whelan, J. C. et al. Electroless Plating of Thin Gold Films Directly onto Silicon Nitride Thin Films and into Micropores. ACS Appl. Mater. Interfaces 6, 1095210957 (2014).

40. Li, J. et al. Ion-beam sculpting at nanometre length scales. Nature 412, 166-169 (2001).

41. Wu, M.-Y. Et al. Control of Shape and Material Composition of Solid-State Nanopores. Nano Lett. 9, 479-484 (2008).

42. Storm, A. J., Chen, J. H., Ling, X. S., Zandbergen, H. W. \& Dekker, C. Fabrication of solid-state nanopores with single-nanometre precision. Nat. Mater. 2, 537-540 (2003). 
43. Kim, M. J., Wanunu, M., Bell, D. C. \& Meller, A. Rapid Fabrication of Uniformly Sized Nanopores and Nanopore Arrays for Parallel DNA Analysis. Adv. Mater. 18, 3149-3153 (2006).

44. Nam, S.-W., Rooks, M. J., Kim, K.-B. \& Rossnagel, S. M. Ionic Field Effect Transistors with Sub-10 nm Multiple Nanopores. Nano Lett. 9, 2044-2048 (2009).

45. Yang, J. et al. Rapid and precise scanning helium ion microscope milling of solidstate nanopores for biomolecule detection. Nanotechnology 22, 285310 (2011).

46. Vlassiouk, I., Apel, P. Y., Dmitriev, S. N., Healy, K. \& Siwy, Z. S. Versatile ultrathin nanoporous silicon nitride membranes. Proc. Natl. Acad. Sci. U. S. A. 106, 21039-21044 (2009).

47. Kwok, H., Briggs, K. \& Tabard-Cossa, V. Nanopore Fabrication by Controlled Dielectric Breakdown. PLoS ONE 9, e92880 (2014).

48. Reiner, J. E. et al. Disease Detection and Management via Single Nanopore-Based Sensors. Chem. Rev. 112, 6431-6451 (2012).

49. Menon, V. P. \& Martin, C. R. Fabrication and Evaluation of Nanoelectrode Ensembles. Anal. Chem. 67, 1920-1928 (1995).

50. Díaz, D. J., Williamson, T. L., Guo, X., Sood, A. \& Bohn, P. W. Electroless deposition of gold and platinum for metallization of the intrapore space in porous gallium nitride. Thin Solid Films 514, 120-126 (2006).

51. Cecchini, M. P. et al. Rapid Ultrasensitive Single Particle Surface-Enhanced Raman Spectroscopy Using Metallic Nanopores. Nano Lett. 13, 4602-4609 (2013). 
52. Wei, R., Pedone, D., Zürner, A., Döblinger, M. \& Rant, U. Fabrication of Metallized Nanopores in Silicon Nitride Membranes for Single-Molecule Sensing. Small 6, 1406-1414 (2010).

53. Love, J. C., Estroff, L. A., Kriebel, J. K., Nuzzo, R. G. \& Whitesides, G. M. SelfAssembled Monolayers of Thiolates on Metals as a Form of Nanotechnology. Chem. Rev. 105, 1103-1170 (2005).

54. Miles, B. N. et al. Single molecule sensing with solid-state nanopores: novel materials, methods, and applications. Chem. Soc. Rev. 42, 15-28 (2013).

55. Arafat, A. et al. Covalent Biofunctionalization of Silicon Nitride Surfaces. Langmuir 23, 6233-6244 (2007).

56. Dudko, O. K., Hummer, G. \& Szabo, A. Theory, analysis, and interpretation of single-molecule force spectroscopy experiments. Proc. Natl. Acad. Sci. 105, 15755-15760 (2008).

57. Kobayashi, Y., Tadaki, Y., Nagao, D. \& Konno, M. Deposition of gold nanoparticles on silica spheres by electroless metal plating technique. J. Colloid Interface Sci. 283, 601-604 (2005).

58. Kobayashi, Y., Salgueiriño-Maceira, V. \& Liz-Marzán, L. M. Deposition of Silver Nanoparticles on Silica Spheres by Pretreatment Steps in Electroless Plating. Chem. Mater. 13, 1630-1633 (2001).

59. Miller, T. C. \& Holcombe, J. A. Evaluation of electroless gold deposited on porous silica for ligand attachment for metal ion-exchange. Anal. Chim. Acta 454, 37-44 (2002). 
60. He Wanbao, Z. B. Preparation and sintering of Ni-coated Si 3N 4 composite powders. Ceram. Int. - CERAM INT 31, 811-815 (2005).

61. Ko, J. W. et al. Electroless Gold Plating on Aluminum Patterned Chips for CMOS-Based Sensor Applications. J. Electrochem. Soc. 157, D46 (2010).

62. Lahann, J. et al. A Reversibly Switching Surface. Science 299, 371-374 (2003).

63. Fan, F. R. et al. Determination of the molecular electrical properties of selfassembled monolayers of compounds of interest in molecular electronics. J. Am. Chem. Soc. 123, 2454-2455 (2001).

64. Palmer, R. E., Robinson, A. P. G. \& Guo, Q. How Nanoscience Translates into Technology: The Case of Self-Assembled Monolayers, Electron-Beam Writing, and Carbon Nanomembranes. ACS Nano 7, 6416-6421 (2013). 
MANUSCRIPT 2: PREFACE

Published: ACS Applied Materials and Interfaces 2014, 6, pp. 10952-10957.

\section{ELECTROLESS PLATING OF THIN GOLD FILMS DIRECTLY ONTO SILICON NITRIDE THIN FILMS AND INTO MICROPORES}

Julie C. Whelan, Buddini Iroshika Karawdeniya, Y.M. Nuwan D.Y. Bandara, Brian D.

Velleco, Caitlin M. Masterson, Jason R. Dwyer

Department of Chemistry, University of Rhode Island, Kingston, RI, USA

Reprinted with permission from:

Electroless Plating of Thin Gold Films Directly onto Silicon Nitride Thin Films and into Micropores. Julie C. Whelan, Buddini Iroshika Karawdeniya, Y.M. Nuwan D.Y.

Bandara Brian D. Velleco, Caitlin M. Masterson, and Jason R. Dwyer. ACS Applied

Materials \& Interfaces 20146 (14) 10952-10957.

Copyright 2014 American Chemical Society.

A subsequent correction was issued, and the corresponding changes have been made within the text of this thesis.

Correction to Electroless Plating of Thin Gold Films Directly onto Silicon Nitride Thin Films and into Micropores.

Julie C. Whelan, Buddini Iroshika Karawdeniya†, Y.M. Nuwan D.Y. Bandara†, Brian

D. Velleco, Caitlin M. Masterson and Jason R. Dwyer*. 
Department of Chemistry, University of Rhode Island, 51 Lower College Road, Kingston, RI, 02881, United States.*E-mail: jdwyer@chm.uri.edu. ACS Appl. Mater. Interfaces, 2015, 7(46), 26004-26004.

Reprinted with permission from:

Correction to Electroless Plating of Thin Gold Films Directly onto Silicon Nitride Thin Films and into Micropores. Julie C. Whelan, Buddini Iroshika Karawdeniya, Y.M. Nuwan D.Y. Bandara Brian D. Velleco, Caitlin M. Masterson, and Jason R. Dwyer. ACS Applied Materials \& Interfaces 20157 (46) 26004-26004. Copyright 2015 American Chemical Society. 


\title{
CHAPTER 2
}

\section{ELECTROLESS PLATING OF THIN GOLD FILMS DIRECTLY ONTO SILICON NITRIDE THIN FILMS AND INTO MICROPORES}

\begin{abstract}
.
A method to directly electrolessly plate silicon-rich silicon nitride with thin gold films was developed and characterized. Films with thicknesses less than 100nm were grown at 3 and $10^{\circ} \mathrm{C}$ between 0.5 and 3 hours, with mean grain sizes between 20-30nm. The method is compatible with plating free-standing ultrathin silicon nitride membranes, and we successfully plated the interior walls of micropore arrays in 200nm-thick silicon nitride membranes. The method is thus amenable to coating planar, curved, and line-of-sight-obscured silicon nitride surfaces.
\end{abstract}

\section{KEYWORDS.}

Electroless plating; thin gold films; silicon nitride; micropores; surface enhanced Raman spectroscopy (SERS); tin sensitization.

\section{BACKGROUND.}

Thin gold films have widespread technological utility, from forming conductive elements and overlayers, to serving as a platform for chemical surface modification by molecular self-assembly ${ }^{1}$. For gold films incorporated into conventional micro- and nanofabricated devices, silicon nitride is an appealing choice for a substrate. It is a standard nanofabrication material, offering, in addition, 
favorable inherent properties such as mechanical strength ${ }^{2-3}$, chemical resistance, and dielectric strength ${ }^{4-5}$. Silicon nitride is thus ubiquitous as a structural and functional element in nanofabricated devices where it plays a variety of roles ${ }^{2,5-8}$. Its surface chemistry, however, presents especial challenges given the complex mixture of silicon-, oxygen-, and nitrogen-bearing surface species $^{5}$. The nominal surface modification of silicon nitride is frequently carried out in practice using silane-based modification of a silica layer that may itself not be well-defined ${ }^{9}$. Thus, there remains both a need and opportunity to expand the suite of approaches useful for surface functionalizing silicon nitride directly. Electroless deposition is a particularly compelling approach to film formation: deposition proceeds from solution allowing the coating of three-dimensional surfaces, including surfaces hidden from line-of-sight deposition methods; no electrochemical instrumentation is required; no electrical power must be supplied nor must the substrate be conductive; there is no need for expensive vacuum deposition equipment; and a variety of classical physicochemical parameters such as reagent composition, solution properties such as $\mathrm{pH}$ and viscosity, and temperature, are available to tune the film properties ${ }^{10-11}$. There is a wealth of familiar approaches for the electroless plating of substrates such as polymers, for example, but no established prior art for the direct metal-cation-mediated electroless plating of gold onto silicon nitride ${ }^{12-13}$. A particularly compelling sequence exists for the electroless gold plating of poly(vinylpyrrolidone)-coated polycarbonate substrates $(\mathrm{Au} / \mathrm{PVP})^{13}$ : direct sensitization of the PVP surface with $\mathrm{Sn}^{2+}$, activation by immersion in ammoniacal silver nitrate to oxidize the surface $\mathrm{Sn}^{2+}$ to $\mathrm{Sn}^{4+}$ by reducing $\mathrm{Ag}^{+}$to elemental silver (producing, also, a small amount of silver oxide), and finally 
gold plating by galvanic displacement of the silver with reduction of $\mathrm{Au}(\mathrm{I})$ to $\mathrm{Au}(0)$ accompanied by the oxidation of formaldehyde. Amine and carbonyl groups in the PVP layer were proposed to complex the tin cation during sensitization ${ }^{13}$. Extending this approach, $\mathrm{Sn}^{2+}$ has been reported to complex effectively with oxygen-rich polymer surfaces ${ }^{12}$ and with quartz and silica substrates ${ }^{10,}{ }^{14-16}$. Tin(II) sensitization has also been reported on $\mathrm{NaOH}$-roughened surfaces ${ }^{17}$, suggesting that a specific chemical interaction may not be essential ${ }^{18}$, and underscoring the utility of electroless plating for rough and high-surface-area surfaces where physical deposition is challenged ${ }^{19}$. In principle, though, a smooth silicon nitride substrate with a welldefined silica surface layer should be amenable to direct tin sensitization. Yet, electroless deposition of gold on planar silicon nitride has been limited to routes requiring the use of a silica layer with organic linkers and metal layers between the silicon nitride and gold overlayer ${ }^{18}$. In the first case, covalent attachment of an organic monolayer using silane chemistry can be beneficial for film adhesion, but adds operational complexity ${ }^{18}$ and can constrain downstream processing conditions. In the second case, the intervening layers may lend beneficial properties, or may similarly introduce compositional constraints on applications, or morphological constraints on the final gold film nanostructure. Regardless of the ability to carry out a silica-based modification, it does not eliminate the benefits of a direct functionalization of silicon nitride. We present a dramatically simplified electroless gold deposition method in which we eliminate the initial covalent attachment of an organic monolayer to the substrate, and in which we do not need to initially mask the silicon nitride surface chemistry with a silica overlayer. Our method directly sensitizes the silicon nitride 
substrate with a $\mathrm{Sn}^{2+}$ solution, followed by a series of metal ion treatments in which we exert control over the gold film thickness using process time and temperature. Film thicknesses ranged from 30 to $100 \mathrm{~nm}$ for deposition times from $0.5-3 \mathrm{~h}$, and temperatures of 3 and $10^{\circ} \mathrm{C}$.

\section{MATERIALS AND METHODS.}

Full details of materials and preparation are provided in the Supporting Information (Appendix 1 in this Thesis). In brief, polished silicon-rich low-pressure chemical vapor deposited (LPCVD) silicon nitride-coated silicon wafers were cleaved into $\sim 1 \mathrm{~cm}^{2}$ chips. The chips were then electrolessly plated with gold deposited from solution as outlined in Scheme 1. Ultrasonic cleaning of the substrate ${ }^{20}$ was strictly avoided so that straightforward extension of the scheme to ultrathin silicon nitride windows would not cause window fracture ${ }^{2-3}$. Each chip was plasma-cleaned and then briefly etched in a dilute hydrofluoric acid (HF) solution to remove unwanted native silicon oxide and expose the silicon nitride surface ${ }^{4,}$. The prepared chips were immersed in a tin(II) chloride sensitizing solution, followed by a soak in ammoniacal silver nitrate solution ${ }^{10,13}$. The chips were carefully rinsed between each step of the process. Electroless gold plating was carried out by immersing chips in $\sim 1.5-3 \mathrm{~mL}$ $\left(0.75 \mathrm{~mL}\right.$ for micropores) of sodium gold sulfite plating solution ${ }^{21}$, with gentle rocking, in a refrigerator $\left(3^{\circ} \mathrm{C}\right.$ plating $)$ or thermoelectric cooler $\left(10^{\circ} \mathrm{C}\right.$ plating $)$. After plating for the desired time at the desired temperature, the chips were carefully rinsed, dried and then characterized. Gold film thicknesses were obtained by atomic force microscopy (AFM) measurements across an edge from the film to the substrate. Film morphology was examined by field-emission scanning electron microscopy (FE-SEM) and 
analyzed using a watershed analysis. Elemental analysis of the gold film was carried out by energy-dispersive x-ray spectroscopy (EDS) and by x-ray photoelectron spectroscopy (XPS). Characterization details are provided in the Supporting Information (Appendix 1 in this Thesis, page 91). 


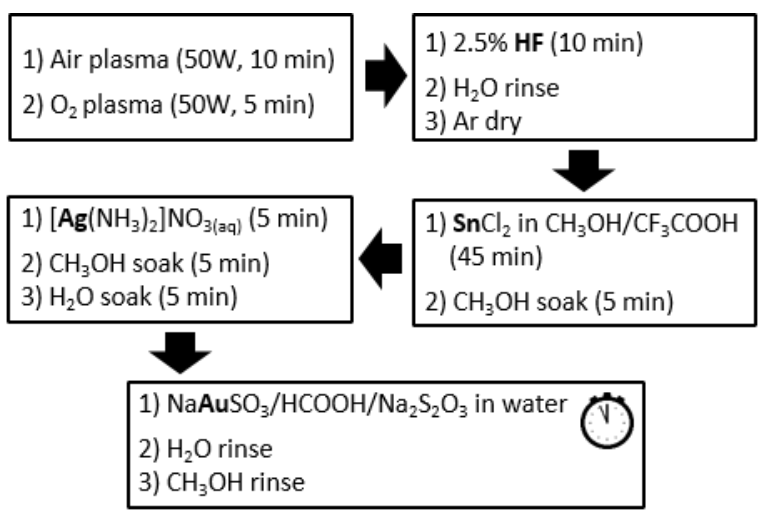

Scheme 1. Electroless plating of silicon nitride. The silicon nitride-coated substrates are plasma-cleaned of organics and HF-etched before the surface is exposed to $\mathrm{Sn}^{2+}$ ions which are oxidized during the redox-driven deposition of an elemental silver layer. Gold plating begins with galvanic displacement of the elemental silver. 


\section{DISCUSSION.}

Figure 2.1 shows photographs of an array of silicon nitride-coated substrates subjected either strictly to the steps in Scheme 1, or to control experiment variations. Adherence to Scheme 1 produced gold films, evaluated by visual inspection, with good quality and excellent macroscopic surface coverage, and delivered these results reliably over many months of repeated trials. More detailed characterization of these films is provided below. Departures from the scheme, however, yielded generally poor or inconsistent results. We focused our attention on varying the surface preparation steps, specifically testing surface preparations that did not involve HF etching designed to remove the oxygen-containing overlayer. Tin(II) sensitization after sodium hydroxide surface roughening had been reported on silicon nitride powders of unknown stoichiometry ${ }^{5}, 17$. Indeed, surface roughening to improve film adhesion is a familiar preliminary process in electroless plating ${ }^{11}$. Substituting $1,4.5$, or $9 \mathrm{M} \mathrm{NaOH}$ treatments for the HF etching of Scheme 1, however, generated only gold smudges after 3 hours of plating at $3^{\circ} \mathrm{C}$. The silicon-rich nature of our LPCVD films is a possible contributing factor to the poor plating quality after $\mathrm{NaOH}$ treatment in comparison to the published results ${ }^{17}$, given the general challenge that silicon nitride stoichiometry and available surface species - and thus functionalization

opportunities $^{20}$ — depend on the details of the silicon nitride synthesis ${ }^{5}$. Our use of large-area, planar substrates introduces another likely explanation: it provides a stringent test of film deposition quality, and easily reveals defects that may be more difficult to discern on a film coating a powder. Traditional silicon nitride surface modification schemes rely frequently on modification of a silica layer on the silicon 
nitride surface ${ }^{22-23}$ rather than of the silicon nitride, itself. Careful attention to the quality of the oxygen-containing surface layer can circumvent difficulties that stem from a lack of definition of this silica layer ${ }^{22}$. Holtzman and Richter used nitric acid to enrich the number of surface hydroxyl groups on silicon nitride so that they could use silane chemistry to provide an organic monolayer foundation for an overlying electrolessly deposited gold film ${ }^{18}$. While successful, the approach must contend with the acknowledged challenges of silane chemistry ${ }^{18}$ and with the persistence of the organic linker layer. Given the affinity of $\mathrm{Sn}^{2+}$ for such an oxygen-enriched silicon nitride surface, and given prior demonstrations of electroless gold plating on silica surfaces $^{10}$, we replaced the HF etch in Scheme 1 with a 20 minute treatment in $10 \%$ $(\mathrm{v} / \mathrm{v})$ nitric acid at $80^{\circ} \mathrm{C}$. The results, shown in Figure 2.1, were promising, with repeated, although not consistent, deposition of (visually inspected) high-quality gold films. It is likely feasible to optimize this route to routinely deposit high-quality, uniform gold films, but our goal was to develop a simple route to electrolessly plate gold directly onto silicon nitride. Treatment of silicon-rich LPCVD silicon nitride surfaces with dilute hydrofluoric acid eliminates the native oxide ${ }^{4,23}$ and leaves a $\mathrm{H}-$ terminated surface with $\mathrm{Si}-\mathrm{H}, \mathrm{NH}$ and $\mathrm{NH}_{2}$ moieties ${ }^{22}$. Given the appeal of this surface for surface functionalizations ${ }^{20,22}$, we tested its compatibility with tin(II)-based sensitization. Scheme 1 thus follows the plasma-based cleaning steps with an HF etch step that removes oxide and $\mathrm{H}$-terminates the surface ${ }^{22}$, and ends with the gold plating treatments ${ }^{13}$. We note that in the absence of the HF-etching step, chips would sporadically be coated with patchy gold layers, but no uniform high-quality gold films were observed on these chips even after 3 hours in the gold plating solution. 


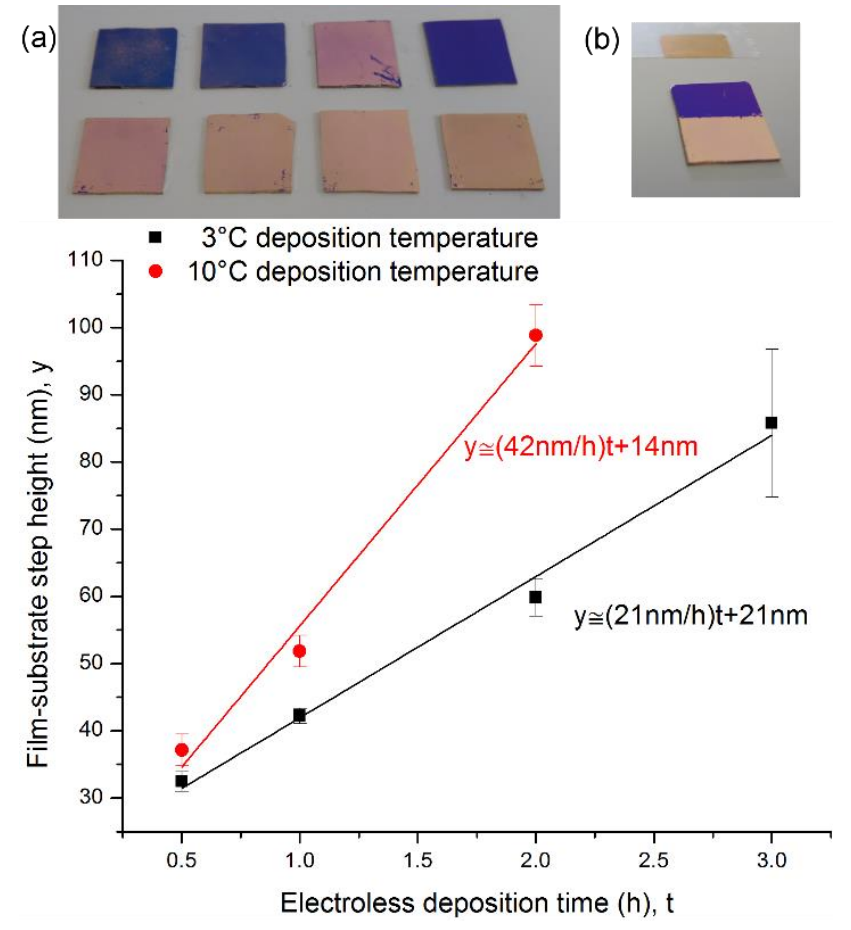

Figure 2.1. (a) Photograph array of plating results at $3^{\circ} \mathrm{C}$. Top row, left-to-right-HF etch omitted, $1 \mathrm{~h}$ plating after $\mathrm{HNO}_{3}$ preparation, $\mathrm{HNO}_{3}$ step replicate, plasmacleaned only (subsequent steps omitted). Bottom row, left-to-right, Scheme 1 followed for plating times of 30 minutes, 1 hour, 2 hours, and 3 hours. The scratches in the film arose during handling of the chips. (b) Adhesive tape could lift most of the gold film to give an edge for (c) AFM measurements of electroless gold deposition film thickness as a function of time and temperature. 
The row of visually high quality, high coverage gold films shown in Figure 2.1 were electrolessly plated at $3{ }^{\circ} \mathrm{C}$ for increasing lengths of time, with strict adherence to Scheme 1. The gold films survived extensive handling including prolonged immersion in liquids interspersed with repeated rinsing and pressurized argon-drying steps, and moreover adhered well to free-standing films that we broke deliberately for imaging (Figure 2.1b). Certainly in applications using gold-coated, freestanding silicon nitride membranes, consideration of membrane robustness will supersede gold adhesion in importance. The films could, however, be scratched with tweezers and mostly removed with adhesive tape (Figure 2.1b), and this afforded us the ability to perform AFM film thickness measurements. A swath of the gold film was removed and the mean difference in height between the film and the bare substrate was averaged across several representative line profiles and several independently plated chips for each plating time and temperature (see Supporting Information, page 91, for details). Figure 2.1 plots the step height from plated film to bare substrate as a function of time: at $3^{\circ} \mathrm{C}$ a step height of $\sim 30 \mathrm{~nm}$ after 30 minutes with a linear fit yielding a $\sim 20 \mathrm{~nm} / \mathrm{h}$ deposition rate thereafter, and at $10^{\circ} \mathrm{C}$ a step height of $\sim 35 \mathrm{~nm}$ after 30 minutes with a linear fit yielding a deposition rate of $\sim 40 \mathrm{~nm} / \mathrm{h}$ thereafter. The intercept likely arises from residual silver nanoislands scattered across the substrate. Shorter plating times than those shown in Figure 2.1 typically produced chips with a purple-blue hue. Fourpoint film resistivities were measured for the films plated at $3^{\circ} \mathrm{C}$ for all the time points listed, and were in the range $\sim 3-5 \times 10^{-6} \Omega \cdot \mathrm{cm}$; thin film resistivities higher than the known bulk gold resistivity $\left(2.2 \times 10^{-6} \Omega \cdot \mathrm{cm}\right)^{11}$ are not surprising ${ }^{18}$. SEM micrographs 


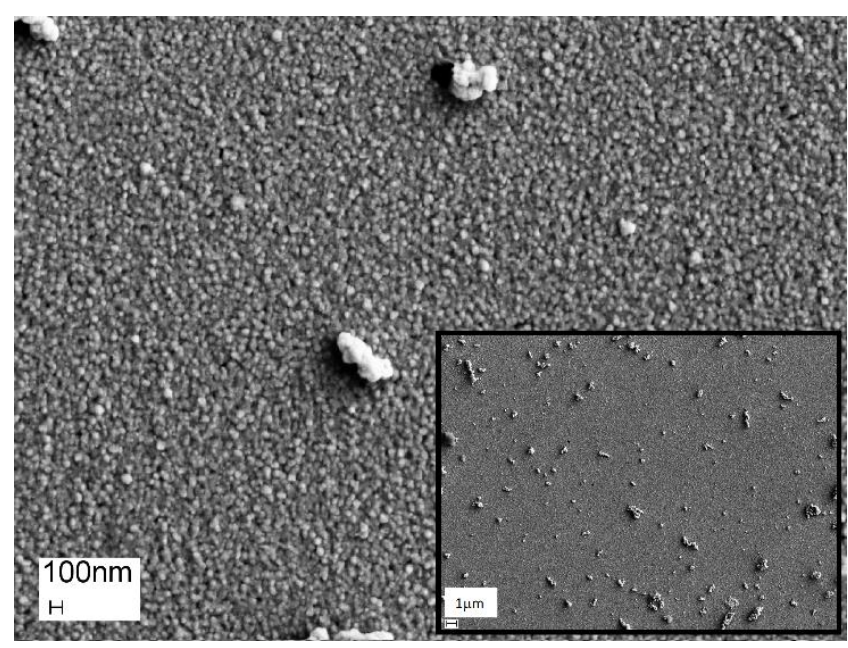

Figure 2.2 SEM images of a film after $2 \mathrm{~h}$ of gold plating at $3^{\circ} \mathrm{C}$. The inset is of the same film at lower magnification. 
afford a further detailed view of the film structure (Figure 2.2). Microscopic substrate coverage was high, but not complete, after 30 minutes of plating at $3^{\circ} \mathrm{C}$, but was on par, after 30 minutes at $10^{\circ} \mathrm{C}$ and 1 hour at $3^{\circ} \mathrm{C}$, with the coverage shown in the SEM micrograph shown in Figure 2.2. Micrographs for both temperatures and all plating times were subjected to watershed analysis (see Supporting Information, page 91, for details) and yielded area-equivalent mean grain radii from $20-30 \mathrm{~nm}$. It is clear from the SEM images, however, that the film structure is more complex than can be represented in a single equivalent grain size. There were large agglomerates on the film surface, seen also in AFM line profiles, with radii of several hundred nanometers. EDS analysis of these larger features showed them to be gold (see Chapter 2 Supporting Information Figure S1). Many of these outcroppings had quite convoluted shapes; there is the potential for quite compelling applications arising from both the regular and irregular film grain structures ${ }^{24-25}$. Indeed, the films are useful as a platform for surface-enhanced Raman spectroscopy (SERS). Figure 2.3 shows a demonstration spectrum of 4-nitrothiophenol (NBT) taken from an electrolessly goldcoated silicon nitride substrate. Annealing of these films caused an attendant decrease in the SERS signal, and after annealing for 24 hours at $280^{\circ} \mathrm{C}$, the mean grain size had increased to nearly $50 \mathrm{~nm}$. 


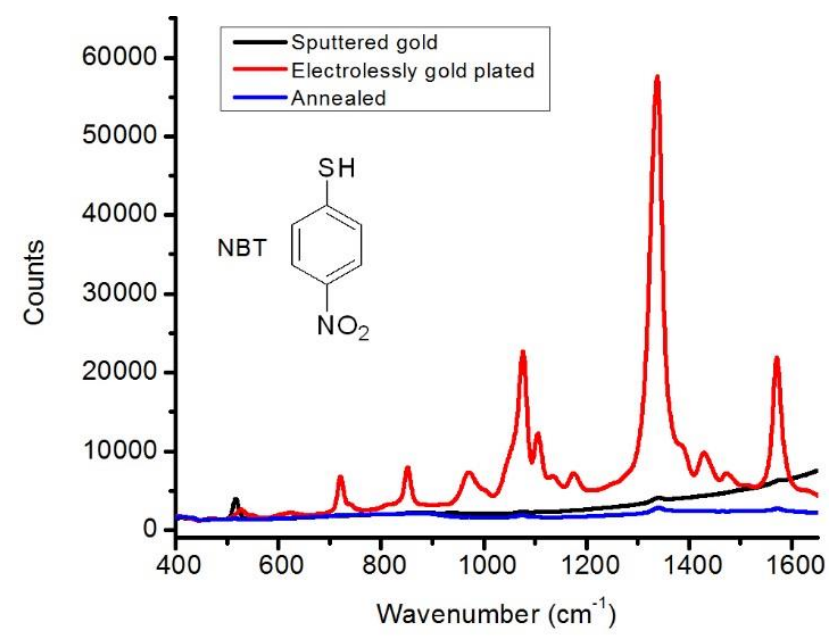

Figure 2.3 Measured spectra from $1 \mathrm{~cm}^{2}$ silicon nitride substrates soaked in $0.01 \mathrm{M}$ NBT for 5 minutes: from a substrate electrolessly gold-plated at $3^{\circ} \mathrm{C}$ for 3 hours (red), from the same chip plasma cleaned, annealed at $280^{\circ} \mathrm{C}$ for 20 minutes, and plasma cleaned again before NBT exposure (blue), and from a sputtered (30s) gold film (black). 
While the electroless gold plating was strongly sensitive to the surface preparation of the silicon nitride, we note, for completeness, that the exposed silicon at the edges of the chips was consistently gold-plated, regardless of whether the wafer was treated with $\mathrm{HF}, \mathrm{HNO}_{3}$ or $\mathrm{NaOH}$. Polished $\sim 1 \mathrm{~cm}^{2}$ silicon chips treated according to Scheme 1 developed uniform, high-quality gold films across the surface. This result suggests that the silicon-rich nature of our silicon nitride films may contribute to the electroless plating process in Scheme 1. Candidate mechanisms for tin-sensitizing silicon nitride thus extend beyond those involving nitrogen-containing surface species $^{13}$. The prospect of definitive elucidation of the mechanism, however, must be weighed in the context of clear precedent in the literature that the complexity of silicon nitride surface chemistry makes it difficult to unravel surface attachment mechanisms ${ }^{20}$. The chemical complexity of the reagents and supporting media involved in electroless plating further compounds the challenges, compared to physical deposition in vacuum or covalent attachment chemistry in solution. Nevertheless, the steps of various electroless plating approaches have a sound electrochemical basis and the method has a demonstrable outcome ${ }^{11}$. XPS spectra were recorded from silicon nitride chips after each major step of Scheme 1. Selected spectra and details of the analysis are provided in the Supporting Information (Chapter 2 Supporting Information Figure S2). XPS spectra were also recorded from silicon chips for use as a guide to unravelling the overlapping contributions to the $\mathrm{Si} 2 \mathrm{p}$ region of the silicon nitride spectra, especially. HF treatment of the oxygen-plasma-cleaned silicon and silicon nitride caused a significant diminution of oxygen-related peaks at $\sim 104 \mathrm{eV}$ (Si2p) and $\sim 533 \mathrm{eV}(\mathrm{O} 1 \mathrm{~s})$, with the first component no longer evident. These spectral 
features-including the residual O1s peak that could indicate surface reoxidation generating a small number of surface hydroxyl groups, but has been principally attributed to presumably surface-inaccessible bulk oxygen—are consonant with those recorded from silicon nitride substrates prepared for direct covalent chemical modification $^{9}$ 20, 22. The tin(II) treatment steps caused an appreciable widening of the residual, post-HF-etch O1s peaks of silicon and silicon nitride. We subjected silicon and silicon nitride substrates to two control treatments at this stage of Scheme 1: in the first, we omitted the hydrofluoric acid step prior to the introduction of the tin solution, and in the second, we prepared the tin sensitizing solution without adding tin. In none of the cases was the appreciable widening of the O1s peak observed. The broad, low-amplitude $102.5 \mathrm{eV} \mathrm{Si} 2 \mathrm{p}$ peak that appeared after Scheme 1 tinsensitization of silicon also appeared after tin-free control processing, and it suggests submonolayer oxygen coverage that can arise from aqueous processing ${ }^{23,26}$. The analogous formation of silicon oxynitride ${ }^{27-28}$ on the silicon nitride substrate would be more difficult to discern from the main Si2p peak due to spectral overlap. Tin oxidation states can be difficult to definitively identify by XPS measurement ${ }^{16,29}$, but the shifts of the best-fit $\sim 487 \mathrm{eV} \operatorname{Sn} 3 \mathrm{~d}_{5 / 2}$ peak to lower binding energy after the addition of silver(I) ions to both substrates (by $\sim 0.5 \mathrm{eV}$ for $\mathrm{SiN}_{\mathrm{x}}$ and $\sim 0.15 \mathrm{eV}$ for $\mathrm{Si}$ ), would be consistent in direction with the oxidation of $\operatorname{tin}(\mathrm{II})$. The $\operatorname{Sn} 3 \mathrm{~d}_{5 / 2}$ peaks were affected by the substrate preparation, with $\sim 0.2 \mathrm{eV}$ greater width on silicon and silicon nitride substrates that had not been treated with hydrofluoric acid, with an accompanying $\sim 0.4 \mathrm{eV}$ shift to higher binding energy on the silicon substrate. Overall, the XPS spectra suggest complex roles for oxygen and tin in the surface sensitization 
steps and, while the detailed mechanism of sensitization remains unresolved, adherence to Scheme 1 exposed the silicon-rich LPCVD silicon nitride surface for direct surface modification and yielded high-quality gold films.

In fact, in spite of complex and challenging surface chemistry, the choice of silicon nitride as a substrate opens a panoply of possible applications for consideration, and the use of a solution-based gold plating method allows us to coat surfaces that are difficult or impossible to reach by line-of-sight metal coating methods. We paid special attention in our development to be able to coat free-standing thin silicon nitride membranes. As a final demonstration of the capabilities of this method, we electrolessly gold plated micropore arrays fabricated in thin $(200 \mathrm{~nm})$ silicon nitride membranes. Figure 2.4 shows two representative gold-coated $2 \mu \mathrm{m}$ micropores, with the first plated into a free-standing portion of the membrane, and the second plated in a region of the silicon nitride pores overlapped with the underlying silicon support frame. Gold plating of the pore walls allows for the straightforward subsequent use of thiol chemistry for surface chemical functionalization. By choosing complementary pore dimensions and gold film thickness, either by fabricating pores with smaller initial sizes, or by increasing the plating time, this electroless plating process can also be used to physically tune the pore dimensions. This method thus provides access to surfaces that may not be accessible to line-of-sight methods, and it moreover provides control over both surface physicochemical properties and physical dimensions of surface and internal pores ${ }^{7}$. In addition, the method is well-suited for tuning and enhancing the properties and performance of thin film and pore-based devices. 


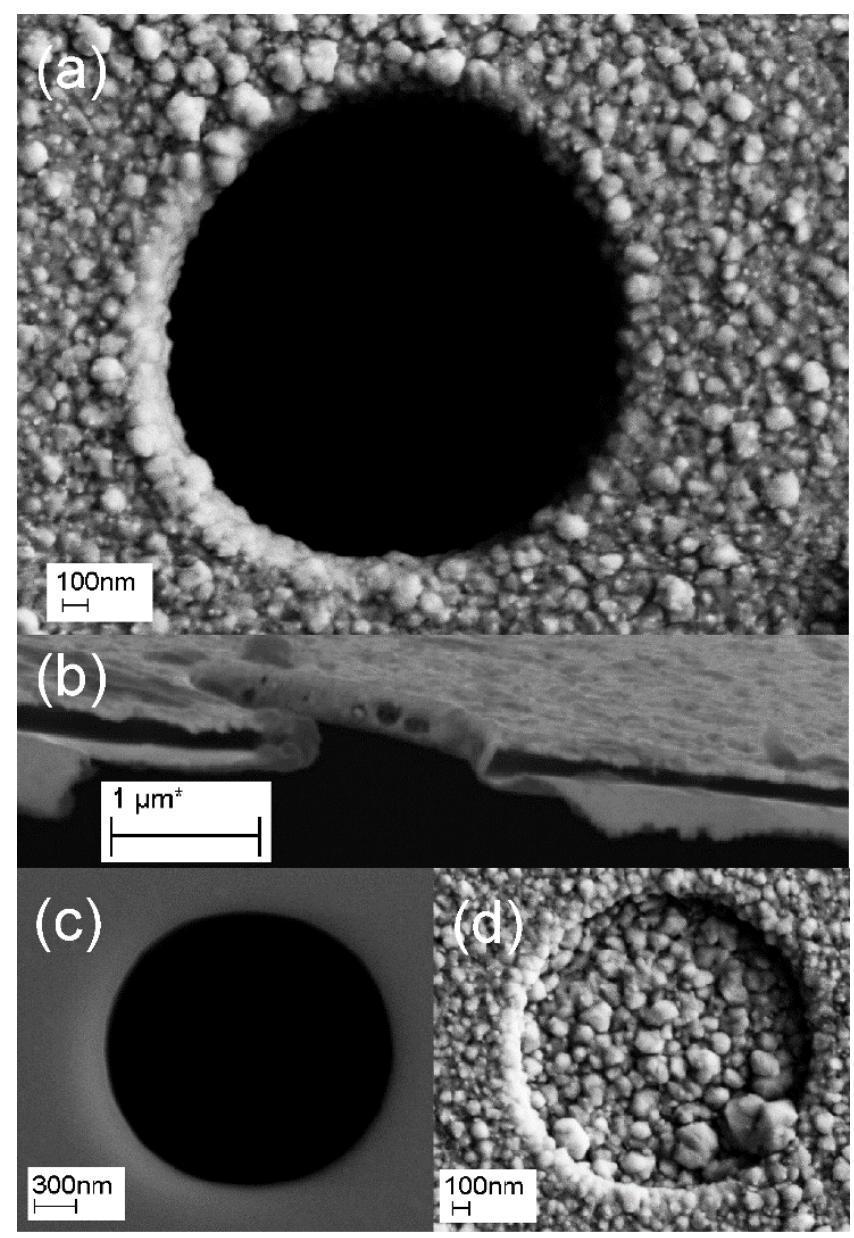

Figure 2.4 Gold coating can be seen to cover (a) the planar membrane and curved inner pore surface of the free-standing membrane area, with its uncoated equivalent shown in (c). A purposefully fractured membrane in (b) shows the gold coating on the micropore surface and the silicon nitride membrane (dark line) with intact gold coating. In image $(d)$, plating also occurred on the bottom of the 200nm-deep well where it intersects with the silicon substrate. 


\section{AUTHOR INFORMATION}

\section{Corresponding Author}

* E-mail: jdwyer@chm.uri.edu.

\section{Author Contributions}

All authors have given approval to the final version of the manuscript. / †These authors contributed equally.

\section{Funding Sources}

NSF CAREER award CBET-1150085, in part by NSF EPSCoR Cooperative Agreement \#IIA-1330406, and by the University of Rhode Island.

\section{ACKNOWLEDGMENT}

We thank Sarah Golden for custom software used in data analysis.

\section{ASSOCIATED CONTENT}

Supporting Information Available: Experimental details, methods and sample characterizations. This material is available free of charge via the Internet at http://pubs.acs.org, and in Appendix 1 of this thesis, page 91.

\footnotetext{
ABBREVIATIONS

AFM, Atomic Force Microscopy; SEM, Scanning Electron Microscopy; FE-SEM, field-emission SEM; EDS, energy-dispersive X-ray spectroscopy; LPCVD, lowpressure chemical vapor deposition; XPS, x-ray photoelectron spectroscopy; PVP, poly(vinylpyrrolidone); SERS; surface-enhanced Raman spectroscopy.
} 


\section{REFERENCES}

1. Love, J. C.; Estroff, L. A.; Kriebel, J. K.; Nuzzo, R. G.; Whitesides, G. M., Self-Assembled Monolayers of Thiolates on Metals as a Form of Nanotechnology. Chem. Rev. 2005, 105, 1103-1170.

2. Mueller, C.; Harb, M.; Dwyer, J. R.; Miller, R. J. D., Nanofluidic Cells with Controlled Pathlength and Liquid Flow for Rapid, High-Resolution In Situ Imaging with Electrons. J. Phys. Chem. Lett. 2013, 4, 2339-2347.

3. Ciarlo, D. R., Silicon Nitride Thin Windows for Biomedical Microdevices. Biomed. Microdevices 2002, 4, 63-68.

4. Williams, K. R.; Muller, R. S., Etch rates for micromachining processing. J. Microelectromech. Syst. 1996, 5, 256-269.

5. Habraken, F. H. P. M.; Kuiper, A. E. T., Silicon Nitride and Oxynitride Films. Mater. Sci. Eng., R 1994, 12, 123-175.

6. Miles, B. N.; Ivanov, A. P.; Wilson, K. A.; Dogan, F.; Japrung, D.; Edel, J. B., Single Molecule Sensing with Solid-State Nanopores: Novel Materials, Methods, and Applications. Chem. Soc. Rev. 2013, 42, 15-28.

7. Frament, C. M.; Bandara, N.; Dwyer, J. R., Nanopore Surface Coating Delivers Nanopore Size and Shape through Conductance-Based Sizing. ACS Appl. Mater. Interfaces 2013, 5, 9330-9337.

8. Fine, D.; Grattoni, A.; Goodall, R.; Bansal, S. S.; Chiappini, C.; Hosali, S.; van de Ven, A. L.; Srinivasan, S.; Liu, X.; Godin, B.; Brousseau, L.; Yazdi, I. K.; 
Fernandez-Moure, J.; Tasciotti, E.; Wu, H.-J.; Hu, Y.; Klemm, S.; Ferrari, M., Silicon Micro- and Nanofabrication for Medicine. Adv. Healthcare Mater. 2013, 2, 632-666.

9. Arafat, A.; Giesbers, M.; Rosso, M.; Sudhölter, E. J. R.; Schroën, K.; White, R. G.; Yang, L.; Linford, M. R.; Zuilhof, H., Covalent Biofunctionalization of Silicon Nitride Surfaces. Langmuir 2007, 23, 6233-6244.

10. Ahn, W.; Taylor, B.; Dall'Asen, A. G.; Roper, D. K., Electroless Gold Island Thin Films: Photoluminescence and Thermal Transformation to Nanoparticle Ensembles. Langmuir 2008, 24, 4174-4184.

11. Møller, P.; Nielsen, L. P., Advanced Surface Technology. Møller \& Nielsen APS: Denmark, 2013; Vol. 1, p 594.

12. Charbonnier, M.; Romand, M., Polymer Pretreatments for Enhanced Adhesion of Metals Deposited by the Electroless Process. Int. J. Adhes. Adhes. 2003, 23, $277-285$.

13. Menon, V. P.; Martin, C. R., Fabrication and Evaluation of Nanoelectrode Ensembles. Anal. Chem. 1995, 67, 1920-1928.

14. Kobayashi, Y.; Tadaki, Y.; Nagao, D.; Konno, M., Deposition of Gold Nanoparticles on Silica Spheres by Electroless Metal Plating Technique. J. Colloid Interface Sci. 2005, 283, 601-604. 
15. Miller, T. C.; Holcombe, J. A., Evaluation of Electroless Gold Deposited on Porous Silica for Ligand Attachment for Metal Ion-Exchange. Anal. Chim. Acta 2002, 454, 37-44.

16. Kobayashi, Y.; Salgueiriño-Maceira, V.; Liz-Marzán, L. M., Deposition of Silver Nanoparticles on Silica Spheres by Pretreatment Steps in Electroless Plating. Chem. Mater. 2001, 13, 1630-1633.

17. Wanbao, H.; Baolin, Z.; Hanrui, Z.; Wenlan, L., Preparation and Sintering of Ni-Coated $\mathrm{Si}_{3} \mathrm{~N}_{4}$ Composite Powders. Ceram. Int. 2005, 31, 811-815.

18. Holtzman, A.; Richter, S., Electroless Plating of Silicon Nitride Using (3Aminopropyl) Triethoxysilane. J. Electrochem. Soc. 2008, 155, D196-D202.

19. Díaz, D. J.; Williamson, T. L.; Guo, X.; Sood, A.; Bohn, P. W., Electroless Deposition of Gold and Platinum for Metallization of the Intrapore Space in Porous Gallium Nitride. Thin Solid Films 2006, 514, 120-126.

20. Rosso, M.; Giesbers, M.; Arafat, A.; Schroën, K.; Zuilhof, H., Covalently Attached Organic Monolayers on $\mathrm{SiC}$ and $\mathrm{Si}_{\mathrm{x}} \mathrm{N}_{4}$ Surfaces: Formation Using UV Light at Room Temperature. Langmuir 2009, 25, 2172-2180.

21. Ko, J. W.; Koo, H. C.; Kim, D. W.; Seo, S. M.; Kang, T. J.; Kwon, Y.; Yoon, J. L.; Cheon, J. H.; Kim, Y. H.; Kim, J. J.; Park, Y. J., Electroless Gold Plating on Aluminum Patterned Chips for CMOS-Based Sensor Applications. $J$. Electrochem. Soc. 2010, 157, D46-D49. 
22. Arafat, A.; Schroën, K.; de Smet, L. C. P. M.; Sudhölter, E. J. R.; Zuilhof, H., Tailor-Made Functionalization of Silicon Nitride Surfaces. J. Am. Chem. Soc. 2004, 126, 8600-8601.

23. Bermudez, V. M., Wet-Chemical Treatment of $\mathrm{Si}_{3} \mathrm{~N}_{4}$ Surfaces Studied Using Infrared Attenuated Total Reflection Spectroscopy. J. Electrochem. Soc. 2005, 152, F31-F36.

24. Soleymani, L.; Fang, Z.; Lam, B.; Bin, X.; Vasilyeva, E.; Ross, A. J.; Sargent, E. H.; Kelley, S. O., Hierarchical Nanotextured Microelectrodes Overcome the Molecular Transport Barrier To Achieve Rapid, Direct Bacterial Detection. ACS Nano 2011, 5, 3360-3366.

25. Stiles, P. L.; Dieringer, J. A.; Shah, N. C.; Van Duyne, R. P., SurfaceEnhanced Raman Spectroscopy. Annu. Rev. Anal. Chem. 2008, 1, 601-626.

26. Chen, M.; Batra, I. P.; Brundle, C. R., Theoretical and Experimental Investigations of the Electronic Structure of Oxygen on Silicon. J. Vac.Sci. Technol. 1979, 16, 1216-1220.

27. Du, H.; Tressler, R. E.; Spear, K. E.; Pantano, C. G., Oxidation Studies of Crystalline CVD Silicon Nitride. J. Electrochem. Soc. 1989, 136, 1527-1536.

28. Vasquez, R. P.; Hecht, M. H.; Grunthaner, F. J.; Naiman, M. L., X-ray Photoelectron Spectroscopy Study of the Chemical Structure of Thermally Nitrided $\mathrm{SiO}_{2}$. Appl. Phys. Lett. 1984, 44, 969-971. 
29. Themlin, J.-M.; Chtaïb, M.; Henrard, L.; Lambin, P.; Darville, J.; Gilles, J.-M., Characterization of Tin Oxides by X-Ray-Photoemission Spectroscopy. Phys. Rev. B: Condens. Matter Mater. Phys. 1992, 46, 2460-2466. 


\section{CHAPTER 3: PREFACE}

\section{ELECTROLESS PLATING OF THIN GOLD FILMS DIRECTLY INTO SILICON NITRIDE NANOPORES FOR SINGLE MOLECULE SENSING}

Julie C. Whelan, Y.M. Nuwan D.Y. Bandara, Buddini Iroshika Karawdeniya, Jason R.

Dwyer*

Department of Chemistry, University of Rhode Island, Kingston, RI, USA

This manuscript is formatted for publication according to ACS Nano standards. 


\title{
CHAPTER 3
}

\section{ELECTROLESS PLATING OF THIN GOLD FILMS DIRECTLY INTO SILICON NITRIDE NANOPORES FOR SINGLE MOLECULE SENSING}

\begin{abstract}
.
Accurate knowledge of the size and surface chemistry of a nanopore sensing element is vital to the successful design and analysis of nanopore experiments. Both properties were tuned by surface deposition of thin gold films by electroless plating in single, $<100 \mathrm{~nm}$ diameter nanopores, with subsequent functionalization by selfassembled monolayers (SAMs), and then were studied via conductance measurements, with removal of the SAM by oxygen plasma between subsequent coatings. Control over the temperature-dependent pore plating rate and plating time can tune the final size of the nanopore to the desired dimension, and choice of SAM provides a method by which to tune the pore's surface chemistry, to control the interaction between the analyte molecules and the pore surface. The conductance measurements shown in this work indicate changes consistent with the applied surface coating. The gold-plated, SAM-functionalized nanopores were additionally shown to function as singlemolecule sensors through studies of the translocation of $\lambda$-DNA through the pores under an applied potential.
\end{abstract}




\section{KEYWORDS.}

Electroless plating; thin gold films; silicon nitride; nanopores; single molecule sensing; $\lambda$-DNA; self-assembled monolayers.

\section{INTRODUCTION.}

When a molecular-scale hole is drilled through a thin, free-standing membrane, a solid-state nanopore is born. A simple single molecule sensor results when the nanopore-containing membrane is used to divide two halves of an electrochemical cell. ${ }^{1,2}$ An applied voltage drives electrolyte ions and suitable analyte species through the nanopore, and analytes can be detected and characterized through their effects on the through-nanopore ionic current. Tremendous challenges-and unique possibilities-emerge from even transiently constraining an analyte molecule within the zeptoliter volume of a typical nanopore ${ }^{2-5}$ : jurisdiction over, and correct treatment and consideration of, nanopore surface effects are vitally important in such a setting ${ }^{6-}$ 9.

Recent developments in nanopore fabrication by dielectric breakdown of silicon nitride $\left(\mathrm{SiN}_{\mathrm{x}}\right)$ have presented the opportunity for minimal handling of the membranes and other important benefits including faster and more reliable surface wetting and lowering the possibility of surface contamination by electron-based fabrication methods. ${ }^{10}$ Even before the pore is formed, the membrane is mounted within a custom Teflon cell: all steps-formation of the pore, chemical functionalization of the surface, conductance-based characterization of the pore dimensions, and detection of analyte molecules—can be carried out in situ. ${ }^{11-15} \mathrm{We}$ have previously reported a solution-based nanopore modification method by which to 
overcome the complications afforded by silicon nitride surface chemistry, resulting in a thin gold film directly deposited onto 3-dimensional, planar, microporous, and nanoporous substrates. ${ }^{16,17}$ This purely solution-phase process eliminates the need for experience-heavy pore fabrication techniques, such as electron-beam drilling, and for line-of-sight gold deposition methods such as sputtering or vapor deposition. The insitu steps reduce the risk of membrane rupture from unmounting and remounting the membrane, and eliminate contamination that could result from electron-microscopybased characterization. Our development of electroless gold plating chemistry suitable for gold-plating silicon nitride has provided us with a straightforward, solution-based method with the potential to tune nanopore physical dimensions through temperaturedependent plating rates, and to customize nanopore surface chemistry through thiol self-assembly methods; knowledge and control over both aspects-the nanopore radius and localized surface chemistry — are vital to pore characterization, and thus, accurate analysis of analyte molecules.

Our electroless deposition method directly sensitizes the silicon nitride substrate with a $\mathrm{Sn}^{2+}$ solution, followed by a series of metal ion treatments in which we exert control over the gold film thickness using processing time and temperature. ${ }^{16}$ Subsequent modification of the plated surfaces by thiol-terminated SAMs adds a second opportunity for further customization and control over the surface characteristics of the nanopore. Exquisitely tailored pore surface chemistry can mitigate the challenges posed by complex analytes ${ }^{18}$. $\lambda$-DNA, a 48,502-base-pair double-stranded bacteriophage DNA molecule isolated from lambda-phage-infected Escherichia coli, while a ubiquitous test molecule in the nanopore world, poses 
challenges when used in unpassivated silicon nitride pores; the DNA tends to stick to the interior of the pore, which can, with time, completely clog. ${ }^{19-21}$ Traditional passivation techniques, such as polyethylene glycol (PEG) soaks ${ }^{21}$, offer temporary solutions to the sticking problem, but covalent modification of an electrolessly deposited gold ${ }^{22,23}$ surface promises a more robust and durable alternative.

We have made progress in functionalizing silicon nitride, but the desired $\sim 10 \mathrm{~nm}$ length-scale of our pores presents severe challenges, especially when imaging the pores to confirm that an electrolessly-plated gold film and subsequent SAM are present within their interior geometries. Moreover, charged particle microscopy is not ideally suited for imaging organic-coated nanopores, and it can lead to contamination and damage that would prevent the coating's subsequent characterization in actual use. To overcome this obstacle, we take advantage of a much simpler method of studying the nanopore interior based on measuring the flow of small monovalent ions through the pore. This technique measures the nanopore conductance, which depends in a direct way, outlined below, upon the nanopore size and shape so that pore narrowing due to gold or monolayer coatings can be directly and nondestructively

measured. ${ }^{13,14,24}$ It has the particular advantages that it is strongly sensitive to the nanopore surface coating, and it is far less likely to cause damage than, for example, $\sim 100 \mathrm{keV}$ electrons in transmission electron microscopy.

\section{THEORY}

Considering a nanopore as a solution-based resistor, the relationship between the applied voltage and the resulting ionic current through the nanopore gives the pore conductance; this is usually plotted as I-V curves, with the slope of the line equaling 
the pore conductance (Figure 3.1). The dominant contributing factors to the pore conductance $^{18,25-27}$ are the pore dimensions and the conductivity of the electrolyte solution being used, as seen in Equation 1.

$G_{\text {bulk }}=K_{\text {electrolyte }}\left(\int \frac{d z}{\pi(r(z))^{2}}\right)^{-1}$

Equation (1)

This term, $G_{b u l k}$, is the bulk ionic conductance, which is treated as a uniform flow of ions through the pore, where Kelectrolyte is the conductivity of the electrolyte and $r(z)$ is the radius of the circularly symmetric pore as a function of the distance into the pore $^{27}$. For ease of calculations, and consistency with previous studies ${ }^{18}$, the pore will be treated as a cylinder, which makes the volume parameter in equation (1) equal to $\pi r_{0}^{2} / L_{0}$, with $r_{0}$ and $L_{0}$ being the initial pore radius and the pore length, respectively. ${ }^{13}$ For our calculations, the manufacturer-specified nominal $\mathrm{SiN}_{\mathrm{x}}$ membrane thickness will be used as the pore length, $L_{0}$.

The bulk conductance model fits high ionic strength data (dotted fit in Figure 3.2), but as the electrolyte concentration in the pore drops, the interaction of the charged pore surface with the ions in solution is no longer negligible, and a second term is needed in the conductance equation, as seen in Equation 2.

$G_{\text {bulktsurface }}=K_{\text {electrolyte }}\left(\int \frac{d z}{\pi(r(z))^{2}}\right)^{-1}+\mu_{K}\left|\sigma_{\text {SiNx }}\right|\left(\int \frac{d z}{2 \pi r(z)}\right)^{-1} \quad$ Equation (2) 


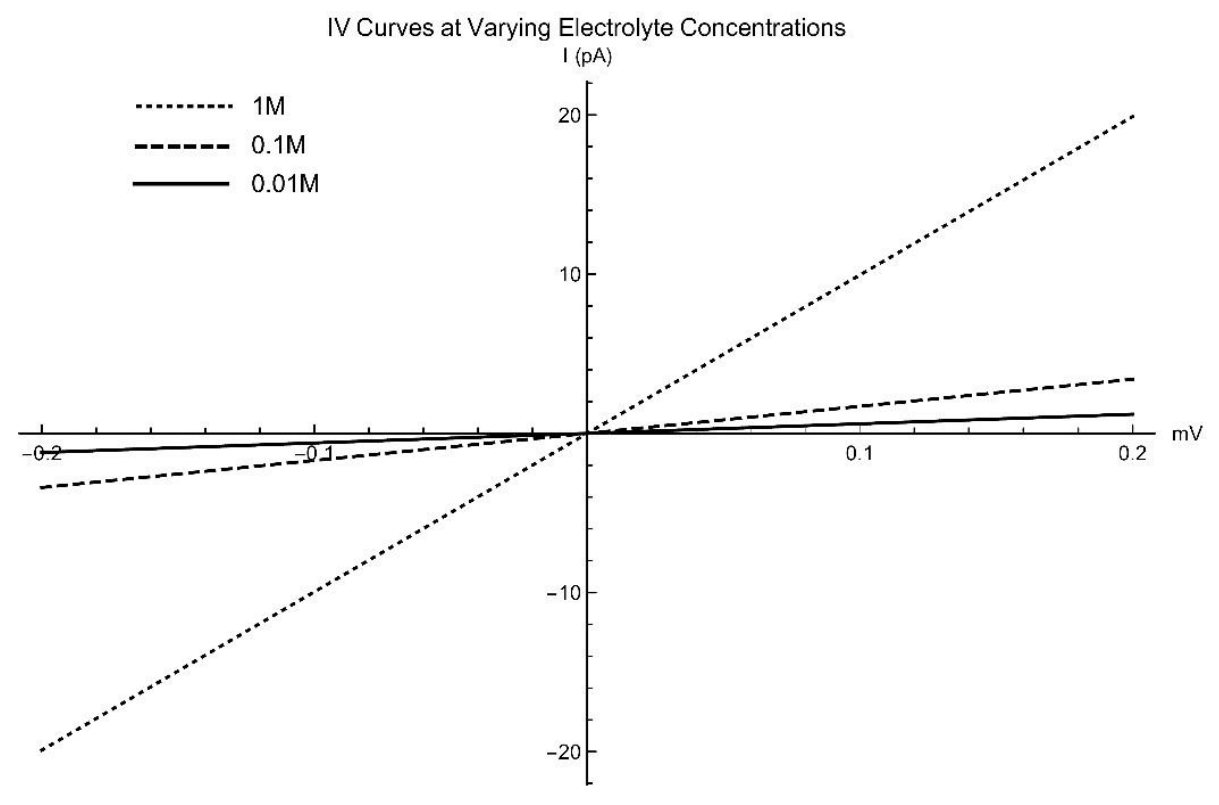

Figure 3.1 IV curves from an 8nm-radius SiN $_{x}$ nanopore fabricated in a 13-nm-thick membrane, measured in $1 M$ (dotted), 0.1M (dashed), and 0.01M (solid) potassium chloride solution, buffered to $\mathrm{pH} 7$ with 10mM HEPES. Pore conductance values are 99.5, 17.0, $6.0 \mathrm{nS}$, respectively. 
The second term ${ }^{13,14}$ in Equation 2 incorporates the total surface charge density of the membrane substrate $\left(\sigma_{S i N x}\right)$, the mobility of the counterions proximal to the surface, $\mu_{K},\left(\mathrm{~K}^{+}\right.$in the case of natively negative $\mathrm{SiN}_{\mathrm{x}}$ pores at our experimental $\mathrm{pH}$ of 7-7.5), and the surface-area parameter, which for a cylindrical pore is $2 \pi r_{0} / L_{0}$.

The inclusion of the surface conductance of the pore (dashed fit in Figure 3.2) dramatically improves the overall fit of the conductance model to the IV curve data, but is not complete without the inclusion of the access resistance ${ }^{28-31}$, which stems from the ionic current flow converging to the restrictive pore mouth, as in Equation 3. $G_{\text {total }}=\left(\frac{1}{G_{\text {bulk }+ \text { surface }}}+2 \times \frac{1}{G_{\text {acosss }}}\right)^{-1}=$

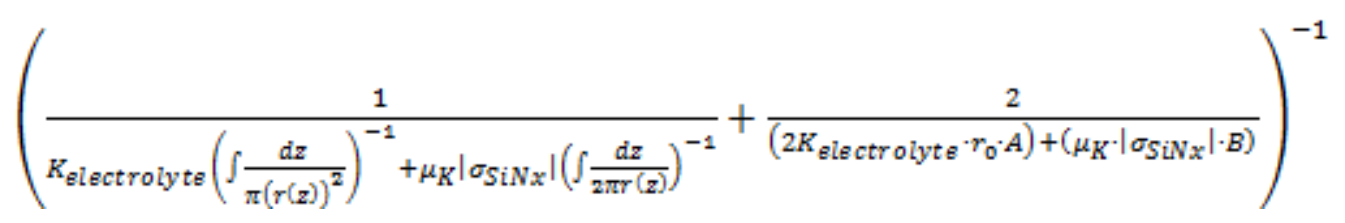

Equation (3)

The access resistance depends upon the bulk electrolyte conductivity, the pore radius, as well as the surface charge density and the layer of counterions that forms on the surface, and it adds in series with the bulk and surface resistances, which are, in turn, added in parallel with each other. ${ }^{33-36}$ There are two adjustable parameters ${ }^{33}, A$ and $B$, which we have found to be 1 and 3, respectively; 


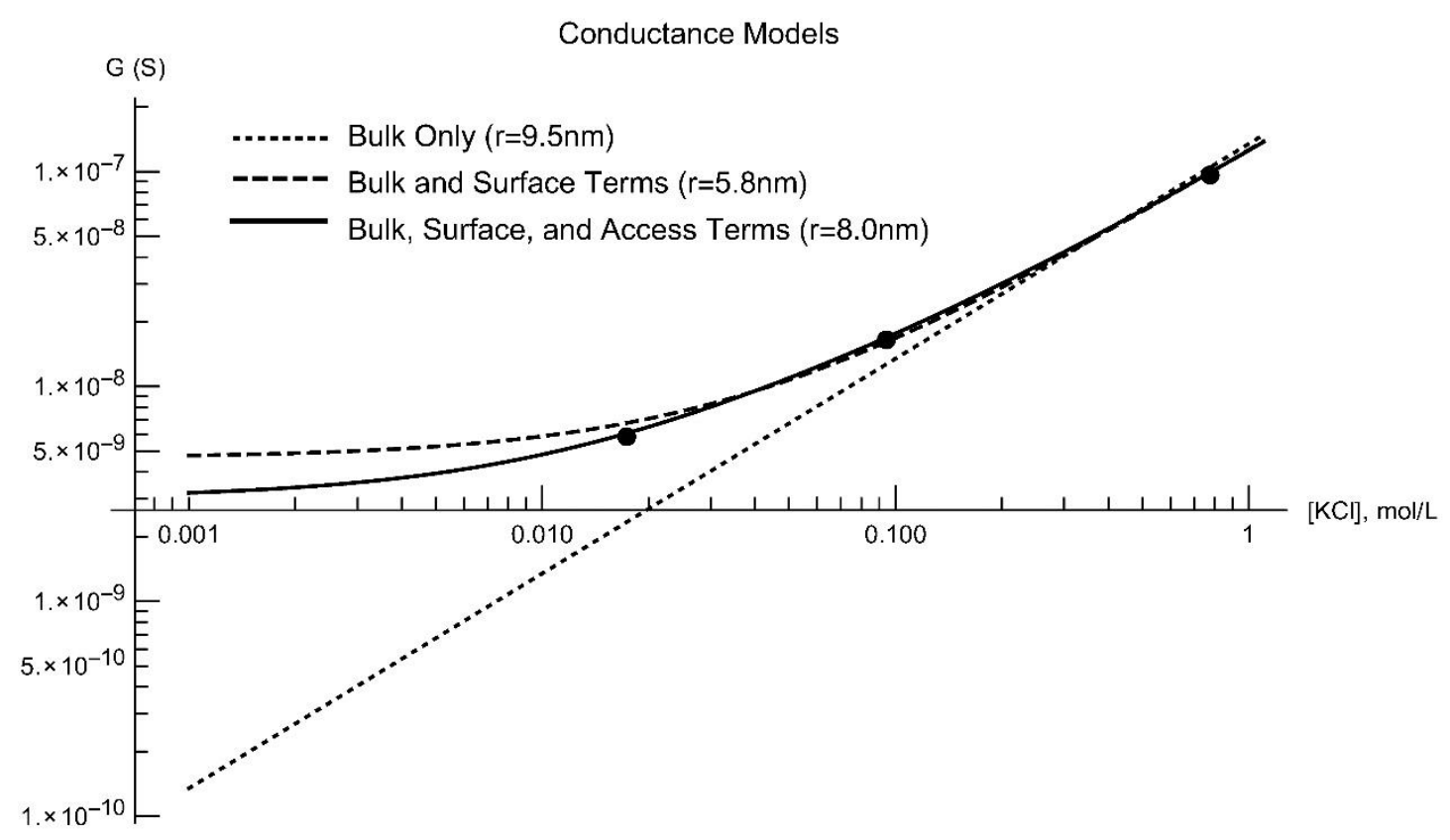

Figure 3.2 Three conductance models fit to the same data points. IV curves of a single SiN $N_{x}$ pore in a 13-nm-thick silicon nitride membrane were measured at 0.01, 0.1, and $1 M, p H 7$ HEPES- buffered potassium chloride electrolyte. The three conductance models shown are a bulk-only fit (dotted), which overestimates the pore radius and diverges from the data points at all but the highest ionic strengths; bulk and surface term fit (dashed), which underestimates the pore radius and diverges from the data at very low ionic strengths; and the combined bulk, surface, and access resistance terms (solid) that fits the data across all ionic strengths. The pore radii extracted with each parameter are indicated in the legend. 
these values were mathematically optimized provide the best fit of Equation 3 to data collected on pores of varying initial radii, pore coatings, and manufacturer-declared nominal thicknesses. The access resistance as shown accounts for half of a sphere at one opening of the pore, and thus must be doubled to account for both ends of the pore. The inclusion of all three terms fits the experimental data (solid fit in Figure 3.2) across the range of electrolyte concentrations examined.

The conductance-based study of a SAM formed on the gold interior of a nanopore has the benefit of providing a clear, albeit indirect, indication that we have gold-plated and SAM-functionalized the inside of the pore when compared to measurements of the pre-coated pore We build on this established geometric framework while noting that it may require modification to reflect the use of an electrically floating, conducting, base layer to coat the nanopore membrane.

To fit a single pore pre- and post-modification, the bare IV curve data at 0.01 , 0.1 , and $1 \mathrm{M} \mathrm{KCl}$ is fit to Equation 3, and the bare pore radius is extracted, along with the surface charge density of the $\mathrm{SiN}_{\mathrm{x}}$ pore, as shown in Table 1 . The initial calculated pore radius (decreased by an unknown coating thickness) is then used as a starting point - along with the post-coating conductance values at $0.01,0.1$, and $1 \mathrm{M} \mathrm{KCl}-$ to solve for the total thickness of the combined gold and SAM. To do this, we make the approximation that the change in measured conductance is solely due to the change in pore radius and effective pore length by the deposition of the coating. Simply put, the degree by which the conductance changes is directly proportional to the thickness of 
the deposited coating, and, if the bare pore radius is known, then the coating thickness can be calculated.

Table 1. Table of calculated surface charge density values for nanopores of various starting radii

\begin{tabular}{|c|c|c|}
\hline Pore & Calculated $\mathrm{r}_{0}(\mathrm{~nm})$ & Calculated $\sigma_{\mathrm{SiNx}}\left(\mathrm{S} / \mathrm{m}^{2}\right)$ \\
\hline 1 & 4.16 & 0.0178 \\
\hline 2 & 9.28 & 0.0177 \\
\hline 3 & 5.09 & 0.0178 \\
\hline 4 & 8.84 & 0.0178 \\
\hline 5 & 7.67 & 0.0178 \\
\hline 6 & 7.98 & 0.0178 \\
\hline $\begin{array}{c}\text { Mean surface charge } \\
\text { density }\end{array}$ & & $0.0178 \pm 0.0001$ \\
\hline $\begin{array}{c}\text { Literature surface charge } \\
\text { density }\end{array}$ & & $0-0.1$ \\
\hline
\end{tabular}

The overall approach draws heavily from a sophisticated treatment of analyteinduced nanopore blockage currents by Reiner and co-workers in which we realized that their treatment of a large surface-immobilized molecule within a nanopore could be extended, with some manipulation, to represent a molecular coating applied to a nanopore surface. ${ }^{33}$ The method detailed by Reiner described discrete regions within the pore: the region of the pore without the molecule adsorbed to its side wall, and the region where the large molecule resided within the pore. The latter region was of a reduced cross-sectional area, due to the physical dimensions of the blockage molecule, and the conductance model for this region incorporated a term to describe affinity of 
the electrolyte ions for the blockage molecule, which differed from the ionic affinity for the pore walls. Our work was particularly inspired by the inclusion of the two different surface conductance terms, which allowed us to create our own model of a two-region pore: one with a molecular coating, and one that remained unmodified, where our partial coating was treated as an analog to Reiner's molecular blockage. The extension of the two-region conductance model afforded the opportunity to study a real-world problem, that of incomplete monolayer coverage, within the nanopore environment with which we were familiar. In our calculations, we assumed that there is a not ideally packed SAM covering the gold-plated surface of the pore. This sparsely-arranged monolayer contained some number of molecules that, when spatially rearranged, could form a full, ideally-packed, monolayer that covered some fraction, $\phi$, of the available pore surface area (Figure 3.3D). Additional modifications of the Reiner equations included the incorporation of surface conductance terms for both regions of the pore, as well the inclusion of an access resistance ${ }^{28-30}$. 
A

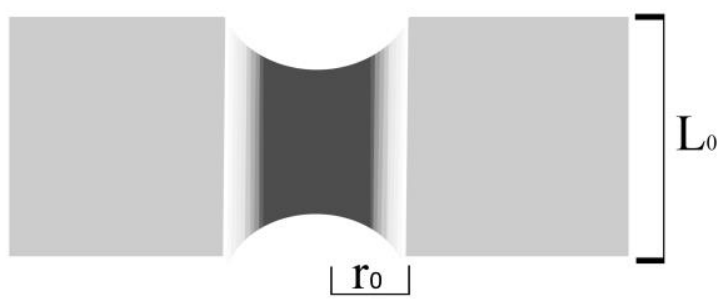

B

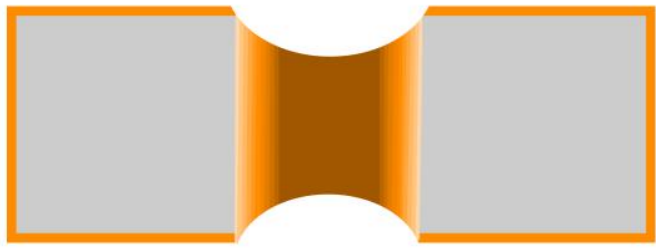

$\mathrm{C}$

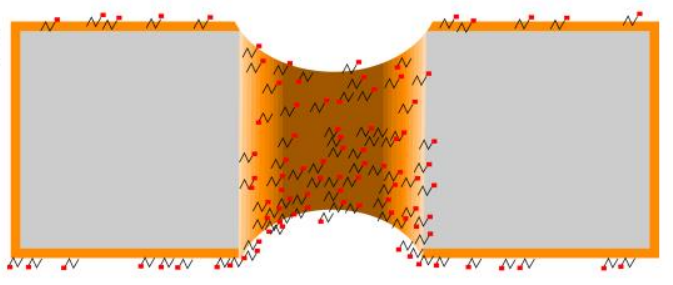

$\mathrm{D}$

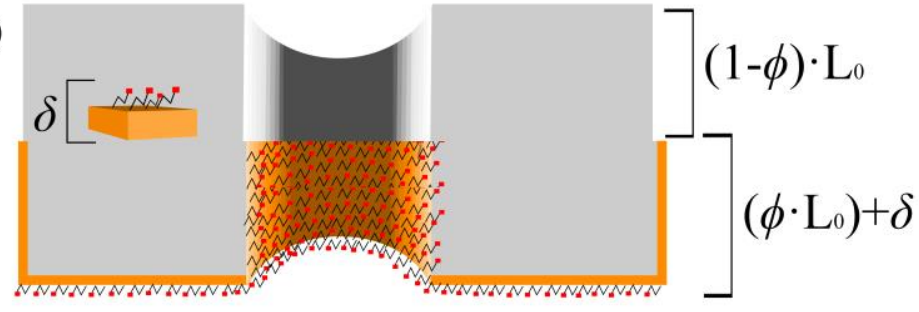

Figure 3.3 Vertical cutaways through a bare silicon nitride nanopore (A), the same pore after electroless gold-plating $(B)$, and the gold pore after functionalizion with an incomplete thiol-terminated SAM (C). To simplify calculations, the incomplete SAM is modelled as an ideally equivalent configuration of complete monolayer covering a fraction, $\phi$, of the available surface area, $(D)$. The total effective thickness of the gold coating plus the thickness of the monolayer, $\delta$, defines the decrease in radius of the coated pore region, and the increase in pore length. 
Here, using an electroless gold layer as a support substrate for a SAM, the fractional coverage is much more complicated than laid out within this paper, and the original silicon nitride surface will be covered with a fractional gold-plated layer, which is in turn functionalized with a fractional SAM. This would create three regions within the pore, but for simplicity, we have condensed this model to two regions: a bare silicon nitride region, and a region coated by gold and a SAM of total effective thickness, $\delta$.

For the sake of simplicity, the coating of the pore is treated as an ideallypacked SAM that covers a fraction, $\phi L_{0}$, of the length of the pore, where (surface area covered by gold $+\mathrm{SAM}) /($ total surface area of pore) is $\phi$. Figure 3.3 shows how a bare pore (Figure 3.3A) is first gold-plated (Figure 3.3B), and then becomes functionalized with an incomplete, sparsely- arranged monolayer (Figure 3.3C), which in the course of our calculations is treated as an ideally-packed monolayer that covers a fraction of the surface area (Figure 3.3D)- i.e. the same number of molecules originally deposited on the pore surface are rearranged from a random packing pattern to one with a maximum packing efficiency. This reduces the pore to our two desired regions; one that is treated with the same parameter values as a bare silicon nitride pore, and one that features an effective gold+SAM coating of thickness $\delta$, where we treat both regions as having the same effective surface charge density.

The uncoated region of the pore can be modelled by bulk, surface, and access resistances very similar to those shown in Equation 3. The difference post-coating becomes that the equations are applied over the length of the unmodified region of the 
pore, instead of over the entire pore length, and that there is only one opening of the uncoated pore to bulk solution in the holder well to contribute to the access resistance. Equation 4 shows these modifications, with the volume and surface parameters for a cylindrical pore included in place of the integrals shown in Equation 3.

$$
\begin{aligned}
& G_{\text {uncoated }}^{\text {total }}=\left(\frac{1}{G_{\text {uncoated }}^{\text {bulk }}+G_{\text {uncoated }}^{\text {surface }}}+\frac{1}{G_{\text {uncoss }}^{\text {acceated }}}\right)^{-1}= \\
& \left(\frac{1}{\left(K_{\text {Electrolyte }} \frac{\pi r_{0}^{2}}{(1-\phi) L_{0}}\right)+\left(\mu_{K} \cdot\left|\sigma_{S i N x}\right| \cdot \frac{2 \pi r_{0}}{(1-\phi) L_{0}}\right)}+\frac{1}{2 K_{\text {Electrolyte }} r_{0} A+\mu_{K}\left|\sigma_{S i N x}\right| B}\right)^{-1}
\end{aligned}
$$

In the second region of the nanopore, the discontinuous gold+SAM covering the entire length of the pore is mathematically treated as a complete layer that only covers a fraction, $\phi$, of the available pore surface area (Figure 3.3C). There is consequently a reduction in the total number of electrolyte ions that can physically fit within the pore volume, due to the gold+SAM occupying some of the internal volume of the pore; the local ionic concentration (molecules/unit volume) is thereby changed, and the equation for the bulk conductance proximal to the coated pore region must be modified, resulting in Equation 5 (evaluated for a cylindrical pore). In addition to the modified volume parameter shown below, $K_{S A M}$ replaces the original bulk electrolyte conductivity, $K_{\text {electrolyte. }}$

$$
G_{\text {coated }}^{b u l k}=K_{\text {SAM }} \frac{\pi\left(r_{0}-\delta\right)^{2}}{\phi L_{0}+\delta}
$$


Within the gold+SAM region of the nanopore, the bulk electrolyte conductivity ( $K_{\text {electrolyte }}$ ) cannot be used, for the electrolyte conductivity is dependent upon the sum of the individual ionic contributions, which change from the bare $\mathrm{SiN}_{\mathrm{x}}$ region to the gold+SAM-coated one. The numerical concentration of ions within the solution can be calculated from the initial molar concentration $(k$, in mol/L), and converted to molecules $/ \mathrm{m}^{3}$ by multiplying by Avogadro's number $\left(N_{A}\right.$, molecules/mol), times $1000 \mathrm{~L} / \mathrm{m}^{3}$. To go from molecules $/ \mathrm{m}^{3}$ to the final conductivity units of $\mathrm{S} / \mathrm{m}$, the molecular ionic mobility, $\mu$, with units of $\mathrm{m}^{2} /(\mathrm{s} \cdot \mathrm{V})$, is multiplied by the elementary charge, $e$, in Coulombs. Equation 6 shows the calculation of the electrolyte conductivity in the coated region of the pore, $K_{S A M}$.

$K_{S A M}=\left(1000 N_{A} \times k \times e \times \mu_{C l}\right)+\left(1000 N_{A} \times k\left(\frac{m_{B}}{m_{T}}\right) \times e \times \mu_{K}\right) \quad$ Equation (6)

Within the above equation, the contribution to the total conductivity by the chloride anion remains unchanged, because that species is not adsorbed onto either the bare $\mathrm{SiN}_{\mathrm{x}}$ surface or the gold+SAM-coated region. ${ }^{33}$ However, the contribution of the cation is scaled by the fraction of cations that are bound to the SAM ( $m_{B}$ Equation $7^{33}$ ) compared to the total number of cations in the entire coated pore volume $\left(m_{T}\right.$, Equation 8 , for a cylindrical pore $)^{33}$. The potassium ions within our pore system have a different association constant for the bare $\mathrm{SiN}_{\mathrm{x}}$, compared to that for the SAM. At high ionic strengths, there exists a complete electrical double layer on the coated region of the pore, and all of the potential $\mathrm{K}^{+}$adsorption sites are occupied, making the ratio $\left(m_{B} / m_{T}\right)$ equal to 1 , and $K_{S A M}=K_{\text {electrolyte }}$, but this is not the case for the lowest ionic strength solutions, and must be incorporated into our conductance model. 
$m_{B}=\frac{\alpha-\sqrt{\alpha^{2}-4 m_{T} n}}{2}$

Equation (7)

$m_{T}=1000 k N_{A}\left(\left(\pi r_{0}^{2} L_{0}\right)-\left(\pi \times\left(r_{0}-\delta\right)^{2} \times\left(\phi L_{0}+\delta\right)\right)\right)$

Equation (8)

In calculating the ratio, $m_{B} / m_{T}$, the number of bound cations, $m_{B}$, is dependent upon a quadratic parameter, $\alpha$, described by Equation 9. This parameter includes a term for the maximum number of cations that can be bound to the surface if the entire pore was coated by the monolayer $(n)$, as well as the association constant of the potassium ions for our SAM, $K_{A}$.

$\alpha=m_{T}+n+\frac{1}{K_{A}}$

Equation (9)

To calculate $n$, some physical properties of the SAM must be known. The radius of the headgroup of the monolayer, $r_{S A M}$, is one factor in determining how many monomeric units can fit onto the pore surface, in an ideal packing conformation. This packing conformation must be modified to account for the curvature of the pore; this becomes exceptionally important with small pores with radii that are of similar length scales to the thickness of the SAM. Finally, with an optimally-packed monolayer on the curved interior surface of the cylindrical pore, the number of monomeric units required to bind a single cation, $x$, must also be known. These factors all combine in Equation 10, resulting in a value for $n$ : the maximum number of potassium ions that could be adsorbed onto the surface of a pore of a given initial radius, $r_{0}$, with a gold+SAM coating of total effective thickness $\delta$. 
$n=\frac{2\left(r_{0}-\delta\right)\left(L_{0}+\delta\right)}{x \cdot r_{S A M}^{2}}$, for $\mathrm{PEG}^{81}: x=4, r_{S A M}=0.332 \mathrm{~nm}$

Equation (10)

The quadratic parameter $(\alpha)$ to the Equation for $m_{B}$ includes one further attribute to discuss: the association constant of the potassium counterion for the surface, $K_{A}$. The traditional expression for an association constant, as calculated from the free energy change, $K_{A}=\exp \left[\Delta G / k_{B} T\right]$, must be modified in this instance. A value ${ }^{24}$ for the increase in free energy of the pore upon the binding of one potassium ion to a surfaceimmobilized PEG molecule $\left(\Delta G_{\text {pore }}\right)$ is needed to describe this first-order kinetic process. Also included in the calculation of $K_{A}$, shown by Equation 11, is a term, $s$, that relates the ratio of the electroosmotic force on a cation within the pore, to the electrophoretic force provided by the applied voltage scaled by the applied voltage, $V$. $K_{A}=\exp \left[\frac{\left(\Delta G_{\text {pore }}+s \cdot V\right)}{k_{B} T}\right]$, for $P_{E G}^{81}: \Delta \mathrm{G}_{\text {pore }}=-0.497 \mathrm{eV}, \mathrm{s}=0.21 \quad$ Equation (11)

In the calculations of pore radius for our experiments, $V$ was held to $0.200 \mathrm{~V}$, the maximum voltage magnitude applied during an IV curve acquisition. The parameter, $s$, represents the ratio of electroosmotic viscous force to electrophoretic force on a cation as a function of its distance into the pore, and has been estimated at 0.21 for PEG residing exactly half-way into a $\mathrm{SiN}_{\mathrm{x}}$ pore ${ }^{24}$.

In addition to the bulk conductance, a surface conductance term ( $\left.G_{\text {coated }}^{\text {surface }}\right)$, and access resistance $\left(G_{\text {coated }}^{\text {acoess }}\right)$ also contribute to the total conductance of the coated region of the pore. The surface conductance and access resistance terms, Equation 12 
and 13, respectively, (shown for a cylindrical pore), include the surface charge density of the coating, $\sigma_{S A M}$. We have assumed for the sake of simplicity that the overall charge density of our gold+SAM coating is not significantly different than that of the bare $\mathrm{SiN}_{\mathrm{x}}$ surface in our electrolyte solution, making $\sigma_{S A M}=\sigma_{S i N x} ; \sigma_{S i N x}$ is one of the two parameters ( $r_{0}$ being the other) that is determined by solving Equation 3 prior to plating and SAM-coating the nanopore.

$G_{\text {coated }}^{\text {surface }}=\mu_{K} \cdot\left|\sigma_{\text {SAM }}\right| \cdot \frac{2 \pi\left(r_{0}-\delta\right)}{\phi L+\delta}$

Equation (12)

$G_{\text {coated }}^{\text {access }}=\left(2 K_{\text {SAM }} \times\left(r_{0}-\delta\right) \cdot A\right)+\left(\mu_{K} \cdot\left|\sigma_{\text {SAM }}\right| \cdot B\right)$

Equation (13)

The three conductance terms from Equations 5, 12, and 13, can be incorporated into one equation (Equation 14) to describe the total conductance through the coated pore region.

$$
\begin{aligned}
& G_{\text {coated }}^{\text {total }}=\left(\frac{1}{G_{\text {coated }}^{\text {bulk }}+G_{\text {coated }}^{\text {Surface }}}+\frac{1}{G_{\text {coated }}^{\text {access }}}\right)^{-1}= \\
& \left(\frac{1}{\left(K_{S A M} \frac{\pi\left(r_{0}-\delta\right)^{2}}{\phi L_{0}+\delta}\right)+\left(\mu_{K} \| \sigma_{S A M} \mid \frac{2 \pi\left(r_{0}-\delta\right)}{\phi L+\delta}\right)}+\frac{1}{\left(2 K_{S A M} \cdot\left(r_{0}-\delta\right)-A\right)+\left(\mu_{K} \| \sigma_{S A M} l-B\right)}\right)^{-1} \text { Equation (14) }
\end{aligned}
$$

A comprehensive equation (Equation 15) incorporates all of the terms described above, for the coated and uncoated regions of the pore, and can be used to calculate the effective fractional coating of the surface $(\phi)$, as well as the effective thickness $(\delta)$ of that coating; here, the coating is the electroless gold layer, plus the SAM on top of it. 


$$
\begin{aligned}
& G_{\text {total }}^{\text {two-region }}=\left(\frac{1}{G_{\text {coated }}^{\text {total }}}+\frac{1}{G_{\text {uncouated }}^{\text {total }}}\right)^{-1}=\left(\left(\frac{1}{\left(K_{S A M} \frac{\pi\left(r_{0}-\delta\right)^{2}}{\phi L_{0}+\delta}\right)+\left(\mu_{K} \cdot \sigma_{S A M} \mid \cdot \frac{2 \pi\left(r_{0}-\delta\right)}{\phi L+\delta}\right)}+\right.\right. \\
& \left.\frac{1}{\left(2 K_{S A M} \cdot\left(r_{0}-\delta\right) \cdot A\right)+\left(\mu_{K} \cdot\left|\sigma_{S A M}\right| \cdot B\right)}\right)+\left(\frac{1}{\left(K_{\text {electrolyte }} \frac{\pi r_{0}^{2}}{(1-\phi) L_{0}}\right)+\left(\mu_{K} \cdot\left|\sigma_{S i N x}\right| \cdot \frac{2 \pi r_{0}}{(1-\phi) L_{0}}\right)}+\right. \\
& \left.\left.\frac{1}{2 K_{\text {Electrolyte }} r_{0} A+\mu_{K} \mid \sigma_{S i N x} \| B}\right)\right)^{-1}
\end{aligned}
$$

Equation (15)

When applying the equations discussed above to real-life data, IV curves from a single nanopore are acquired at $0.01,0.1$, and $1 \mathrm{M} \mathrm{KCl}$ concentrations prior to coating and again after the full gold+SAM coating has been applied. Equation 3 is used with the unmodified pore data to yield the initial pore radius $\left(r_{0}\right)$ and the surface charge density $\left(\sigma_{S i N x}\right)$. These values are used with Equation 15 to fit the post-coating pore conductance data, resulting in a value for the effective coating thickness, $\delta$, and the fraction of the pore surface covered by the applied coating, $\phi$. One caveat to this conductance model is that it does not account for the complexities introduced by an electrically-conductive, ungrounded surface, and thus the results retain a degree of inherent inaccuracy. Moreover, the assumption we have made to treat a three-region system by a two-region scheme would introduce further inaccuracy. However, our final two-region approach could prove to be quite useful in a situation where a silicon nitride pore is directly and covalently functionalized by an organic monolayer ${ }^{15}$, this two-region model would provide a much more accurate representation of the 
monolayer thickness and surface coverage than it does for the gold-SAM system described herein. 


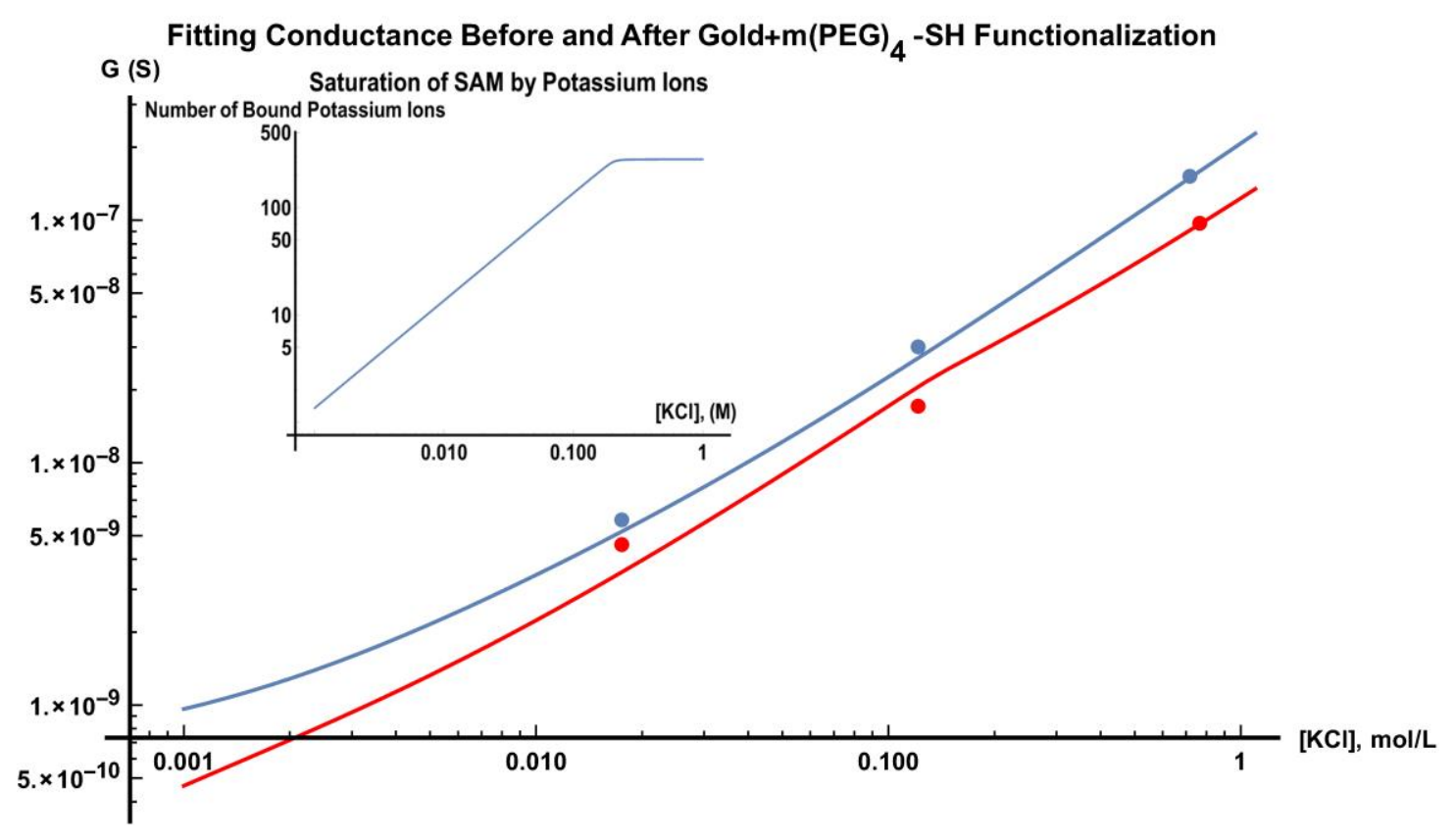

Figure 3.4 Nanopore conductance fits before (blue, fit using Equation 3) and after (red, fit using Equation 15) electroless plating a single, nominally-10-nm-long, 9.2nm-radius SiN $_{x}$ nanopore with a film of electroless gold, followed by self-assembly of a methyl-(PEG) $)_{4}$-thiol monolayer, totaling $5.2 \mathrm{~nm}$ in effective thickness and $54 \%$ in fractional coverage. There are two fit regions seen post-functionalization, which converge at $0.2 \mathrm{M}$ - the point of $90 \% \mathrm{~K}^{+}$saturation of the monolayer for this given pore, given its particular degree of coverage (inset). The maximum number of potassium ions that could be bound to the SAM within this pore $\left(m_{B}\right)$ was 282; below that number, at electrolyte concentrations less than $0.2 M$ there is one fit region, and above the saturation point, the trace features a second region. 


\section{RESULTS AND DISCUSSION}

\section{Imaging Nanoporous Substrates}

The conductance-based techniques discussed above provided indirect evidence consistent with the formation of an electrolessly plated film and subsequent SAM attachment within the pore, but an effort was made to directly confirm the success of the coatings. Instead of immediately undertaking the challenge of imaging single nanopores, a micron-scale imaging step (described in Chapter 2 of this thesis) was undertaken using microporous arrays ${ }^{16}$, featuring $2.5 \mu \mathrm{m}$ diameter pores, followed here by a step down in length scale to nanopore arrays, featuring $650 \mathrm{~nm}$ diameter pores. Proof-of-principle testing in the micropores, in which we demonstrated plating throughout the pores of a 200 -nm-thick substrate ${ }^{16}$, confirmed that it was possible to translate the gold-plating process from planar substrates to those with areas of high curvature, and that the plating solution had access to all interior surfaces of the pores, even with an increased pore length compared to the final target pore length of $\sim 10$-nm single nanopores. Nanosieve membranes - uniform nanopore arrays for microfiltration applications - have been used to study mass transport processes ${ }^{34-36}$, and provided a convenient intermediate step for extending our electroless plating and imaging procedure from planar and microporous surfaces to nanoporous ones.

We tested the suitability of this process for plating nanopores in membranes in a thicker $(\sim 650 \mathrm{~nm})$ film of silicon nitride supported by a silicon frame. It was unclear if this plating procedure would work on the nanoscale, and if the smaller, longer, pores would still have complete solution access. From the top-down view of the pore arrays, the planar surfaces plated evenly, as seen in Figure 3.5a, and the secure solution-tight seal provided by the silicone gaskets allowed for a controlled area of gold deposition 


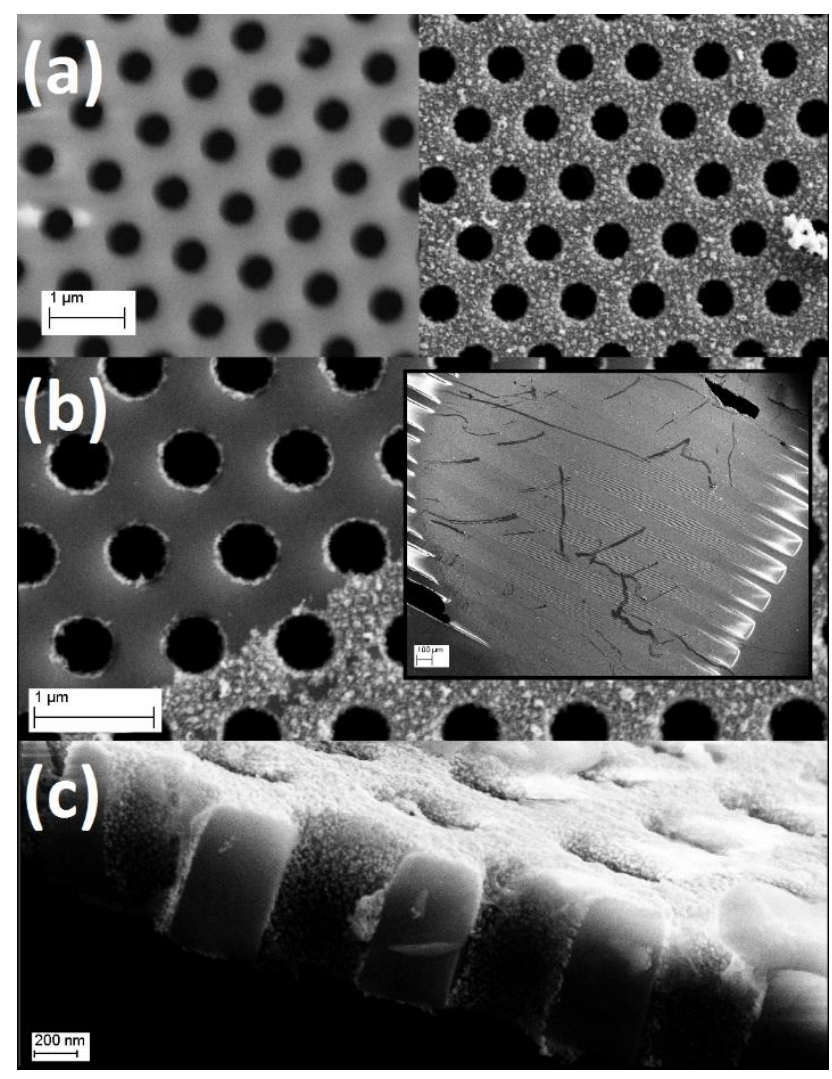

Figure 3.5 A nanoporous silicon nitride membrane prior to plating (a, left), contrasted to electroless gold after plating ( $a$, right). In an example where the gold film was intentionally removed by a gentle scrape with plastic tweezers $(b)$, the gold film inside the pores can still be seen, and the underlying silicon nitride substrate is visible in contrast with the gold-plated portion of the membrane. The inset in (b) shows the area that was not covered by the gasket in the center, with various scratches due to handling, with the gasket-masked outer edge showing electron charging effects (bright outer regions) upon the non-gold-plated region of the insulating silicon nitride surface. A cross-section (c) of the same membrane reveals the gold film penetrated throughout the nanopores and on the top side of the membrane, although the film had not plated to continuous coverage. The viewing angle for the fractured membrane seen in (c) obscures the bottom halves of the coated pore, obscuring the gold in those regions from view. Debris resulting from the fracturing process can also be seen in panel (c) of this figure, and is not representative of an unfractured surface. 
(inset, Figure 3.5b). The images from the field-emission scanning electron microscope (FE-SEM) of the deliberately fractured membranes were facilitated by the number of nanopores in the membrane; no matter the fracture axis, minimal searching would yield at least one cross-sectional view of the interior of a representative pore. In contrast with the microporous substrates, the cross-sections of the nanopores did not appear to be continuously plated with a gold film along the length of the pores, as seen in Figure $3.5 \mathrm{c}$ of a deliberately fractured nanoporous membrane. The one hour plating time of the nanoporous membrane in Figure $3.5 \mathrm{c}$ has been shown to deposit essentially void-free films of approximately $42 \mathrm{~nm}$ in thickness on planar substrates, but the deposition process did not proceed in the same manner into the nanoporous substrate, nor as into the micropores ${ }^{16}$ from earlier studies, which featured continuous gold films of $\sim 10 \mathrm{~nm}$ thickness, as determined by SEM, for the same hour plating duration. The discontinuity of the gold film on the nanoporous sample may be an artificial effect due to focal-depth limitations; the bright islands seen are those protruding from the plating surface.

It is important to note the length of these nanosieve nanopore arrays-650 $\mathrm{nm}$ — in comparison to the length of the micropore arrays $-200 \mathrm{~nm}$ - and the single nanopores $-10-30 \mathrm{~nm}$ - may contribute to the incomplete through-pore plating seen. The micropores had the favorable combination of minimally restricted solution access, along with a shorter pore length, and thus were fully coated. It is possible that the nanopore channels were simply too long, and/or needed to be in the plating solution for longer than one hour, for there to be adequate deposition of a continuous gold film given the asymmetric plating conditions. The $10-30 \mathrm{~nm}$ thickness of most single 
nanopores should be thin enough to afford solution access throughout the pore channel, but that access will be more restricted due to the pore's limited diameter.

With the initial promising results from the nanoporous membranes, we proceeded with proof-of-principle experiments in our target of a $<100 \mathrm{~nm}$ nanopore. In an effort towards electroless deposition of gold into these smaller, and thinner, nanopores, the aforementioned gold deposition procedure was carried out asymmetrically (Figure 3.6) on a set of five-by-five helium-ion-drilled nanopore $\operatorname{arrays}^{37,38}$, in which the original nanopore diameters post-fabrication were less than 20 $\mathrm{nm}$, as determined by calibrated He-ion beam dwell times, and the manufacturerspecified membrane thickness was $30 \mathrm{~nm}$. This experiment also allowed us to examine the penetration of plating solution into the pore, and to ease into nanopore imaging for a pore size where many-pore arrays are not available. The images seen in Figure 3.7 are the result of this set of experiments. Most noteworthy is the diffusion of gold through the two nanopore arrays drilled into the free-standing portion of the silicon nitride membrane. Due to the restriction on the nanopore radii, the spacing, and the number of nanopores traversing the membrane, the mixing of the gold and formaldehyde solutions through the pores was localized, so that the diffusion bloom footprint could be clearly imaged. 


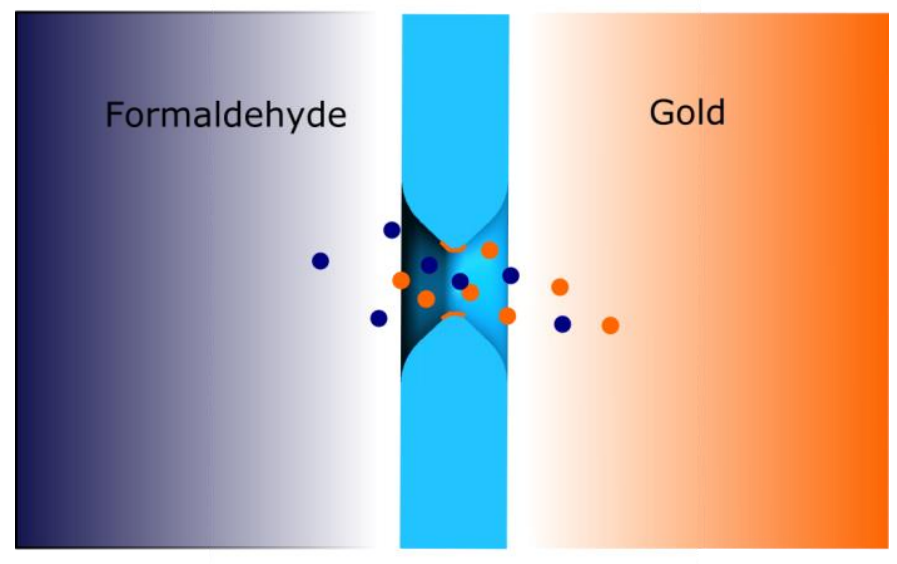

Figure 3.6 Asymmetric plating conditions. After full sensitization steps were carried out on both sides of the membrane, one solution well was filled with the reducing agent-formaldehyde (blue)—and the other side with the formaldehyde-free gold plating bath (orange). The nanopore provides a mixing area for the two solutions, resulting in deposition of gold onto the tin-sensitized surface where the two solutions meet. 
This set of experiments demonstrates that gold plating can occur through the nanopores, where the diffusion of gold ions, and the conversely diffusing formaldehyde, move from one well through the corresponding nanopore to the other well, and that this process can clearly be imaged. The imaging of the ionic masstransport process here demonstrates plating results that add convincing direct evidence in support of the symmetric plating results characterized by conductance (Figure 3.5). The asymmetric imaging shows that it is certainly possible for enough gold solution to diffuse through the pore so that it comes in contact with all internal pore surfaces, thereby suggesting that solution access should be sufficient to support gold-plating the interior of a nanopore.

The conductance-based measurements allow for testing of pores for coverage after gold-plating, as well as molecular-coating via thiol-attachment to the gold surfaces. Additionally, the molecular functionalization may be reversible ${ }^{39-41}$, which would allow the study of conductance changes in fixed spatial increments before and after molecular monolayer formation, rather than time-dependent ones. Non-imaging based techniques have been developed to indirectly size-profile single nanopores, including those coated with fragile organic monolayers that would be damaged upon exposure to a high-energy electron beam in an electron microscope. ${ }^{14,23}$ 

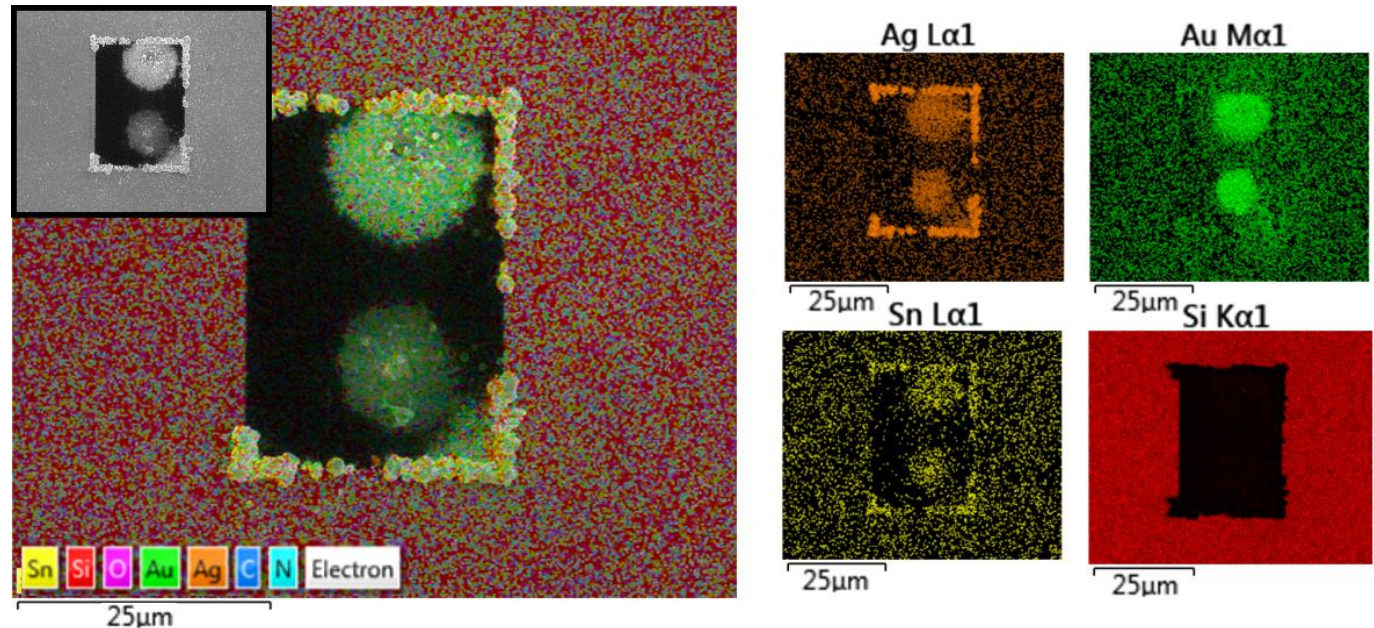

Figure 3.7 Layered EDS image of two $5 \times 5$ nanoarrays drilled into a free-standing silicon nitride membrane, with the corresponding electron image inset in the upperleft corner. Prior to purchase of the substrate, LPCVD silicon nitride was deposited onto a silicon support wafer, which was anisotropically etched to reveal a freestanding portion of the silicon nitride (center rectangular region on images). A helium-ion microscope was used to create the two arrays of nanopores indirectly seen here through the plated footprints. The individual energy channels shown at right correspond to (clockwise) silver, gold, silicon, and tin $x$-rays signals. The micronscale crystals seen around the edge of the silicon nitride window in the center are comprised largely of tin and silver, and the gold channel fails to show localized buildups of gold. We hypothesize that incomplete solution exchanges between steps left residual tin and silver on the surface of the membrane, which were later reduced by formaldehyde during the final 3-hour gold-plating step of the procedure. ${ }^{89,90}$ Such crystals are not seen in the area around the nanopore arrays, themselves, where gold is found in the highest concentrations. The light dispersion of gold across the entire silicon nitride membrane attests to the mass transport of gold ions through the pore, and was most likely facilitated by the gentle rocking of the membrane during the plating process. The sharp contrast between the dusting of gold coating the entire surface and the gold plated around the pore arrays provides evidence for supporting the mass-transport process of gold and formaldehyde through the nanopore array. 


\section{Conductance-Based Characterization of Coating Steps ${ }^{13,14}$}

The ultimate goal of this electroless plating procedure was to symmetrically coat single nanopores in free-standing silicon nitride membranes, followed by surface modification by attachment of thiol-terminated self-assembled monolayers. Measurements of through-pore currents as a function of applied voltage yielded conductance values for two individual helium-ion drilled nanopores fabricated in 30nm-thick silicon nitride membranes, as shown in Figure 3.8 as a function of surface modification step. Both pores had an initial radius greater than $75 \mathrm{~nm}$, and as expected, when the pore diameter was reduced by a film of gold or formation of a SAM on top of the gold layer, the conductance measurement dropped accordingly; conversely, the conductance increased after a plasma-cleaning step was introduced to remove the SAM.

Based on the gradual increase in overall conductance of the coated nanopores seen over a month of experimentation, it was hypothesized that a portion of the first deposition of gold onto the surface of the wafers, and into their corresponding nanopores, may have equilibrated into the electrolyte, to be washed away during solution exchanges; may have become damaged upon un-mounting and re-mounting for plasma-cleaning; or may have become annealed during exposure to the elevated temperatures of the plasma chamber. This prompted a second electroless deposition process to fill in any gaps, most likely catalyzed by the gold already on the surface, to ideally complete the continuity of the gold film. For one of the pores studied, there was a corresponding decrease in measured conductance after this second round of 
plating, while there was an unexpected increase in conductance for a second pore subjected to the same procedure. Both nanopores, though internally inconsistent with respect to the renewal of the gold film, did show a decrease in conductance after exposure to a fresh solution of the mPEG-SH molecules (see inset Figure 3.8 which compose the respective SAMs. This step, referenced as step number 6 of Figure 3.8, was done as a simple experiment to demonstrate that we can exert chemical control over the terminal surface functionalities within the nanopore. The mPEG-SH coating for one nanopore was carried out at $3^{\circ} \mathrm{C}$ for 12 hours to ensure a uniform coating ${ }^{44}$, with an expected decrease in conductance confirming its assembly on the thin gold film within the pore. The second nanopore was subjected to carboxy-PEG-SH soak, which also resulted in a corresponding decrease in conductance. The conductance decreases seen in both pores from step 5 to 6 , and the corresponding decrease in pore diameter (consistent with a $2.1 \mathrm{~nm}$-thick mPEG SAM, as reported ${ }^{44}$ from dry film XPS measurements), suggest that the SAM was indeed bound to the gold surfaces of the nanopores, thus demonstrating our ability to coat the interior of nanopores with a chemically functionalized layer of our choosing. 
Average Conductance Values for Silicon Nitride Nanopores

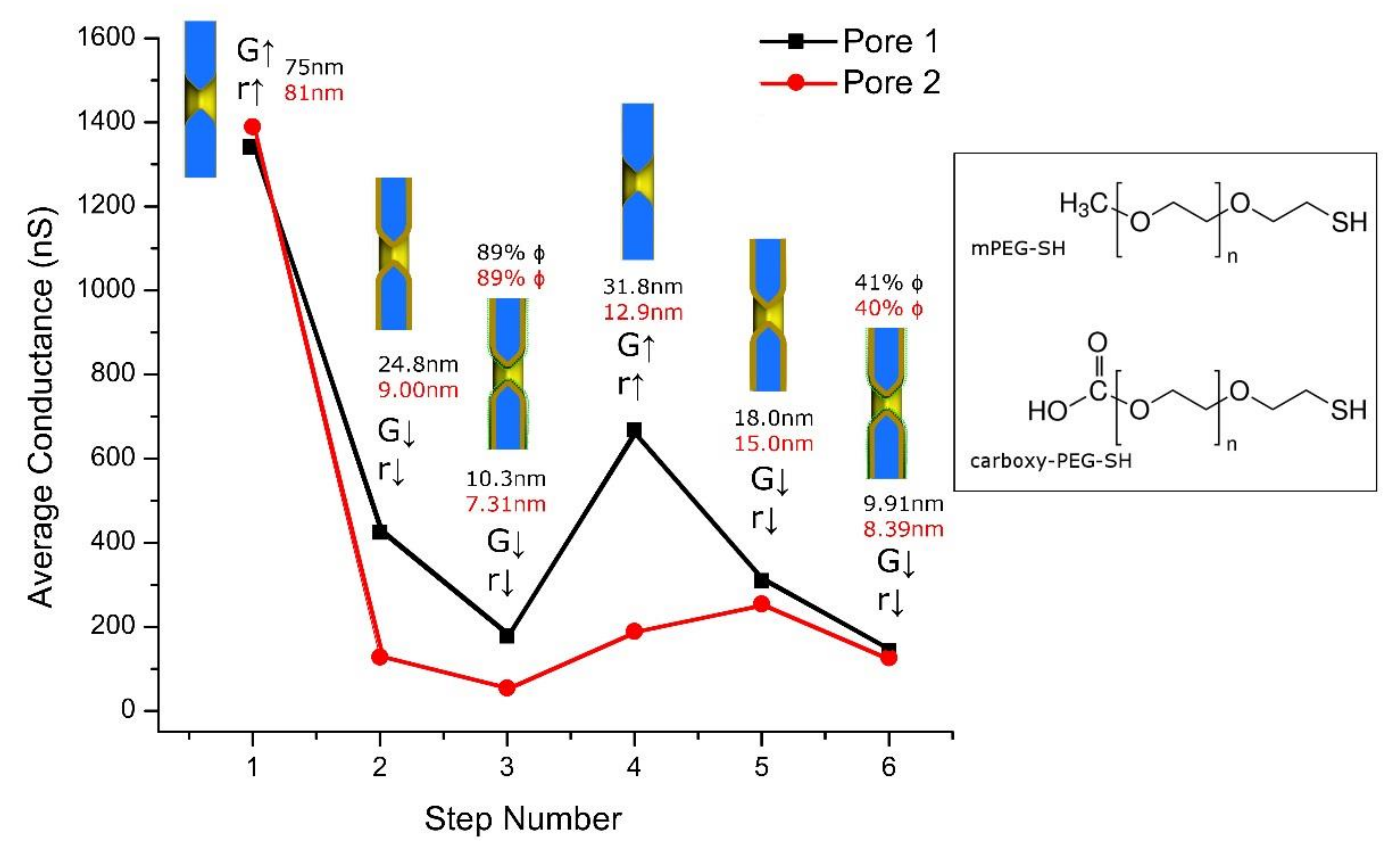

Figure 3.8 The IV-curve-measured conductance values of two different nanopores in silicon nitride (30 nm declared nominal thickness) after a series of treatment steps. The step numbers correspond to the treatments in order: (1) $2.5 \% \mathrm{HF}$ etch series, total of 30 minutes etch in 10 minute increments; (2) 30 minutes electroless gold deposition at $3^{\circ} \mathrm{C}$; (3) after 12 hour soak in 0.1mM mPEG-SH (average molecular weight $5000 \mathrm{Da}$, structure seen in inset) SAM at $3^{\circ} \mathrm{C}$; (4) plasma-cleaning to remove SAM; (5) second 30 min electroless gold deposition at $3^{\circ} \mathrm{C}$; (6) SAM of $\mathrm{mPEG}-\mathrm{SH}$ (pore 1) and carboxy-PEG-SH (pore 2, average molecular weight 5000 Da, structure shown in inset), after immersion of pores for 12 hours in appropriate 0.1mM solution at $3^{\circ} \mathrm{C}$. Equation 3 was used to determine the pore sizes at steps 0, 1, 2, 4, and 5 . Equation 15 was used for calculating the coating thickness and fractional coverage at steps 3 and 6, with the starting radius taken from the calculation used in the previous step. Note that the coating thickness is an effective combined thickness of the gold plus the SAM. 


\section{Single Molecule Sensing}

As the last proof-of-concept experiment, a 4.2-nm-radius pore (determined from Equation 3, using a declared nominal membrane thickness of 10nm), fabricated by dielectric breakdown, was gold-plated and functionalized with $\mathrm{m}(\mathrm{PEG})_{4}-\mathrm{SH}$ to a radius of $2.4 \mathrm{~nm}\left(40 \%\right.$ complete, $1.8 \mathrm{~nm}$-thick gold $+\mathrm{m}(\mathrm{PEG})_{4}-\mathrm{SH}$ layer, as calculated with Equation 15; fit shown in Figure 3.9), then used to study the translocation of $\lambda$ DNA through the modified system. Current histograms, Figure 3.10, from the $\lambda$-DNA experiments were compared to those from the analyte-free system, and clearly show there are three separate regimes present. These current histograms were created from current measurements acquired at an applied $200 \mathrm{mV}$ potential at $100 \mathrm{kHz}$ with a $10 \mathrm{kHz}$ low-pass filter. Experiments were run for ten minutes in $1 \mathrm{M} \mathrm{KCl}, 10 \mathrm{mM}$ HEPES electrolyte solution with the analyte present in the system at $33.6 \mathrm{pM}$, and show a large fraction of current blockages that correspond to $~ 80 \%$ of the open current (5260 pA blocked, $6580 \mathrm{pA}$ open), and a second group of blockages that correspond to $\sim 55 \%$ of the open current magnitude (3600 pA blocked, 6580 open). A total of 1078 blockage events were extracted from one hour of data collection. Representative current events can be seen in Figure 3.11, where a decrease in current represents partial blockage (by an analyte molecule) of the ionic current flow through the pore. The individually extracted events shown in Figure 3.11 of $\lambda$-DNA in the same 2.4-nmradius gold- and PEG-SH-functionalized pore have a shape characteristic of the translocation of long, negatively-charged polymers, and are consistent with the translocation of $\lambda$-DNA through unmodified $\mathrm{SiN}_{\mathrm{x}}$ nanopores studied in the literature. $^{10,24,45-47}$ 


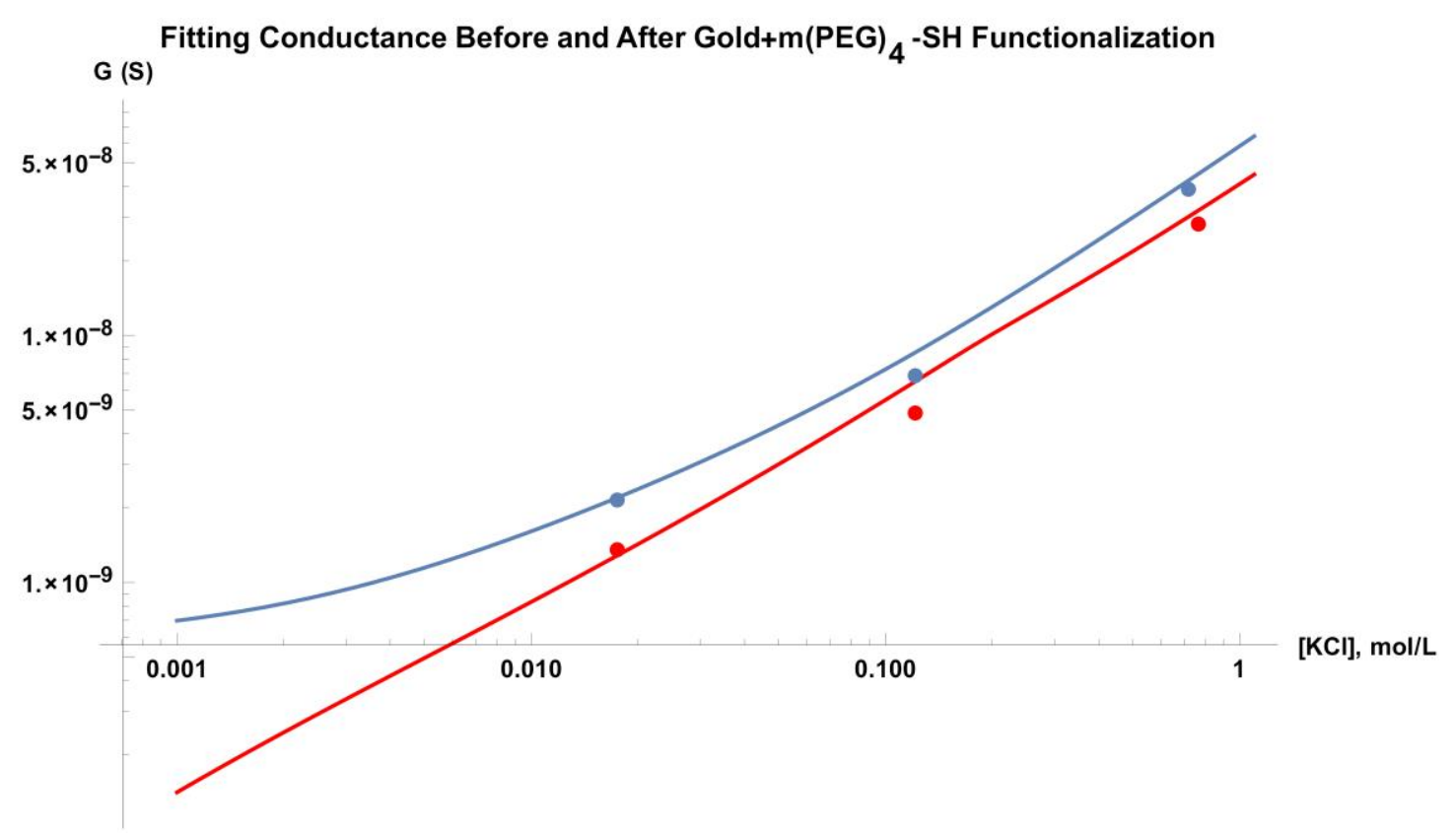

Figure 3.9 Nanopore conductance values as a function of electrolyte concentration for a 4.2-nm radius $S_{i} N_{x}$ pore before (blue) and after (red) electroless gold deposition and $m(P E G)_{4}-S H$ monolayer assembly. A $40 \%$ complete layer of 1.8-nm-thick gold+SAM was calculated using Equation 15. This nanopore was used for subsequent $\lambda$-DNA analysis. 


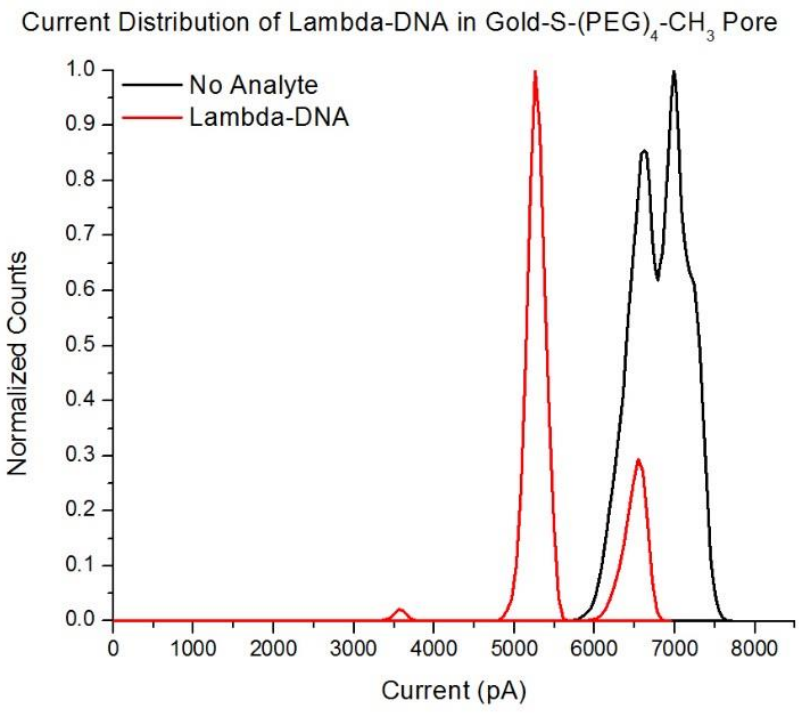

Figure 3.10 Ten minutes of data acquisition at 200mV for a single dielectric breakdown pore with a starting radius of $4.2 \mathrm{~nm}$ by Equation 3, coated to a final radius of $2.4 \mathrm{~nm}$. The pore was plated with a gold film and functionalized with a $40 \%$ complete monolayer of $m(P E G)_{4}-S H$ with a total effective gold+SAM thickness of $1.8 \mathrm{~nm}$, as calculated by Equation 14. Current populations are shown with no analyte (black trace) and with 33.6pM $\lambda$-DNA in $1 M \mathrm{KCl}$, 10mM HEPES, $\mathrm{pH}=7$ electrolyte in a single well of the Teflon holder (red trace, 97 events extracted). Data was acquired with an Axopatch $200 \mathrm{~B}$ sampled at $100 \mathrm{kHz}$ and low-pass filtered at $10 \mathrm{kHz}$. 
The known radius of $\lambda$-DNA, $r_{D N A}, 1.1 \mathrm{~nm}^{48}$, can be used as a means to confirm the radius of the coated nanopore, based upon the blocked current (I, $5260 \mathrm{pA})$ and the open current $\left(\mathrm{I}_{0}, 6580 \mathrm{pA}\right)$ of the nanopore, as in Equation 16. Using the most populated current state seen in the data from Figure $3.10, \frac{I}{I_{0}}=\frac{5260}{6580}=0.80$, the calculated coated radius is $2.5 \mathrm{~nm}$.

$r_{\text {coated }}=\sqrt{\frac{r_{D N A}^{2}}{1-\frac{I}{I_{0}}}}$

Equation (16)

This is a not a significant difference from the 2.4-nm radius calculated for this pore by using the conductance (Equation 15), and the small discrepancy is most likely due to the differing surface conductance values; i.e. the differing interactions between the cations in solution and the gold and the SAM-functionalized surfaces, which are not accounted for in the bulk conductance model, ${ }^{24,33,49}$ as well as the two-region model that was used in place of the actual (most-likely) three-region arrangement.

A heat map can be generated from the events in Figure 3.10, along with the rest of the 1078 events collected in an hour of experiments with the same pore, showing the relationship between the number of events, the magnitude of the current blockage, and the duration of the events. The current histogram in Figure 3.10 and the shows that the most populated blockage state $\left(\sim 0.80-0.85 \mathrm{I} / \mathrm{I}_{0}, \mathrm{I} \sim 5300 \mathrm{pA}\right)$ would correspond to a single strand of $\lambda$-DNA in the pore. The smallest blockage populations, around $70 \% \quad I / I_{0} \quad(\mathrm{I} \sim 4600 \mathrm{pA})$, are likely due to the nonlinear conformations of DNA as it passes through the pore. ${ }^{10,24,45-47}$ For example, a doubled strand of DNA, folded over onto itself, would have an effective radius of $2.2 \mathrm{~nm}$ and 
would result in a $20 \%$ ratio of $\mathrm{I} / \mathrm{I}_{0}$. There aren't any blockages of that magnitude in the heat map (Figure 3.12) of this data set, which suggests that different types of $\lambda$ DNA/surface interactions may be at play. The lack of events lower than $\mathrm{I} / \mathrm{I}_{0} \sim 0.95$ may also be explained by examining the very small event population in Figure 3.10 at $\mathrm{I} / \mathrm{I}_{0}=0.55$ that is not seen in the heat map (Figure 3.12) — when compiling the entire hour's-worth of events, there were too few events at that blockage ratio to show up on the heat map scale. 

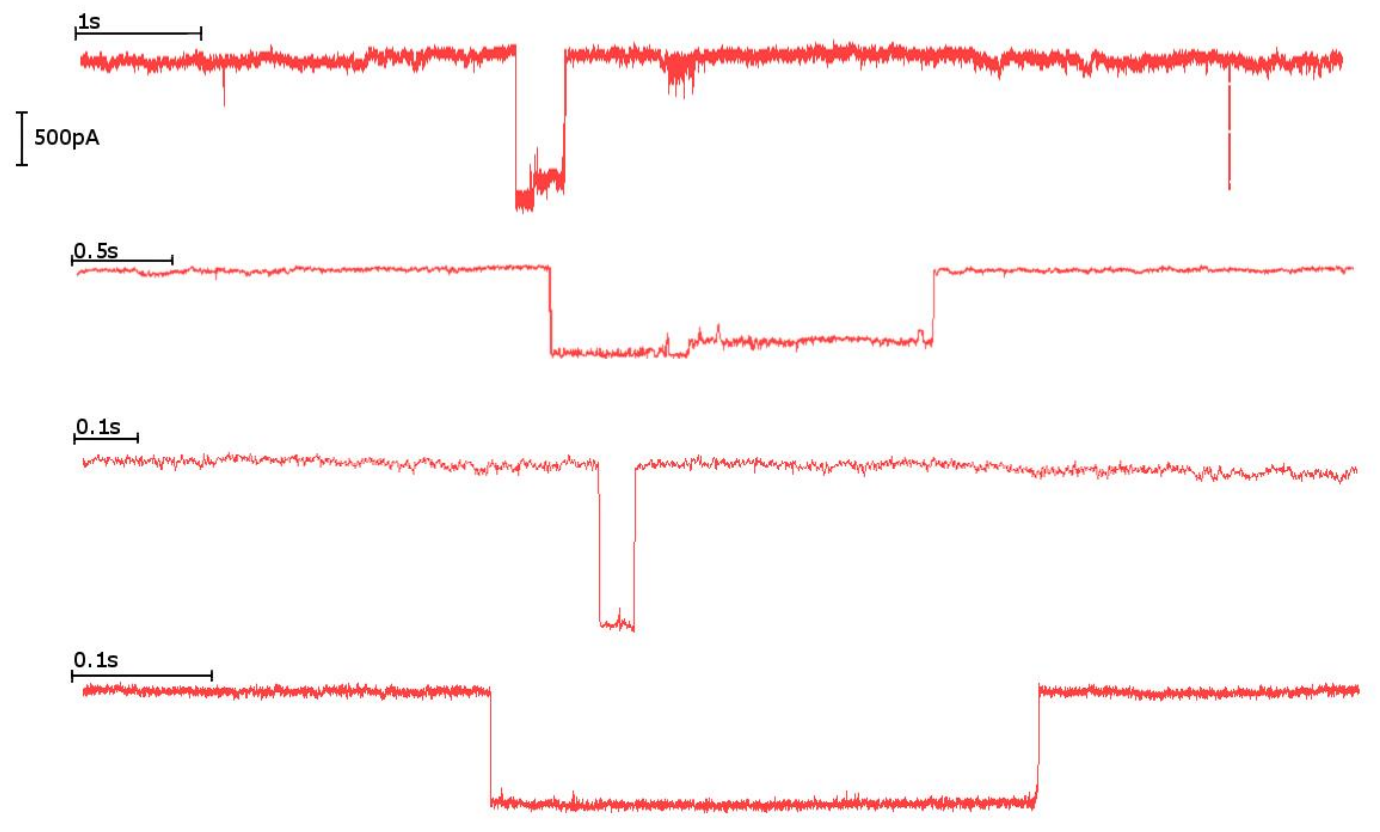

Figure 3.11 Representative $\lambda$-DNA translocation events from a single 10-minute run from one well containing 33.6pM $\lambda$-DNA in a $500 \mu \mathrm{L}$ well containing $1 \mathrm{M} \mathrm{KCl}$ electrolyte, buffered to $\mathrm{pH} 7$ with $10 \mathrm{mM}$ HEPES, to a second $500 \mu \mathrm{L}$ well containing only the electrolyte. The coated pore radius was calculated to be $2.4 \mathrm{~nm}$ using Equation 14 and $40 \%$ coverage of a 1.8-nm-thick gold + PEG $_{4}-S H$ monolayer. 


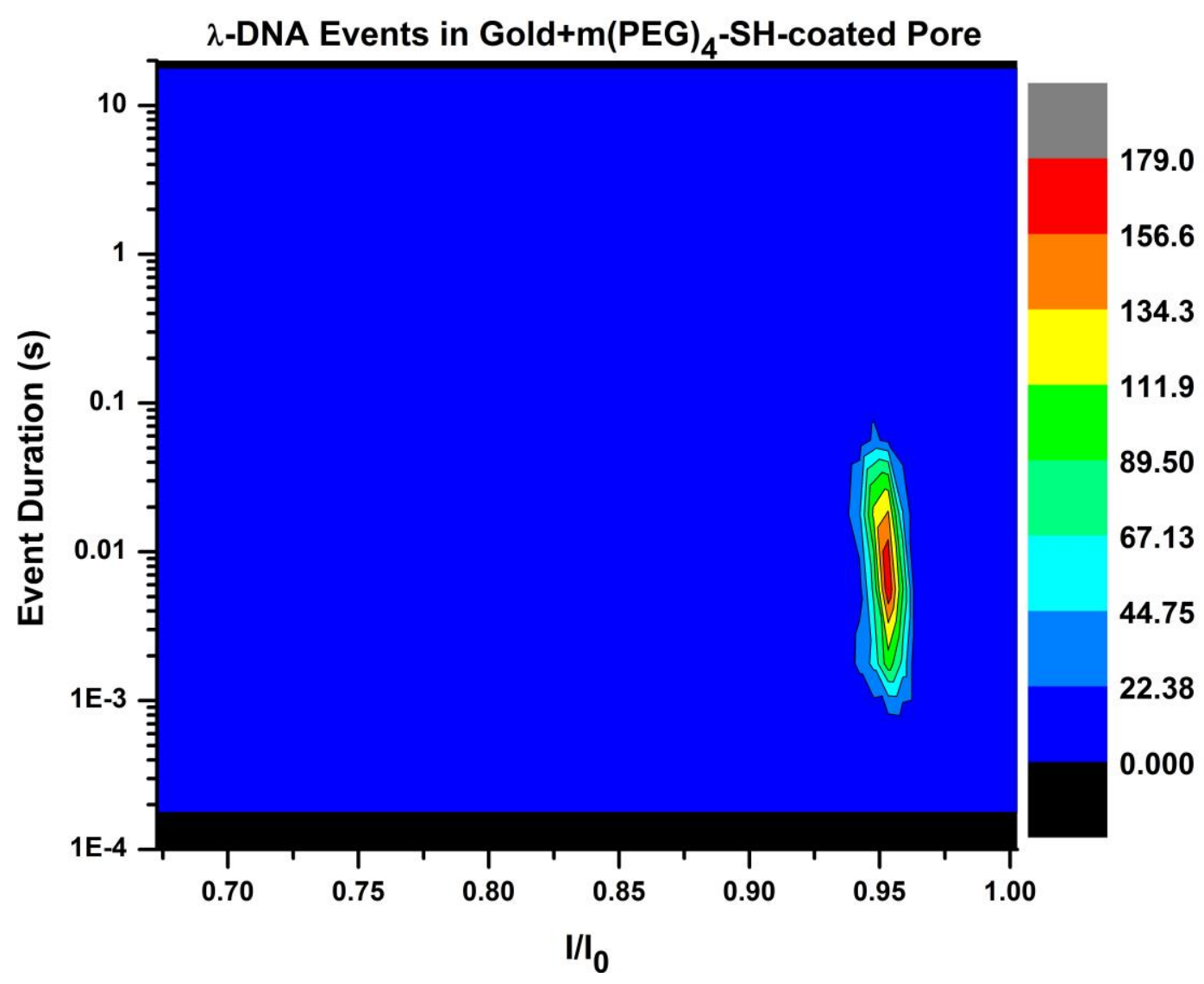

Figure 3.12. Heat map generated from 1078 events resulting from the translocation of 33.6pM $\lambda$-DNA in a 500 $\mu \mathrm{L}$ well containing $1 \mathrm{M} \mathrm{KCl}$ electrolyte, buffered to $\mathrm{pH} 7$ with $10 \mathrm{mM}$ HEPES, to a second $500 \mu \mathrm{L}$ well containing only the electrolyte. The pore radius calculated from the conductance was found to be $2.4 \mathrm{~nm}$ after coating $(4.8 \mathrm{~nm}$ starting radius, $40 \%$ fractional coating of effective thickness $1.8 \mathrm{~nm}$ ), while the pore radius calculated from the $0.80 \mathrm{I} / \mathrm{I}$ o population seen in Figure 3.10 was found to be $2.5 \mathrm{~nm}$. The color scale corresponds to the number of events at a given blockage magnitude and duration. A value of 0 for $I / I_{0}$ would represent total blockage of the pore, and conversely, a value of 1.0 represents a fully open pore. 


\section{CONCLUSIONS}

The use of gold-plated and surface-modified nanopores provides new ways of precise control over internal nanopore dimensions and surface chemistry. This has a two-fold advantage for nanopore research; the size and shape of nanopores can be precisely tailored to specific analyte dimensions; and the control over the surface chemistry of the nanopore can be used to optimize the conditions for specific experiments. The functionalization procedure outlined within this paper has been applied to planar silicon nitride, and has been shown to plate three-dimensional surfaces such as micro- and nanoporous membranes. Conductance measurements on single nanopores exposed to the gold-plating procedure have supported the hypothesis that the internal dimensions of nanopores can be controlled by the thickness of gold deposited on their interiors. By choosing complementary pore dimensions, gold film thickness, and SAM functionalities, this electroless plating process might also be used to physically and chemically tune the pore dimensions. This method of nanopore customization has been shown to successfully deposit successive coatings into the

pore, as confirmed by conductance measurements, and the pores have furthermore been used to detect translocation of single molecules of $\lambda$-DNA that are consistent with translocation shapes and blockage populations shown in unfunctionalized pores. 


\title{
AUTHOR INFORMATION
}

\section{Corresponding Author}

* E-mail: jdwyer@chm.uri.edu.

\section{Funding Sources}

NSF CAREER award CBET-1150085, in part by NSF EPSCoR Cooperative Agreement \#IIA-1330406, and by the University of Rhode Island.

\section{ACKNOWLEDGMENT}

This research has been supported by NSF CAREER award CBET-1150085, in part by NSF EPSCoR Cooperative Agreement \#IIA-1330406, and by the University of Rhode Island.

\begin{abstract}
ABBREVIATIONS
$\mathrm{SiN}_{\mathrm{x}}$, silicon nitride; SEM, scanning electron microscopy; FE-SEM, field-emission SEM; SAM, self-assembled monolayer; PEG, polyethylene glycol; IV, currentvoltage; $\lambda$-DNA, lambda-deoxyribonucleic acid; HEPES, 4-(2-hydroxyethyl)-1piperazineethanesulfonic acid.
\end{abstract}




\section{REFERENCES}

(1) Movileanu, L. Interrogating Single Proteins through Nanopores: Challenges and Opportunities. Trends Biotechnol. 2009, 27 (6), 333-341.

(2) Branton, D.; Deamer, D. W.; Marziali, A.; Bayley, H.; Benner, S. A.; Butler, T.; Di Ventra, M.; Garaj, S.; Hibbs, A.; Huang, X.; et al. The Potential and Challenges of Nanopore Sequencing. Nat. Biotechnol. 2008, 26 (10), 1146-1153.

(3) Astier, Y.; Braha, O.; Bayley, H. Toward Single Molecule DNA Sequencing: Direct Identification of Ribonucleoside and Deoxyribonucleoside 5`Monophosphates by Using an Engineered Protein Nanopore Equipped with a Molecular Adapter. J. Am. Chem. Soc. 2006, 128 (5), 1705-1710.

(4) Ayub, M.; Bayley, H. Individual RNA Base Recognition in Immobilized Oligonucleotides Using a Protein Nanopore. Nano Lett. 2012, 12 (11), 5637-5643.

(5) Howorka, S.; Siwy, Z. Nanopore Analytics: Sensing of Single Molecules. Chem. Soc. Rev. 2009, 38 (8), 2360-2384.

(6) Wanunu, M.; Meller, A. Chemically Modified Solid-State Nanopores. Nano Lett. 2007, 7 (6), 1580-1585.

(7) Wei, R.; Pedone, D.; Zürner, A.; Döblinger, M.; Rant, U. Fabrication of Metallized Nanopores in Silicon Nitride Membranes for Single-Molecule Sensing. Small 2010, 6 (13), 1406-1414.

(8) Miles, B. N.; Ivanov, A. P.; Wilson, K. A.; Doğan, F.; Japrung, D.; Edel, J. B. Single Molecule Sensing with Solid-State Nanopores: Novel Materials, Methods, and Applications. Chem. Soc. Rev. 2013, 42 (1), 15-28. 
(9) Pla-Roca, M.; Isa, L.; Kumar, K.; Reimhult, E. Selective (Bio)Functionalization of Solid-State Nanopores. ACS Appl. Mater. Interfaces 2015, 7 (11), 6030-6035.

(10) Kwok, H.; Briggs, K.; Tabard-Cossa, V. Nanopore Fabrication by Controlled Dielectric Breakdown. PLoS ONE 2014, 9 (3), e92880.

(11) Briggs, K.; Kwok, H.; Tabard-Cossa, V. Automated Fabrication of 2-Nm Solid-State Nanopores for Nucleic Acid Analysis. Small 2014, 10 (10), 20772086.

(12) Kwok, W. H. H. New Approach in Fabrication of Solid-State Nanopore for Bio-Sensing Applications. 2015.

(13) Frament, C. M.; Dwyer, J. R. Conductance-Based Determination of Solid-State Nanopore Size and Shape: An Exploration of Performance Limits. J. Phys. Chem. C 2012, 116 (44), 23315-23321.

(14) Frament, C. M.; Bandara, N.; Dwyer, J. R. Nanopore Surface Coating Delivers Nanopore Size and Shape through Conductance-Based Sizing. ACS Appl. Mater. Interfaces 2013, 5 (19), 9330-9337.

(15) Bandara, Y. M. N. D. Y.; Karawdeniya, B. I.; Dwyer, J. R. Real-Time Profiling of Solid-State Nanopores During Solution-Phase Nanofabrication. ACS Appl. Mater. Interfaces 2016, 8 (44), 30583-30589.

(16) Whelan, J. C.; Karawdeniya, B. I.; Bandara, Y. M. N. D. Y.; Velleco, B. D.; Masterson, C. M.; Dwyer, J. R. Electroless Plating of Thin Gold Films Directly onto Silicon Nitride Thin Films and into Micropores. ACS Appl. Mater. Interfaces 2014, 6 (14), 10952-10957. 
(17) Dwyer, J. R.; Bandara, Y. M. N. D. Y.; Whelan, J. C.; Karawdeniya, B. I.;

Nichols, J. W. Silicon Nitride Thin Films for Nanofluidic Device Fabrication. In Nanofluidics; Edel, J., Ivanov, A., Kim, M., Eds.; RSC Nanoscience \& Nanotechnology; Royal Society of Chemistry, 2016; pp 190-236.

(18) Yusko, E. C.; Johnson, J. M.; Majd, S.; Prangkio, P.; Rollings, R. C.; Li, J.;

Yang, J.; Mayer, M. Controlling Protein Translocation through Nanopores with

Bio-Inspired Fluid Walls. Nat. Nanotechnol. 2011, 6 (4), 253-260.

(19) Feng, Y.; Zhang, Y.; Ying, C.; Wang, D.; Du, C. Nanopore-Based FourthGeneration DNA Sequencing Technology. Genomics Proteomics Bioinformatics $\mathbf{2 0 1 5}, 13(1), 4-16$.

(20) Ando, G.; Hyun, C.; Li, J.; Mitsui, T. Directly Observing the Motion of DNA Molecules near Solid-State Nanopores. ACS Nano 2012, 6 (11), 10090-10097.

(21) Tang, Z.; Lu, B.; Zhao, Q.; Wang, J.; Luo, K.; Yu, D. Surface Modification of Solid-State Nanopores for Sticky-Free Translocation of Single-Stranded DNA. Small 2014, 10 (21), 4332-4339.

(22) Martin, C. R.; Nishizawa, M.; Jirage, K.; Kang, M. Investigations of the Transport Properties of Gold Nanotubule Membranes. J. Phys. Chem. B 2001, 105 (10), 1925-1934.

(23) Siwy, Z.; Trofin, L.; Kohli, P.; Baker, L. A.; Trautmann, C.; Martin, C. R. Protein Biosensors Based on Biofunctionalized Conical Gold Nanotubes. J. Am. Chem. Soc. 2005, 127 (14), 5000-5001. 
(24) Kowalczyk, S. W.; Grosberg, A. Y.; Rabin, Y.; Dekker, C. Modeling the Conductance and DNA Blockade of Solid-State Nanopores. Nanotechnology 2011, 22 (31), 315101.

(25) Liebes, Y.; Drozdov, M.; Avital, Y. Y.; Kauffmann, Y.; Rapaport, H.; Kaplan, W. E.; Ashkenasy, N. Reconstructing Solid State Nanopore Shape from Electrical Measurements. Appl. Phys. Lett. 2010, 97 (22), 223105.

(26) Smeets, R. M. M.; Keyser, U. F.; Krapf, D.; Wu, M.-Y.; Dekker, N. H.;

Dekker, C. Salt Dependence of Ion Transport and DNA Translocation through Solid-State Nanopores. Nano Lett. 2006, 6 (1), 89-95.

(27) DeBlois, R. W.; Bean, C. P. Counting and Sizing of Submicron Particles by the Resistive Pulse Technique. Rev. Sci. Instrum. 1970, 41 (7), 909-916.

(28) Wang, J.; Ma, J.; Ni, Z.; Zhang, L.; Hu, G. Effects of Access Resistance on the Resistive-Pulse Caused by Translocating of a Nanoparticle through a Nanopore. RSC Adv. 2014, 4 (15), 7601-7610.

(29) Merchant, C. A.; Healy, K.; Wanunu, M.; Ray, V.; Peterman, N.; Bartel, J.; Fischbein, M. D.; Venta, K.; Luo, Z.; Johnson, A. T. C.; et al. DNA Translocation through Graphene Nanopores. Nano Lett. 2010, 10 (8), 2915-2921.

(30) Wanunu, M.; Dadosh, T.; Ray, V.; Jin, J.; McReynolds, L.; Drndić, M. Rapid Electronic Detection of Probe-Specific microRNAs Using Thin Nanopore Sensors. Nat. Nanotechnol. 2010, 5 (11), 807-814.

(31) Schneider, G. F.; Kowalczyk, S. W.; Calado, V. E.; Pandraud, G.; Zandbergen, H. W.; Vandersypen, L. M. K.; Dekker, C. DNA Translocation through Graphene Nanopores. Nano Lett. 2010, 10 (8), 3163-3167. 
(32) Sonnefeld, J. Determination of Surface Charge Density Parameters of Silicon Nitride. Colloids Surf. Physicochem. Eng. Asp. 1996, 108 (1), 27-31.

(33) Reiner, J. E.; Kasianowicz, J. J.; Nablo, B. J.; Robertson, J. W. F. Theory for Polymer Analysis Using Nanopore-Based Single-Molecule Mass Spectrometry. Proc. Natl. Acad. Sci. 2010, 107 (27), 12080-12085.

(34) Du, N.; Park, H. B.; Robertson, G. P.; Dal-Cin, M. M.; Visser, T.; Scoles, L.; Guiver, M. D. Polymer Nanosieve Membranes for CO2-Capture Applications. Nat. Mater. 2011, 10 (5), 372-375.

(35) Tong, H. D.; Jansen, H. V.; Gadgil, V. J.; Bostan, C. G.; Berenschot, E.; van Rijn, C. J. M.; Elwenspoek, M. Silicon Nitride Nanosieve Membrane. Nano Lett. 2004, 4 (2), 283-287.

(36) Unnikrishnan, S.; Jansen, H. V.; Falke, F. H.; Tas, N. R.; Wolferen, H. A. G. M. V.; Boer, M. J. D.; Sanders, R. G. P.; Elwenspoek, M. C. Transition Flow through an Ultra-Thin Nanosieve. Nanotechnology 2009, 20 (30), 305304.

(37) Yang, J.; Ferranti, D. C.; Stern, L. A.; Sanford, C. A.; Huang, J.; Ren, Z.; Qin, L.-C.; Hall, A. R. Rapid and Precise Scanning Helium Ion Microscope Milling of Solid-State Nanopores for Biomolecule Detection. Nanotechnology 2011, 22 (28), 285310.

(38) Marshall, M. M.; Yang, J.; Hall, A. R. Direct and Transmission Milling of Suspended Silicon Nitride Membranes With a Focused Helium Ion Beam. Scanning 2012, 34 (2), 101-106. 
(39) Kim, D. J.; Pitchimani, R.; Snow, D. E.; Hope-Weeks, L. J. A Simple Method for the Removal of Thiols on Gold Surfaces Using an NH4OH-H2O2-H2O Solution. Scanning 2008, 30 (2), 118-122.

(40) Choi, S.; Chae, J. A Regenerative Biosensing Surface in Microfluidics Using Electrochemical Desorption of Short-Chain Self-Assembled Monolayer. Microfluid. Nanofluidics 2009, 7 (6), 819.

(41) Böhringer, K. F. Surface Modification and Modulation in Microstructures: Controlling Protein Adsorption, Monolayer Desorption and Micro-Self-Assembly. J. Micromechanics Microengineering 2003, 13 (4), S1.

(42) Bokisa, G. S.; Bishop, C. V.; Kochilla, J. R. Tin Whisker-Free Printed Circuit Board. US6720499 B2, April 13, 2004.

(43) Joshi, N. H. Metallization of Non-Conductive Surfaces with Silver Catalyst and Electroless Metal Compositions. US6645557 B2, November 11, 2003.

(44) Yu, S.; Lee, S. B.; Kang, M.; Martin, C. R. Size-Based Protein Separations in Poly(ethylene Glycol)-Derivatized Gold Nanotubule Membranes. Nano Lett. 2001, 1 (9), 495-498.

(45) Keyser, U. F.; Koeleman, B. N.; van Dorp, S.; Krapf, D.; Smeets, R. M. M.; Lemay, S. G.; Dekker, N. H.; Dekker, C. Direct Force Measurements on DNA in a Solid-State Nanopore. Nat. Phys. 2006, 2 (7), 473-477.

(46) Chen, P.; Gu, J.; Brandin, E.; Kim, Y.-R.; Wang, Q.; Branton, D. Probing Single DNA Molecule Transport Using Fabricated Nanopores. Nano Lett. 4 (11), 2293-2298. 
(47) Li, J.; Gershow, M.; Stein, D.; Brandin, E.; Golovchenko, J. A. DNA Molecules and Configurations in a Solid-State Nanopore Microscope. Nat. Mater. 2003, 2 (9), 611-615.

(48) Robertson, R. M.; Laib, S.; Smith, D. E. Diffusion of Isolated DNA Molecules: Dependence on Length and Topology. Proc. Natl. Acad. Sci. U. S. A. 2006, 103 (19), 7310-7314.

(49) Wanunu, M.; Sutin, J.; McNally, B.; Chow, A.; Meller, A. DNA Translocation Governed by Interactions with Solid-State Nanopores. Biophys. J. 2008, 95 (10), $4716-4725$. 


\section{APPENDICES}




\section{APPENDIX 1: CHAPTER 2 SUPPORTING INFORMATION}

\section{Supporting Information.}

Electroless Plating of Thin Gold Films Directly onto Silicon Nitride Thin Films and into Micropores.

Julie C. Whelan, Buddini Iroshika Karawdeniya†, Y.M. Nuwan D.Y. Bandara†, Brian D. Velleco, Caitlin M. Masterson and Jason R. Dwyer*.

Department of Chemistry, University of Rhode Island, 51 Lower College Road, Kingston, RI, 02881, United States.*E-mail: jdwyer@chm.uri.edu.

\section{Materials.}

The following chemicals were used as-supplied, and purchased from SigmaAldrich Corp. (St. Louis, MO, USA), and can be identified by (product number, specifications): potassium chloride $(60130, \geq 99.5 \%)$, (HEPES) $(\mathrm{H} 0527, \geq 99.5 \%)$, methanol (34860, CHROMASOLV® for HPLC $\geq 99.9 \%$ ), tin(II) chloride (208256, Reagent Grade 98\%), trifluoroacetic acid (6508, ReagentPlus $\left.{ }^{\circledR} 99 \%\right)$, silver nitrate (S6506, ReagentPlus ${ }^{\circledR} \geq 99.0 \%$ ), ammonium hydroxide solution (320145, ACS Reagent $28.0-30.0 \%$ NH3 basis), sodium tetrachloroaurate(III) dihydrate (298174, 99\%), barium hydroxide octahydrate (B2507, $\geq 98 \%$ ), sodium hydroxide (S5881, reagent grade $\geq 98 \%$ ), sodium sulfite (S0505, $\geq 98 \%$ ), and formaldehyde (252549, ACS reagent, $37 \mathrm{wt} \%$ in water, methanol-stabilized). A 5\% solution of hydrofluoric acid (C4354) was purchased from Science Lab Supplies (St. Augustine, FL) and diluted to $2.5 \%$ prior to use. mPEG-SH, 5000 average molecular weight (PG1-TH-5k), was purchased from Nanocs, Inc (Boston, MA). All aqueous dilutions and washes were performed using $18 \mathrm{M} \Omega \cdot \mathrm{cm}$ ultrapure water (Millipore Synergy UV, Billerica, MA). 
All electrolyte solutions were filtered using Stericup filter units (SCVPU11RE) from EMD Millipore (Billerica, MA). Silicon nitride-coated wafers were purchased from Rogue Valley Microdevices, Inc. (Medford, OR), and consisted of 200nm-thick, lowstress (<250 MPa Tensile; silicon-rich), LPCVD silicon nitride films deposited on 3" diameter, $<100\rangle$ polished silicon wafers. A diamond scribe was used to create $\sim 1 \mathrm{~cm}^{2}$ sample chips. The silicon nitride micropore arrays had $2 \mu \mathrm{m}$ diameter pores in $200 \mathrm{~nm}$ thick membranes and were purchased from Protochips (DTM-25231, Raleigh, NC). The efficacy of Scheme 1 for electrolessly plating gold onto silicon was examined using polished <111> silicon wafers (University Wafer, product number 1080). Nanoporous silicon nitride substrates were purchased from Innosieve Diagnostics (Wageningen, Netherlands). Single nanopores were drilled in silicon nitride substrates purchased from Protochips (DTF-030523, Raleigh, NC).

\section{Electroless Plating.}

\section{Planar and Microporous Silicon Nitride Substrates.}

Each chip was plasma-cleaned prior to use in a Glow Research (Phoenix, AZ) Autoglow plasma cleaner with 10 minutes of $50 \mathrm{~W}$ air plasma (0.8-1.2Torr pressure) followed by 5 minutes of $50 \mathrm{~W} \mathrm{O}_{2}$ plasma (0.8-1.2Torr pressure). Each chip was then etched for 10 minutes in $2 \mathrm{~mL}$ of a $2.5 \%$ aqueous $\mathrm{HF}$ solution to remove unwanted silicon oxide from the silicon nitride surface ${ }^{1-2}$, followed by 3 immersion rinses in water and then drying under an argon stream. The prepared chips were immersed for 45 minutes in $2 \mathrm{~mL}$ of a $50 / 50$ methanol/water solution that was $0.025 \mathrm{M}$ tin(II) chloride and $0.07 \mathrm{M}$ trifluoroacetic acid, followed by a methanol rinse and 5-minute methanol soak, a 5 -minute soak in $2 \mathrm{~mL}$ of ammoniacal silver nitrate solution ${ }^{3,5}$ 
minutes in methanol and finally 5 minutes in water ${ }^{3}$. Electroless gold plating involved submersing the chips in aqueous plating baths comprised of $7.9 \times 10^{-3} \mathrm{M}$ sodium gold sulfite $^{4}, 0.127 \mathrm{M}$ sodium sulfite and $0.625 \mathrm{M}$ formaldehyde ${ }^{5}$. The chips were plated in 1.5-3mL of plating solution in small plastic beakers with gentle rocking in a refrigerator $\left(3^{\circ} \mathrm{C}\right.$ plating $)$ or thermoelectric cooler $\left(10^{\circ} \mathrm{C}\right.$ plating $)$. After plating for the desired time at the desired temperature, the chips were thrice rinsed in alternating methanol and water, and dried in an argon stream (Airgas PP300). For comparison, we additionally sputter-coated (Denton Vacuum Desk II, Moorestown, NJ) a plasmacleaned silicon nitride-coated wafer with gold.

Even dilute hydrofluoric acid presents significant chemical hazards upon operator exposure, requiring special working precautions. All beakers for $\mathrm{HF}$ containment were polypropylene, instead of glass which can be etched and rendered permeable. Dilute (5\%) stock solutions were purchased to avoid handling concentrated solutions and Calgonate (Port St. Lucie, FL) $2.5 \%$ calcium gluconate gel was kept at hand in case of accidental skin exposure. To minimize exposure risk, all personnel wore a full-face shield, a disposable polypropylene apron and thick neoprene longsleeved gloves over standard chemical safety glasses, laboratory coat and long-sleeved nitrile gloves, respectively. Finally, we employed a "buddy system" so that one researcher monitored the other's work with HF. All labware and gloves were thoroughly rinsed with water after use.

\section{Self-Assembled Monolayer Coating and Removal.}

An aqueous solution of $\mathrm{mPEG}-\mathrm{SH} 0.1 \mathrm{mM}$ in concentration was prepared and 9 $\mathrm{mL}$ was exchanged into each well of the Teflon pore holders. The pores were allowed 
to soak in the refrigerator for 12-16 hours. The mPEG-SH solution was cleared from the wells of the Teflon holders by a carful $3 \mathrm{~mL}$ ultrapure water exchange to remove any unbound PEG, followed by a careful $6 \mathrm{~mL}$ exchange of electrolyte (1M $\mathrm{KCl}$, 5mM HEPES, $\mathrm{pH}$ 7.5). The removal of the SAM was accomplished by unmounting the silicon nitride substrates from their Teflon holders and subjecting the membranes to plasma etching ( 2 minutes $10 \mathrm{~W} \mathrm{~N}_{2}$ plasma, followed by 1-minute $10 \mathrm{~W} \mathrm{O}_{2}$ plasma).

\section{Preparation of ammoniacal silver nitrate ${ }^{3}$.}

This solution was prepared by adding 4 drops of $1 \mathrm{M}$ sodium hydroxide solution to $0.010 \mathrm{~g}$ of silver nitrate. Ammonium hydroxide was slowly added, dropwise, until all traces of dark precipitate had dissolved. The solution was then diluted to a final volume of $10 \mathrm{~mL}$ using ultrapure water.

Ammoniacal silver nitrate solution can form explosives if allowed to dry. This solution should be prepared on only a scale sufficient for immediate use, and should preferably be deactivated by precipitation by the addition of dilute hydrochloric acid or sodium chloride prior to disposal ${ }^{6}$.

\section{Preparation of sodium gold sulfite ${ }^{4,7}$.}

The synthesis of the gold plating solution was in accordance with the Abys et al. patent ${ }^{4}$ modified by the addition of a drying step ${ }^{7}$, as described here. $0.275 \mathrm{~g}$ sodium tetrachloroaurate dihydrate was added to approximately $15 \mathrm{~mL}$ ultrapure water at $80^{\circ} \mathrm{C}$ with stirring. To this solution were added $0.1500 \mathrm{~g}$ barium hydroxide octahydrate and $54 \mu \mathrm{L}$ of $50 \% \mathrm{w} / \mathrm{w}$ sodium hydroxide to yield an orange-yellow precipitate. The solution was boiled until all visible water had evaporated, and then allowed to cool to room temperature. The precipitate was slurried with approximately $10 \mathrm{~mL}$ of ultrapure 
water and filtered through a medium porosity Buchner funnel. The precipitate was slurried with approximately $10 \mathrm{~mL}$ of ultrapure water, heated to $60-65^{\circ} \mathrm{C}$ with stirring, cooled, and then filtered (bis). The precipitate was then slurried with approximately $20 \mathrm{~mL}$ of ultrapure water, and $0.500 \mathrm{~g}$ sodium sulfite was added to the solution. The solution was heated to $60-65^{\circ} \mathrm{C}$ with stirring until the precipitate turned blue-purple. This solution was filtered while still warm, and the resulting filtrate was diluted to a final volume of $25 \mathrm{~mL}$. The $\mathrm{pH}$ was adjusted with $1 \mathrm{M}$ sodium hydroxide to a final $\mathrm{pH}$ above 10 .

\section{Characterization.}

Gold film depositions were carried out in triplicate at each temperature and time point, and the $3^{\circ} \mathrm{C}$ trial was repeated so that each film thickness was based on deposition and measurements from between 3-6 different silicon nitride chips (allowing for occasional chip breakage). A step edge from gold film to exposed silicon nitride substrate was created by selectively removing gold film with adhesive tape (Scotch ${ }^{\circledR} 810$ Magic $^{\mathrm{TM}}$ tape) or, when film adhesion to the substrate was stronger, with a gentle pass of plastic tweezers across the substrate. AFM measurements of gold film thickness were performed in tapping mode at $0.1 \mathrm{~Hz}$ across $10 \mu \mathrm{m} \times 10 \mu \mathrm{m}$ segments of the step edge with an AFM Workshop (Signal Hill, CA) TT-AFM (equipped with SensaProbesTM190-A-15, 190kHz, aluminum-coated probes with tip radius $<10 \mathrm{~nm}$ ). Line profiles at several points across the step edge were analyzed, using the planar silicon nitride surface as a reference for quadratic background subtractions. For each background-subtracted profile, the means of the coated and uncoated sides were calculated (omitting large particle outliers from the statistics), and averaged for each 
chip over several profiles. These mean step heights were then averaged over each deposition time and temperature point, propagating the standard deviation as an uncertainty to yield the final reported step heights (Figure 2.1).

Gold film morphology was examined using a Zeiss Sigma VP FE-SEM at an electron energy of $8 \mathrm{keV}$ (Oberkochen, Germany), and elemental analysis by EDS was performed on the same instrument equipped with an Oxford Instruments X-MaxN $50 \mathrm{~mm}^{2}$ silicon drift detector (Concord, MA). Custom code was written in Mathematica 9 (Wolfram Research, Champaign, IL) to yield gold film grain size estimates via watershed analysis. X-ray photoelectron spectroscopy was used for the majority of the elemental analysis. XPS spectra were acquired using a PHI 5500 system (Physical Electronics, Inc., Chanhassen, MN) using unmonochromatized Al $\mathrm{K} \alpha$ radiation $(1486.6 \mathrm{eV})$ and an aperture size of $600 \times 600(\mu \mathrm{m})^{2}$. Survey scans were performed with $0.8 \mathrm{eV}$ step sizes and $20 \mathrm{~ms}$ per step, with a pass energy of $187.85 \mathrm{eV}$ and 10 scans per spectrum. High resolution spectra were recorded with 50 scans per spectrum, $0.1 \mathrm{eV}$ step sizes, $40 \mathrm{~ms}$ per step and a pass energy of $23.50 \mathrm{eV}$. Spectra were analyzed initially with Multipak 6.1 (Physical Electronics). All curve fitting was performed using XPSPeak 4.18 using linear baselines and the minimum meaningful number of fixed 90\% Gaussian-10\% Lorentzian peak profiles per peak, with all other peak parameters free. To compensate for substrate charging, we aligned the N1s peak from silicon nitride substrates to $398.00 \mathrm{eV}$, and the lower binding energy Si2p peak from silicon substrates to $99.25 \mathrm{eV} 9$, shifting spectra by up to $0.49 \mathrm{eV}$. The particular choice of reference precludes analysis based on the binding energy, alone, of that component of the XPS spectrum. We chose these peaks, rather than the commonly 
used $\mathrm{C} 1 \mathrm{~s}$ peak ${ }^{10}$, because they had better signal-to-noise ratios; the peak fitting reliability would be less frequently compromised by the presence of multiple contributing features; and the $\mathrm{C} 1 \mathrm{~s}$ binding energy, itself, has been shown to be variable, notably in response to the particular surface treatment of silicon ${ }^{9,11}$. To gain a measure of the binding energy uncertainties useful for guiding the interpretation of binding energy shifts, and of the consistency of the reference alignment, we fit the main, shifted, C1s peak centers, yielding a range of values between 284.61 and $285.49 \mathrm{eV}$ that arises from a combination of the shortcomings of multicomponent peak fitting and any real shifts in binding energy. As an additional check on the silicon nitride alignment, we also aligned the spectra using the Si2p region by fixing its principal component at $102.5 \mathrm{eV}$. For silicon-rich silicon nitride, the $\mathrm{Si} 2 \mathrm{p}$ peaks include overlapping contributions from hydrogen-, oxygen-, silicon- and nitrogenbound silicon, with magnitudes weighted by the substrate processing conditions; the N1s binding energies, referenced to the $102.5 \mathrm{eV}$ components of fits of the Si2p peaks, were $398.35,398.48,398.53$ and $398.43 \mathrm{eV}$ after plasma, HF, tin and silver treatments, respectively. These results of these referencing sensitivity studies helped to guide the interpretation of Si2p-referenced silicon XPS spectra and N1s-referenced silicon nitride XPS spectra.

Gold film conductivity was measured using an Alessi 4-point probe head with spring-loaded contacts, mounted on a translation stage. Voltages of $\sim 3-6 \mathrm{mV}$ were applied with an HP 6115a precision power supply and measured with a Keithley 196 DMM (Cleveland, $\mathrm{OH}$ ); the current was measured using a Hewlett-Packard 973a multimeter. 
SERS measurements were performed on an R3000QE Raman Systems spectrometer using $290 \mathrm{~mW}$ laser excitation at $785 \mathrm{~nm}$. Substrates were submerged in a $0.01 \mathrm{M}$ solution of NBT for 5 minutes before $3 \times$ rinsing in acetonitrile and argon drying. Spectra were collected at three random locations for each substrate and averaged together after correcting to a zero baseline at $\sim 494 \mathrm{~cm}-1$.

Current measurements were performed on a Molecular Devices, Inc. Axopatch 200B (Sunnyvale, CA) patch-clamp amplifier system fitted with Ag/AgCl electrodes. 

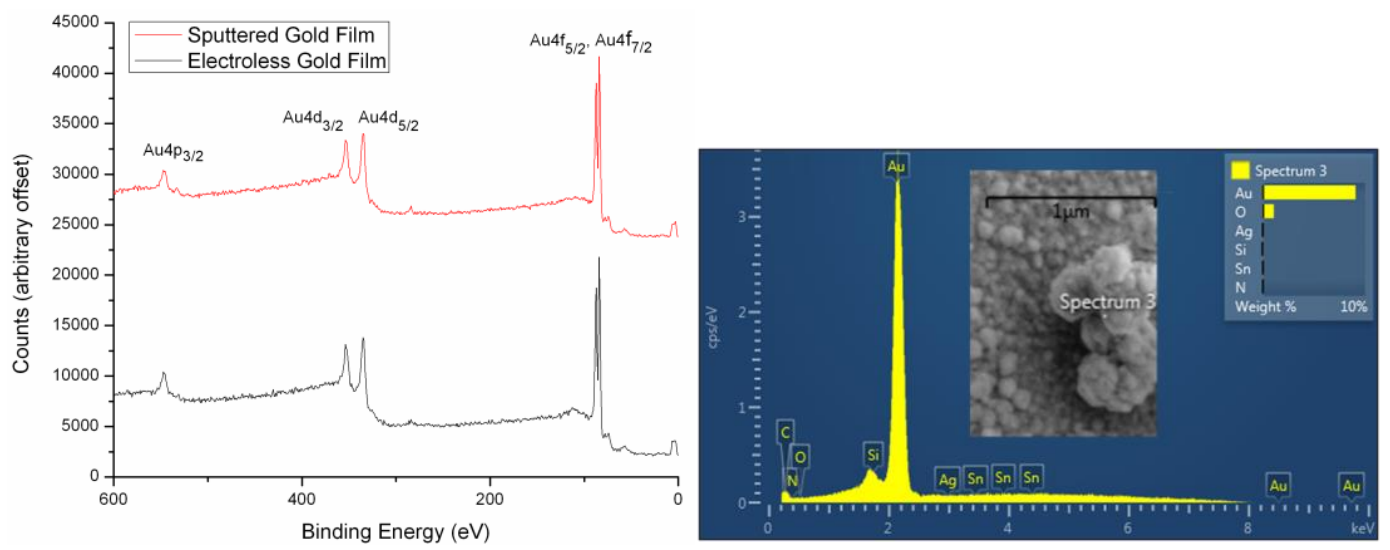

Chapter 2 Supporting Information Figure S1. Elemental analysis of gold films. At left, XPS scans comparing a sputtered gold film with an electrolessly plated gold film. The curves are vertically offset for clarity. At right, EDS profiling confirms the gold composition of one of the larger surface particles. 

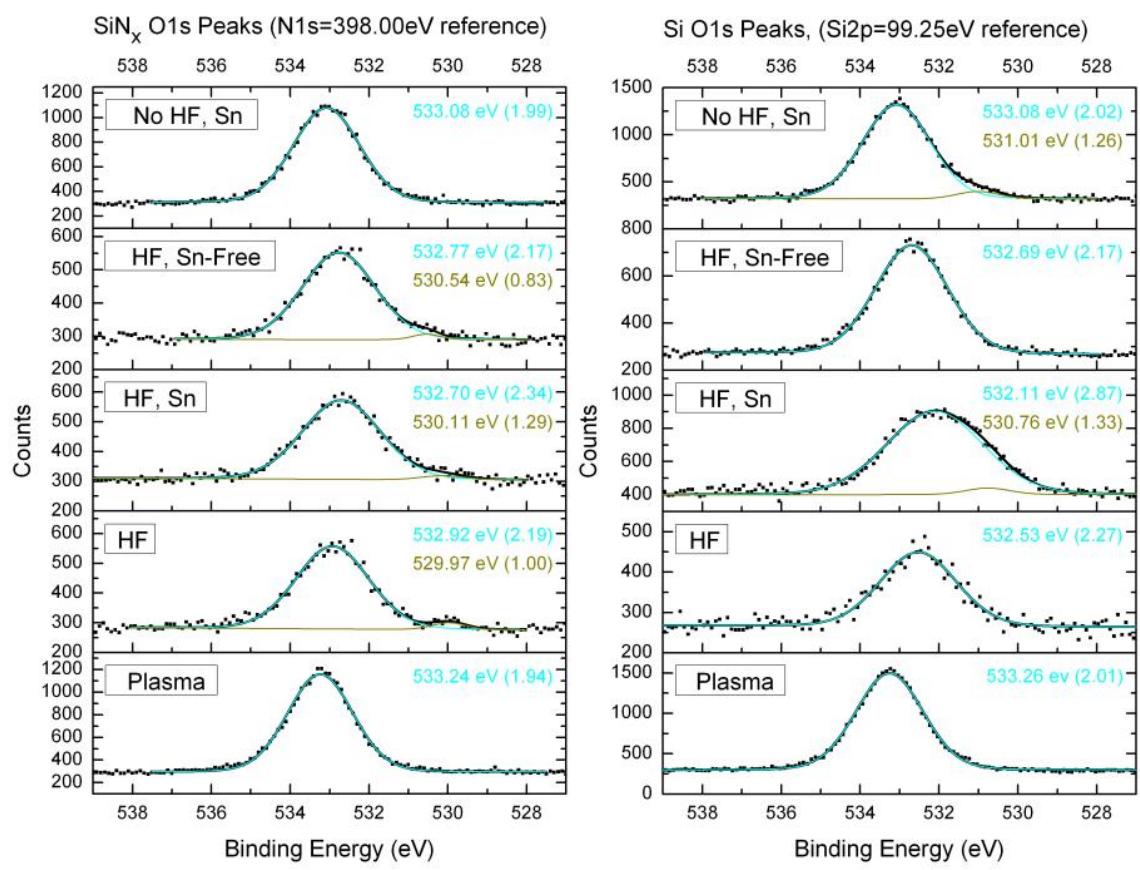

(a)

Chapter 2 Supporting Information Figure S2a. XPS spectra at key steps in the application of Scheme 1, and after selected control experiments. The label given to each spectrum indicates the terminal steps of Scheme 1 (or control experiment variation) that were performed on the substrate. The control data center on the effect of HF etching (performed or omitted) and tin sensitization (with standard solution or tin-free control). The scattered points are experimental data, and solid lines are used for the fit to the data (individual components and their sum). Each plot includes the center value and (width) of each component used to fit the experimental spectrum. Elements shown are O1s (a), Si2p (b), and $\operatorname{Sn} 3 d(c)$. 

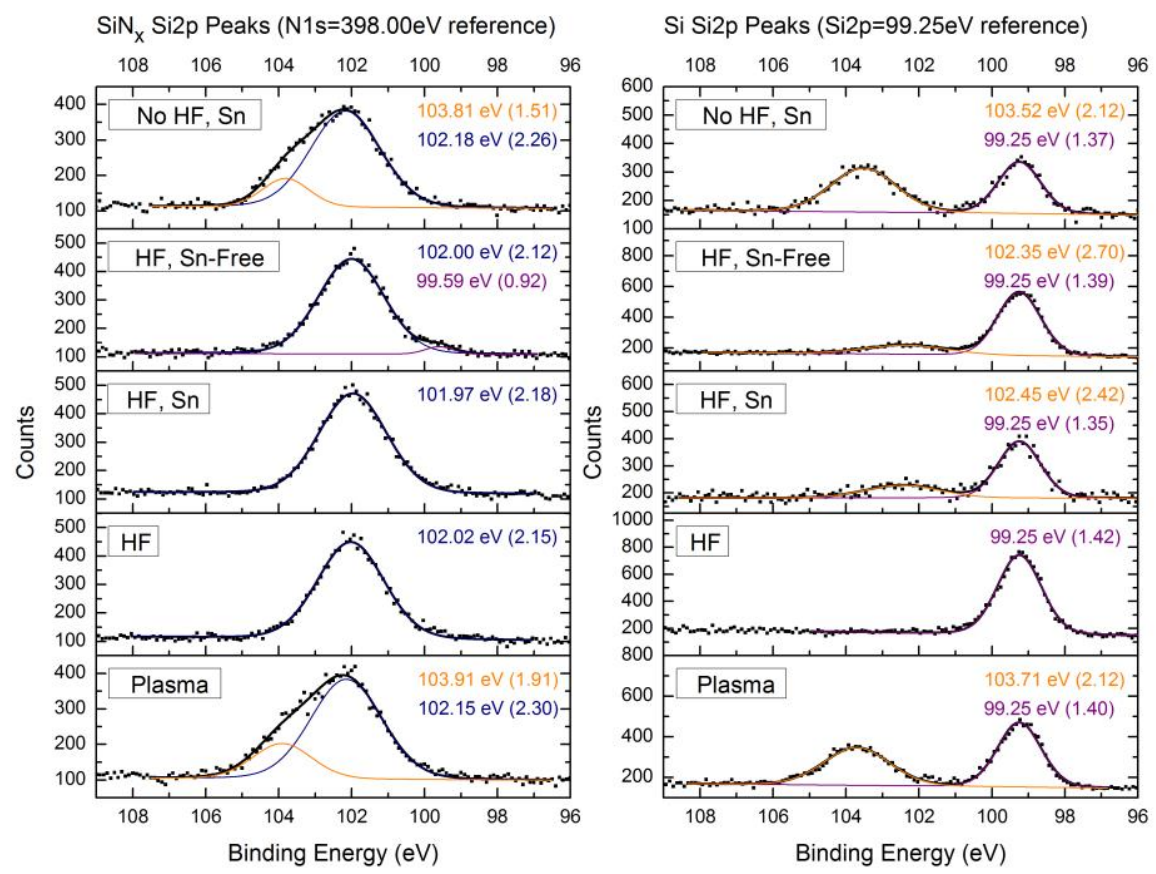

(b)

Chapter 2 Supporting Information Figure S2b. XPS spectra at key steps in the application of Scheme 1, and after selected control experiments. The label given to each spectrum indicates the terminal steps of Scheme 1 (or control experiment variation) that were performed on the substrate. The control data center on the effect of HF etching (performed or omitted) and tin sensitization (with standard solution or tin-free control). The scattered points are experimental data, and solid lines are used for the fit to the data (individual components and their sum). Each plot includes the center value and (width) of each component used to fit the experimental spectrum. Elements shown are O1s (a), Si2p (b), and $\operatorname{Sn3d}(c)$. 

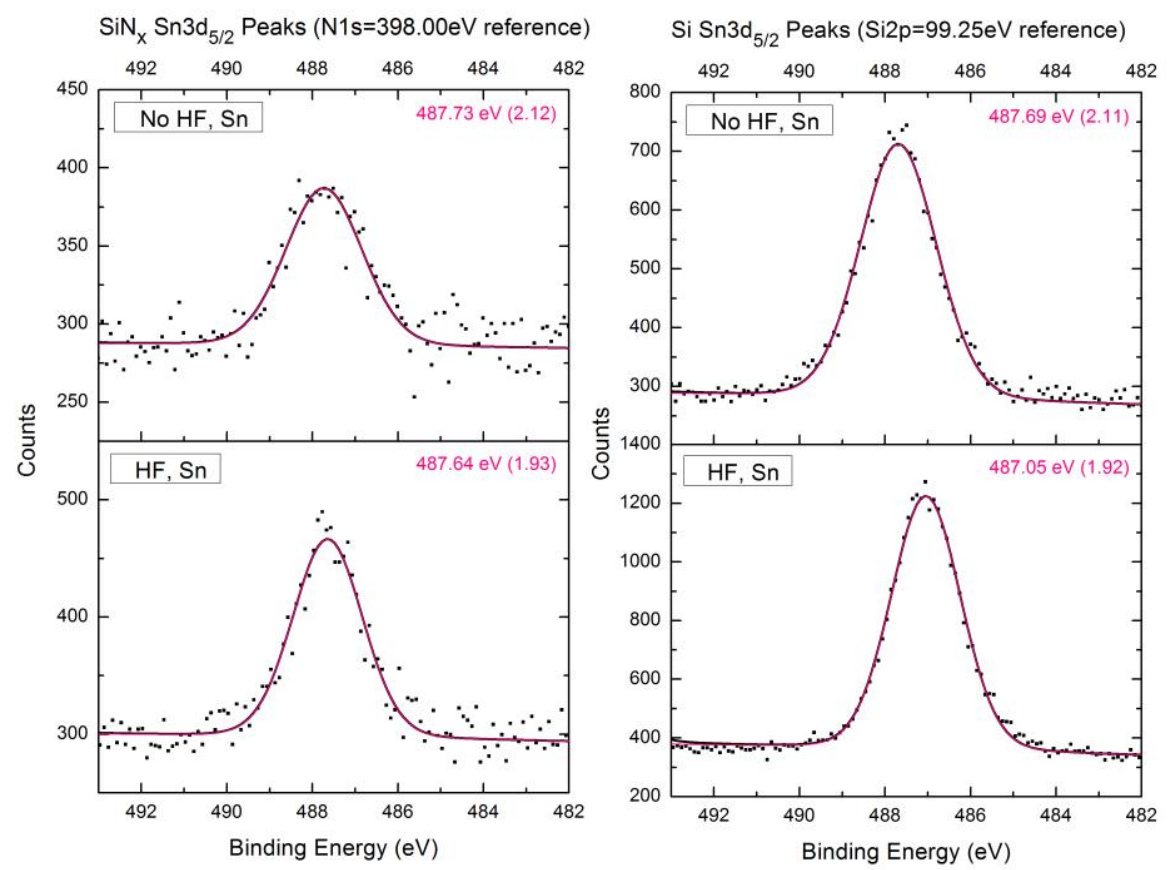

(c)

Chapter 2 Supporting Information Figure S2c XPS spectra at key steps in the application of Scheme 1, and after selected control experiments. The label given to each spectrum indicates the terminal steps of Scheme 1 (or control experiment variation) that were performed on the substrate. The control data center on the effect of HF etching (performed or omitted) and tin sensitization (with standard solution or tin-free control). The scattered points are experimental data, and solid lines are used for the fit to the data (individual components and their sum). Each plot includes the center value and (width) of each component used to fit the experimental spectrum. Elements shown are O1s (a), Si2p (b), and $\operatorname{Sn} 3 d(c)$. 


\section{References.}

1. Rosso, M.; Giesbers, M.; Arafat, A.; Schroën, K.; Zuilhof, H., Covalently Attached Organic Monolayers on SiC and SixN4 Surfaces: Formation Using UV Light at Room Temperature. Langmuir, 25, 2172-2180. 2009.

2. Williams, K. R.; Muller, R. S., Etch rates for micromachining processing. J. Microelectromech. Syst., 5, 256-269. 1996.

3. Menon, V. P.; Martin, C. R., Fabrication and Evaluation of Nanoelectrode Ensembles. Anal. Chem. 67, 1920-1928. 1997.

4. Abys, J. A.; Maisano, J. J. Process for Making Sodium Gold Sulfite Solution. 6,126,807, 2000.

5. Ko, J. W.; Koo, H. C.; Kim, D. W.; Seo, S. M.; Kang, T. J.; Kwon, Y.; Yoon, J. L.; Cheon, J. H.; Kim, Y. H.; Kim, J. J.; Park, Y. J., Electroless Gold Plating on Aluminum Patterned Chips for CMOS-Based Sensor Applications. J. Electrochem. Soc. 157, D46-D49. 2010.

6. Sigma-Aldrich ACCUSTAIN® RETICULUM STAIN (Procedure No. HT102). $\quad$ http://www.sigmaaldrich.com/content/dam/sigmaaldrich/docs/Sigma/General_Information/1/ht102.pdf (accessed 3/5/2014).

7. Ahn, W.; Taylor, B.; Dall'Asén, A. G.; Roper, D. K., Electroless Gold Island Thin Films: Photoluminescence and Thermal Transformation to Nanoparticle Ensembles. Langmuir 24, 4174-4184. 2008.

8. Kwok, R. W. M. XPSPeak, 4.1; 2009. 
9. Zazzera, L. A.; Moulder, J. F., XPS and SIMS Study of Anhydrous HF and UV/Ozone-Modified Silicon (100) Surfaces. J. Electrochem. Soc., 136, 484491. 1989.

10. Arafat, A.; Giesbers, M.; Rosso, M.; Sudhölter, E. J. R.; Schroën, K.; White, R. G.; Yang, L.; Linford, M. R.; Zuilhof, H., Covalent Biofunctionalization of Silicon Nitride Surfaces. Langmuir, 23, 6233-6244. 2007.

11. Cros, A., Charging Effects in X-Ray Photoelectron Spectroscopy. J. Electron. Spectrosc. Relat. Phenom. 59, 1-14. 1992. 


\section{APPENDIX 2: CHAPTER 3 SUPPORTING INFORMATION}

\section{Supporting Information.}

Electroless Plating of Thin Gold Films Directly into Silicon Nitride Nanopores for

Single Molecule Sensing.

Julie C. Whelan, Y.M. Nuwan D.Y. Bandara, Buddini Iroshika Karawdeniya, and

Jason R. Dwyer*.

Department of Chemistry, University of Rhode Island, 140 Flagg Road, Kingston, RI, 02881, United States.*E-mail: jdwyer@chm.uri.edu.

\section{Materials and Methods.}

\section{Materials.}

The following chemicals were used as-supplied, and purchased from SigmaAldrich Corp. (St. Louis, MO, USA), and can be identified by (product number,

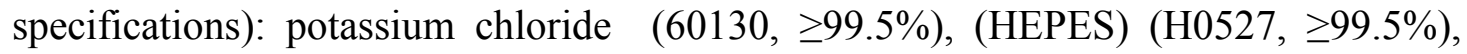
methanol (34860, CHROMASOLV® for HPLC $\geq 99.9 \%$ ), tin(II) chloride (208256, Reagent Grade 98\%), trifluoroacetic acid (6508, ReagentPlus® 99\%), silver nitrate (S6506, ReagentPlus ${ }^{\circledR} \geq 99.0 \%$ ), ammonium hydroxide solution (320145, ACS Reagent 28.0-30.0\% NH3 basis), sodium tetrachloroaurate(III) dihydrate (298174, 99\%), barium hydroxide octahydrate (B2507, $\geq 98 \%$ ), sodium hydroxide (S5881, reagent grade $\geq 98 \%$ ), sodium sulfite (S0505, $\geq 98 \%$ ), and formaldehyde (252549, ACS reagent, $37 \mathrm{wt} \%$ in water, methanol-stabilized). A 5\% solution of hydrofluoric acid (C4354) was purchased from Science Lab Supplies (St. Augustine, FL) and diluted to 2.5\% prior to use. Test SAM: mPEG-SH, 5000 average molecular weight (PG1-TH5k), thiol carboxylic PEG (PG2-CATH-5k), and thiol PEG amine (PG2-AMTH-5k) 
were purchased from Nanocs, Inc (Boston, $\mathrm{MA}) ; \mathrm{m}(\mathrm{PEG})_{4}-\mathrm{SH}$ was purchased from Thermo Scientific (Pierce, PI26132) and dissolved in dimethylformamide (Sigma Aldrich, D4551, $\geq 99 \%$ ). All aqueous dilutions and washes were performed using $18 \mathrm{M} \Omega \cdot \mathrm{cm}$ ultrapure water (Millipore Synergy UV, Billerica, MA), and electrolyte solutions were filtered using Stericup filter units (SCVPU11RE) from EMD Millipore (Billerica, MA). Nanoporous silicon nitride substrates were purchased from Innosieve Diagnostics (Wageningen, Netherlands). Single nanopores were formed by dielectric breakdown in silicon nitride substrates purchased from Protochips (DTF-030523, Raleigh, NC), and the same substrates were used in the fabrication of the Helium-Ionmicroscope-drilled array.

\section{Dielectric Breakdown Nanopore Fabrication.}

Commercial transmission electron microscopy (TEM) substrates, fabricated from freestanding silicon nitride membranes (from $10 \mathrm{~nm}$ in thickness), and supported by silicon frames, were mounted in custom Teflon holders (Chapter 3 Supporting Information Figure S1), with silicone elastomer gaskets between each side of the membrane and the holder to ensure a water-tight seal for the plating solutions, which were contained in $0.5 \mathrm{~mL}$ wells. Each well contained solutions that touched one side of the silicon nitride chip via a channel cut into the Teflon. Each well of the Teflon holder was initially filled with ethanol and put into a small vacuum chamber to remove any air present between the silicon nitride membrane and gaskets, and from inside the pores of the membrane. Each side of the membrane was then exposed to solution by exchanging the ethanol within the solution wells for $1 \mathrm{M} \mathrm{KCl}, \mathrm{pH} 7.5$ for breakdown. After being mounted in their holders, the membranes were subjected to an 
applied potential of $\sim 15 \mathrm{~V}$ until a single pore was formed, as monitored by the transpore current and using $\mathrm{Ag} / \mathrm{AgCl}$ electrodes. The circuit diagram from the TabardCossa paper ${ }^{1}$ was followed exactly for constructing the dielectric breakdown setup; a DC power supply (9121A; B\&K Precision; Yorba Linda, CA, USA) and current amplifier (Keithley 428; Tektronix, Inc; Beaverton, OR, USA) were built into the circuit. 


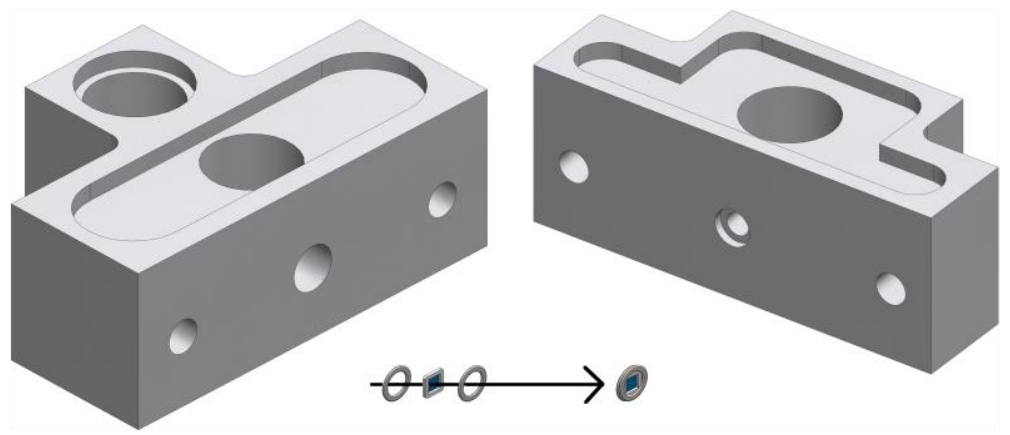

Chapter 3 Supporting Information Figure S1. Schematic of Teflon holder for asymmetric electroless plating of micro- and nanoporous substrates. The silicon support chip is mounted in between two silicone gaskets, which fit into a recessed area between the two halves of the Teflon holder. Small channels in the holder allow the solutions in each well to come into contact with one half of the chip, with the only mixing points of the two solutions being the pores in the silicon nitride membrane. 


\section{Electroless Plating of Nanopores.}

The porous membranes were then prepared for plating with a dilute HF etch. For imaging purposes, this was done asymmetrically — there were different solutions in each well during the process. Plating solutions were exchanged on each side of the pore asymmetrically in volumes from $0.5-9 \mathrm{~mL}$. One half of the membrane was immersed for 45 minutes in a 50/50 methanol/water solution that was $0.025 \mathrm{M}$ tin(II) chloride and $0.07 \mathrm{M}$ trifluoroacetic acid, while the other half was only exposed to water for the same duration of time; both exchanges were $5 \mathrm{~mL}$ in volume. Both sides were exposed to a 9-mL methanol exchange and 5-minute methanol soak, followed by a 9-mL ultrapure water exchange. The tin-sensitized half of the membrane then underwent a 5-minute sensitization soak in ammoniacal silver nitrate solution, 5-mL exchange, with the other half of the membrane refreshed with a 5-mL exchange of ultrapure water. A subsequent 9-mL water exchange on both sides of the membrane was performed. Electroless gold plating involved exchanging $0.75 \mathrm{~mL}$ of an aqueous plating bath comprised of $7.9 \times 10-3 \mathrm{M}$ sodium gold sulfite and $0.127 \mathrm{M}$ sodium sulfite into the non-sensitized half of the Teflon cell, with $30.3 \mu \mathrm{L}$ formaldehyde (aqueous) directly added to the $0.5 \mathrm{~mL}$ solution volume on the previously sensitized half. This would ensure plating would occur as the gold bath and the formaldehyde reducing agent mixed through the nanopore channel(s). The chips were plated with gentle rocking (BenchRocker 3D, Benchmark Scientific, Edison, NJ) in a refrigerator at approximately 3 degrees Celsius. After plating for the desired time, the chips were thrice rinsed by alternating $3 \mathrm{~mL}$ methanol and water exchanges. The same procedure was followed for the dielectrically-fabricated single nanopores in silicon nitride 
windows, as well as for a series of nanopores drilled by a helium ion microscope (HIM), (Zeiss), but both sides of the membrane were exposed to the same set of sensitization and plating solutions. See Scheme S2 for an outline of the plating steps and reactions occurring in each step.

It is important to be reminded that hydrofluoric acid, even at dilute concentrations, presents significant chemical hazards upon operator exposure, requiring special working precautions. All beakers for HF containment were polypropylene, instead of glass which can be etched and rendered permeable. Dilute (5\%) stock solutions were purchased to avoid handling concentrated solutions and Calgonate (Port St. Lucie, FL) 2.5\% calcium gluconate gel was kept at hand in case of accidental skin exposure. To minimize exposure risk, all personnel wore a full-face shield, a disposable polypropylene apron, and thick neoprene long-sleeved gloves over standard chemical safety glasses, laboratory coat, and long-sleeved nitrile gloves, respectively. Finally, we employed a "buddy system" so that one researcher monitored the other's work with HF. All labware and gloves were thoroughly rinsed with water after use. 


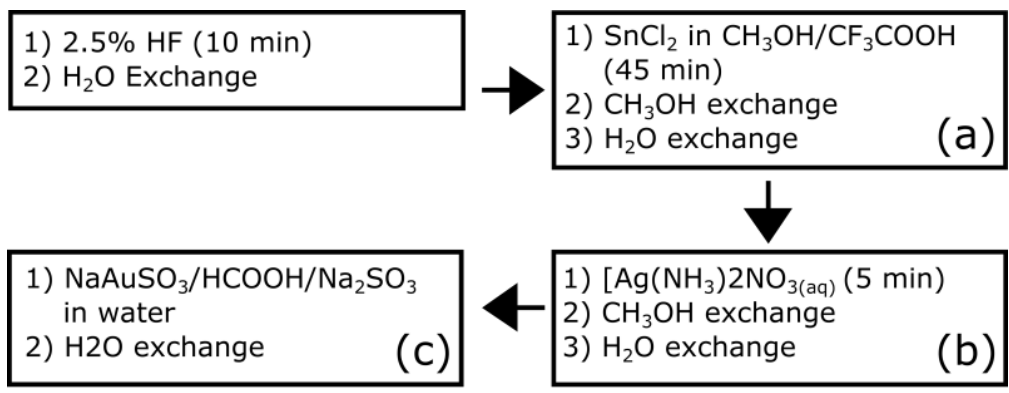
(a) $\mathrm{Sn}^{2+}+2 \mathrm{Ag}^{+}->\mathrm{Sn}^{4+}+2 \mathrm{Ag}(\mathrm{s})$
(b) $\mathrm{Ag}(\mathrm{s})+\mathrm{Au}^{+}->\mathrm{Ag}^{+}+\mathrm{Au}(\mathrm{s})$
(c) $2 \mathrm{Au}^{+}+\mathrm{HCHO}+3 \mathrm{OH}^{-}->2 \mathrm{Au}(\mathrm{s})+\mathrm{HCOO}^{-}+2 \mathrm{H}_{2} \mathrm{O} \quad \mathrm{S}$

Scheme S2. Electroless plating of silicon nitride. The silicon nitride-coated substrates are $\mathrm{HF}$-etched before the surface is exposed to $\mathrm{Sn}^{2+}$ ions which are oxidized during the redox-driven deposition of an elemental silver layer (reaction a) Gold plating begins with galvanic displacement of the elemental silver (reaction b) and proceeds also by formaldehyde reduction (reaction $c$ ). 


\section{Self-Assembled Monolayer Coating and Removal.}

An aqueous solution the chosen PEG-thiol- $0.1 \mathrm{mM}$ in ethanol- was prepared, and $9 \mathrm{~mL}$ was exchanged into each well of the Teflon pore holders. The pores were allowed to soak in the refrigerator for 12-16 hours. $^{2}$ The PEG-SH solution was cleared from the wells of the Teflon holders by a carful $3 \mathrm{~mL}$ ultrapure water exchange to remove any unbound PEG, followed by a careful $6 \mathrm{~mL}$ exchange of electrolyte (1M KCl, 5mM HEPES, $\mathrm{pH} 7.5)$. The removal of the SAM was accomplished by unmounting the silicon nitride substrates from their Teflon holders and subjecting the membranes to plasma etching ( 2 minutes 10W N2 plasma, followed by 1 minute 10W O2 plasma) in a Glow Research (Phoenix, AZ) Autoglow plasma cleaner.

\section{Preparation of ammoniacal silver nitrate ${ }^{3}$.}

This solution was prepared by adding 4 drops of $1 \mathrm{M}$ sodium hydroxide solution to $0.010 \mathrm{~g}$ of silver nitrate. Ammonium hydroxide was slowly added, dropwise, until all traces of dark precipitate had dissolved. The solution was then diluted to a final volume of $10 \mathrm{~mL}$ using ultrapure water.

Ammoniacal silver nitrate solution can form explosives if allowed to dry. This solution should be prepared on only a scale sufficient for immediate use, and should preferably be deactivated by precipitation by the addition of dilute hydrochloric acid or sodium chloride prior to disposal.

\section{Preparation of sodium gold sulfite 4}

The synthesis of the gold plating solution was in accordance with the Abys et al. patent 4 modified by the addition of a drying step ${ }^{5}$, as described here. $0.275 \mathrm{~g}$ 
sodium tetrachloroaurate dihydrate was added to approximately $15 \mathrm{~mL}$ ultrapure water at $80^{\circ} \mathrm{C}$ with stirring. To this solution were added $0.1500 \mathrm{~g}$ barium hydroxide octahydrate and $54 \mu \mathrm{L}$ of $50 \% \mathrm{w} / \mathrm{w}$ sodium hydroxide to yield an orange-yellow precipitate. The solution was boiled until all visible water had evaporated, and then allowed to cool to room temperature. The precipitate was slurried with approximately $10 \mathrm{~mL}$ of ultrapure water and filtered through a medium porosity Buchner funnel. The precipitate was slurried with approximately $10 \mathrm{~mL}$ of ultrapure water, heated to 60 $65^{\circ} \mathrm{C}$ with stirring, cooled, and then filtered (bis). The precipitate was then slurried with approximately $20 \mathrm{~mL}$ of ultrapure water, and $0.500 \mathrm{~g}$ sodium sulfite was added to the solution. The solution was heated to $60-65^{\circ} \mathrm{C}$ with stirring until the precipitate turned blue-purple. This solution was filtered while still warm, and the resulting filtrate was diluted to a final volume of $25 \mathrm{~mL}$. The $\mathrm{pH}$ was adjusted with $1 \mathrm{M}$ sodium hydroxide to a final $\mathrm{pH}$ above 10 .

\section{Nanopore Imaging.}

Gold-plated nanopores were imaged using field-emission scanning electron microscopy (FE-SEM) and elemental analysis of the gold film was carried out by energy-dispersive x-ray spectroscopy (EDS). This imaging was done using a Zeiss Sigma VP FE-SEM at an electron energy of $8 \mathrm{keV}$ (Oberkochen, Germany), and elemental analysis by EDS was performed on the same instrument equipped with an Oxford Instruments X-MaxN 50 $\mathrm{mm}^{2}$ silicon drift detector (Concord, MA). Single nanopore diameters were approximated based on conductance measurements.

\section{Analysis of Plated Nanopores.}


Conductance measurements were acquired in $20 \mathrm{mV}$ increments between -200 and $+200 \mathrm{mV}$ of applied potential. The resulting slope of the I-V relationship at 0.01 , 0.1 , and $1 \mathrm{M}$ electrolyte concentration were fit to the total conductance model for a cylindrical pore as shown in Equations 3 and 15 (for bare and coated pores, respectively) of the main manuscript ${ }^{6-13}$. Conductance fits for the pores used in this paper can be seen in Chapter 3 Supporting Information Figure S2 through Chapter 3 Supporting Information Figure S5. 


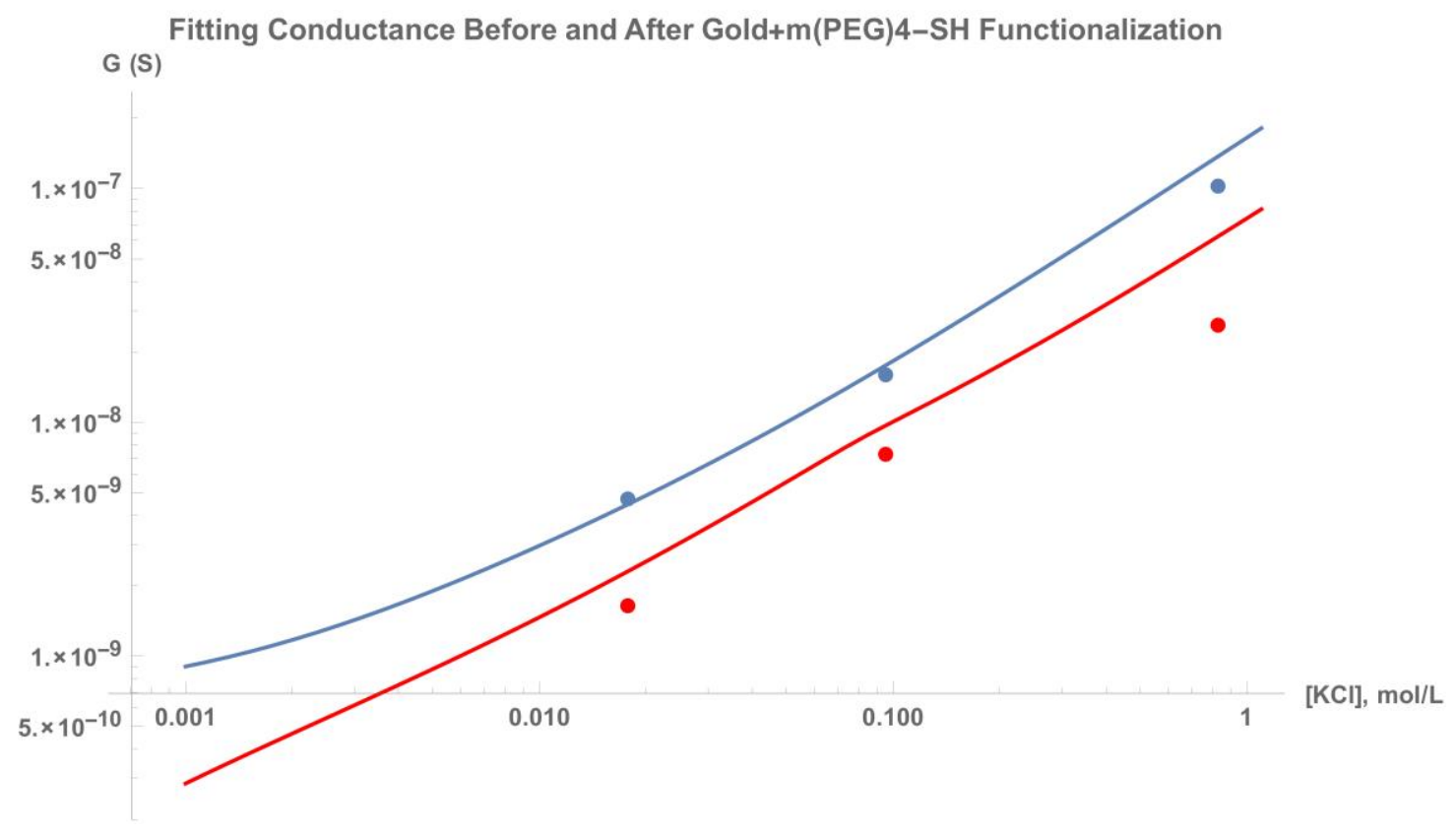

Chapter 3 Supporting Information Figure S2. Silicon nitride nanopore before (blue) and after (red) electroless gold + SAM deposition. Initial pore radius was calculated to be $7.98 \mathrm{~nm}$, with a gold+SAM coating of effective thickness of $5.1 \mathrm{~nm}$ covering $27.2 \%$ of the pore surface. 
Fitting Conductance Before and After Gold+m(PEG)4-SH Functionalization

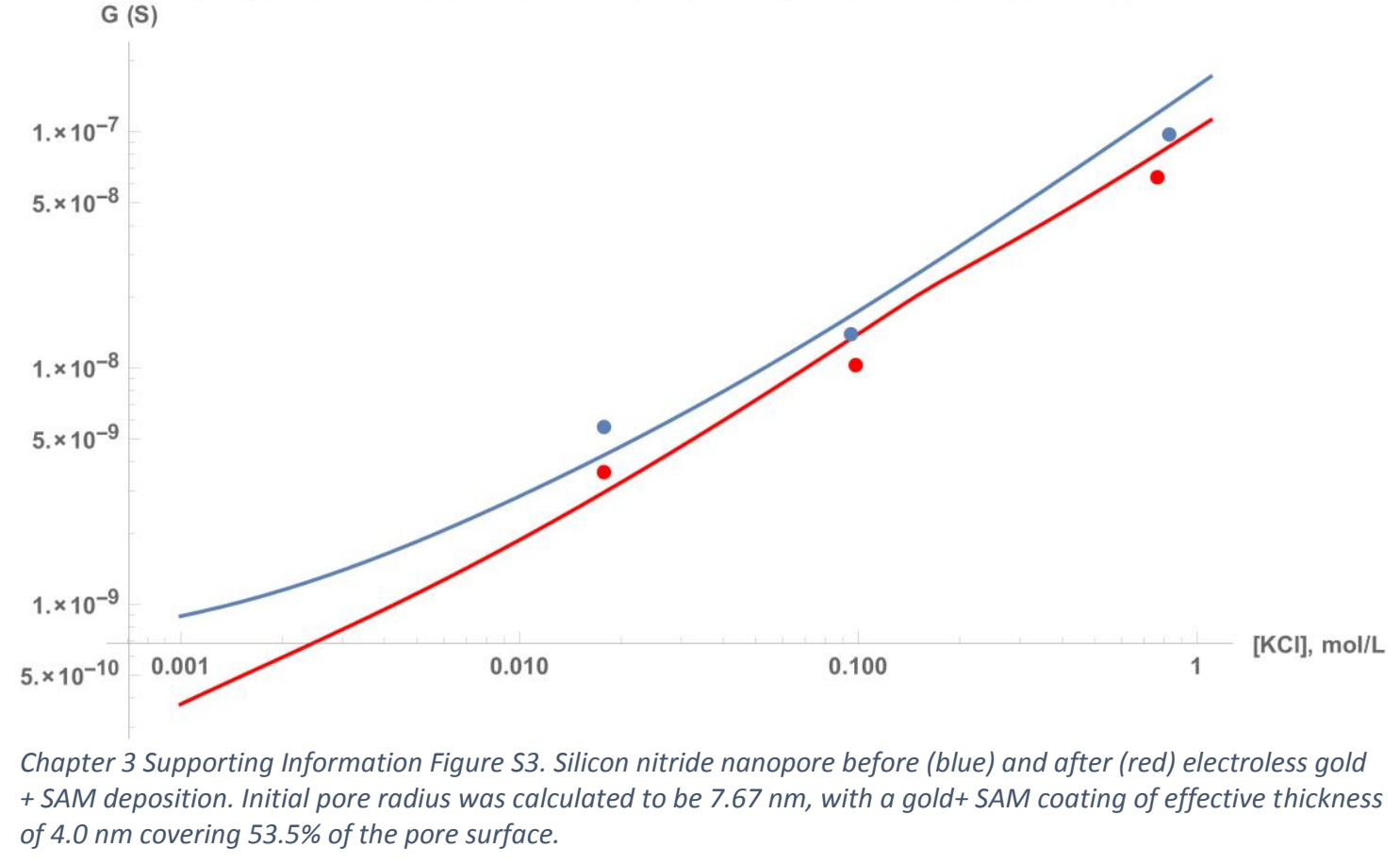




\section{Fitting Conductance Before and After Gold+m(PEG)4-SH Functionalization}

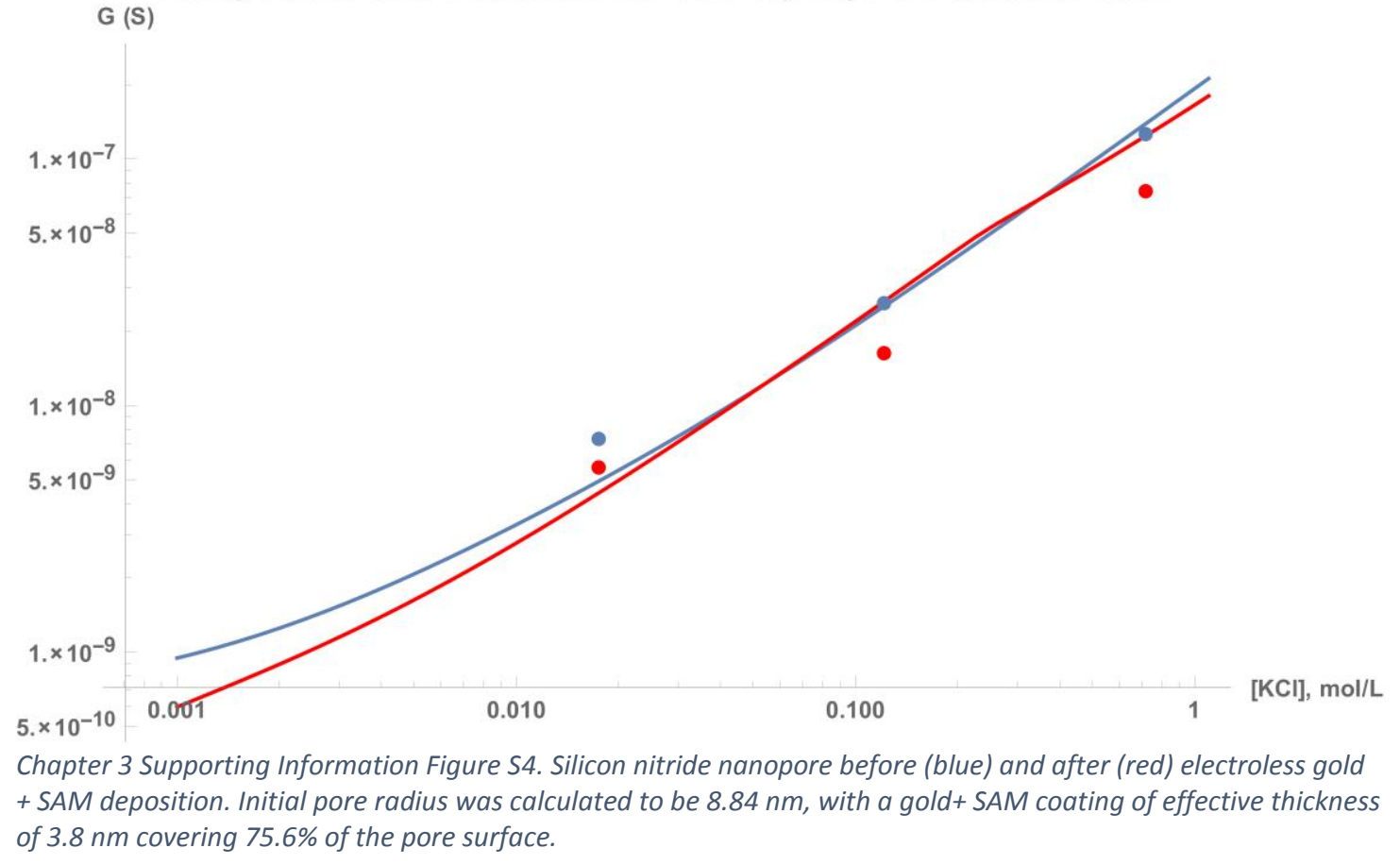



G (S)

Fitting Conductance Before and After Gold+m(PEG)4-SH Functionalization

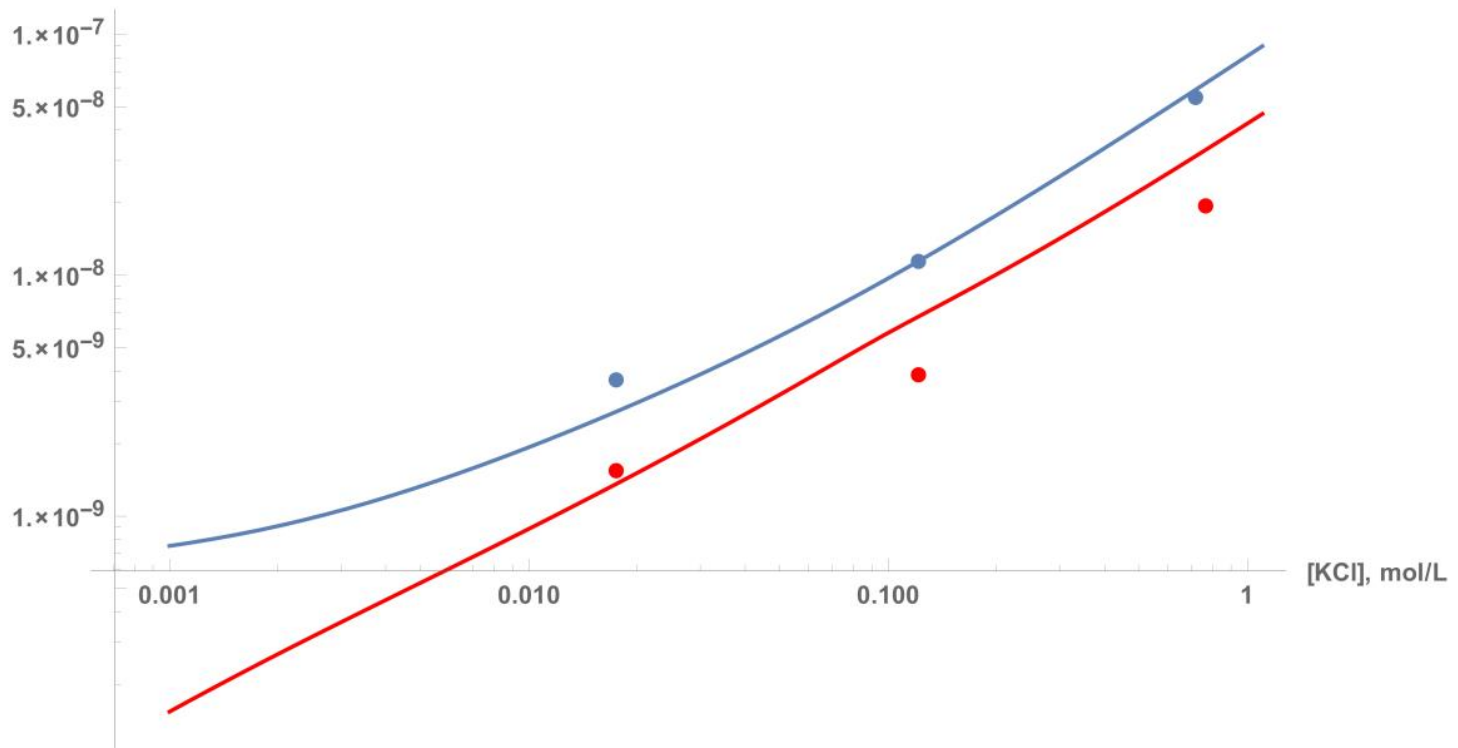

Chapter 3 Supporting Information Figure S5. Silicon nitride nanopore before (blue) and after (red) electroless gold + SAM deposition. Initial pore radius was calculated to be $5.08 \mathrm{~nm}$, with a gold+SAM coating of effective thickness of $2.9 \mathrm{~nm}$ covering $17.8 \%$ of the pore surface. 


\section{$\lambda$-DNA Experiments ${ }^{13-17}$.}

$\lambda$-DNA experiments were conducted in $1 \mathrm{M} \mathrm{KCl}$ electrolyte, buffered to $\mathrm{pH} \sim 7$ with 10mM 4-(2-hydroxyethyl)-1-piperazineethanesulfonic acid (HEPES). Each solution well contains approximately $500 \mu \mathrm{L}$ of electrolyte, to which was added 5$15 \mu \mathrm{L}$ of a dilute $\lambda$-DNA solution to give a final concentration of $16.8-50.4$ pM DNA in the solution well. DNA was added to the cis side of the Teflon holder, opposite to the working electrode, and positive applied voltages were used to drive the translocation of the molecules. An Axopatch200B (Molecular Devices, Sunnyvale, $\mathrm{CA}$ ) with $\mathrm{Ag} / \mathrm{AgCl}$ electrodes were used in conjunction with custom-written LabView software to control the experiments. Data was acquired at $100 \mathrm{kHz}$ with a $10 \mathrm{kHz}$ lowpass Bessel filter.

Events were extracted using a threshold of $0.93 \mathrm{I} / \mathrm{I}_{0}$ and the blockage magnitude was normalized to the initial open pore current. Events shorter than $1 \mathrm{~ms}$ and longer than 10 s in duration were not used.

\section{References.}

1. Kwok, H., Briggs, K. \& Tabard-Cossa, V. Nanopore Fabrication by Controlled Dielectric Breakdown. PLoS ONE 9, e92880 (2014)

2. Martin, C. R., Nishizawa, M., Jirage, K. \& Kang, M. Investigations of the Transport Properties of Gold Nanotubule Membranes. J. Phys. Chem. B 105, 1925-1934 (2001).

3. Sigma-Aldrich. ACCUSTAIN (R) RETICULUM STAIN (Procedure No. HT102). 
4. Abys, J. A. \& Maisano, J. J. Process for making sodium gold sulfite solution. (2000).

5. Whelan, J. C. et al. Electroless Plating of Thin Gold Films Directly onto Silicon Nitride Thin Films and into Micropores. ACS Appl. Mater. Interfaces 6, 1095210957 (2014).

6. Reiner, J. E.; Kasianowicz, J. J.; Nablo, B. J.; Robertson, J. W. F. Theory for Polymer Analysis Using Nanopore-Based Single-Molecule Mass Spectrometry. Proc. Natl. Acad. Sci., 107 (27), 12080-12085, (2010).

7. Frament, C. M.; Dwyer, J. R. Conductance-Based Determination of Solid-State Nanopore Size and Shape: An Exploration of Performance Limits. J. Phys. Chem. C, 116 (44), 23315-23321, (2012).

8. Frament, C. M.; Bandara, N.; Dwyer, J. R. Nanopore Surface Coating Delivers Nanopore Size and Shape through Conductance-Based Sizing. ACS Appl. Mater. Interfaces, 5 (19), 9330-9337, (2013).

9. Liebes, Y.; Drozdov, M.; Avital, Y. Y.; Kauffmann, Y.; Rapaport, H.; Kaplan, W. E.; Ashkenasy, N. Reconstructing Solid State Nanopore Shape from Electrical Measurements. Appl. Phys. Lett, 97 (22), 223105, (2010).

10.Wang, J.; Ma, J.; Ni, Z.; Zhang, L.; Hu, G. Effects of Access Resistance on the Resistive-Pulse Caused by Translocating of a Nanoparticle through a Nanopore. RSC Adv., 4 (15), 7601-7610, (2014).

11. Merchant, C. A.; Healy, K.; Wanunu, M.; Ray, V.; Peterman, N.; Bartel, J.; Fischbein, M. D.; Venta, K.; Luo, Z.; Johnson, A. T. C.; et al. DNA Translocation through Graphene Nanopores. Nano Lett., 10 (8), 2915-2921 (2010). 
12. Wanunu, M.; Dadosh, T.; Ray, V.; Jin, J.; McReynolds, L.; Drndić, M. Rapid Electronic Detection of Probe-Specific microRNAs Using Thin Nanopore Sensors. Nat. Nanotechnol., 5 (11), 807-814, (2010).

13. Kowalczyk, S. W.; Grosberg, A. Y.; Rabin, Y.; Dekker, C. Modeling the Conductance and DNA Blockade of Solid-State Nanopores. Nanotechnology, 22 (31), 315101, (2011).

14. Bustamante, C., Smith, S. B., Liphardt, J. \& Smith, D. Single-molecule studies of DNA mechanics. Curr. Opin. Struct. Biol. 10, 279-285 (2000).

15. Meller, A., Nivon, L. \& Branton, D. Voltage-Driven DNA Translocations through a Nanopore. Phys. Rev. Lett. 86, 3435-3438 (2001).

16. Storm, A. J. et al. Fast DNA Translocation through a Solid-State Nanopore. Nano Lett. 5, 1193-1197 (2005).

17. Bayley, H. Sequencing single molecules of DNA. Curr. Opin. Chem. Biol. 10, 628-637 (2006). 